\title{
Particle Size Reduction of Propellants by Cryocycling
}

\author{
L. Whinnery, S. Griffiths, J. Lipkin, R. Nilson, S. Goods, D. Dawson, \\ H. Radloff, R. Larson, B. Long, J. Swearengen, and J. Hruby
}

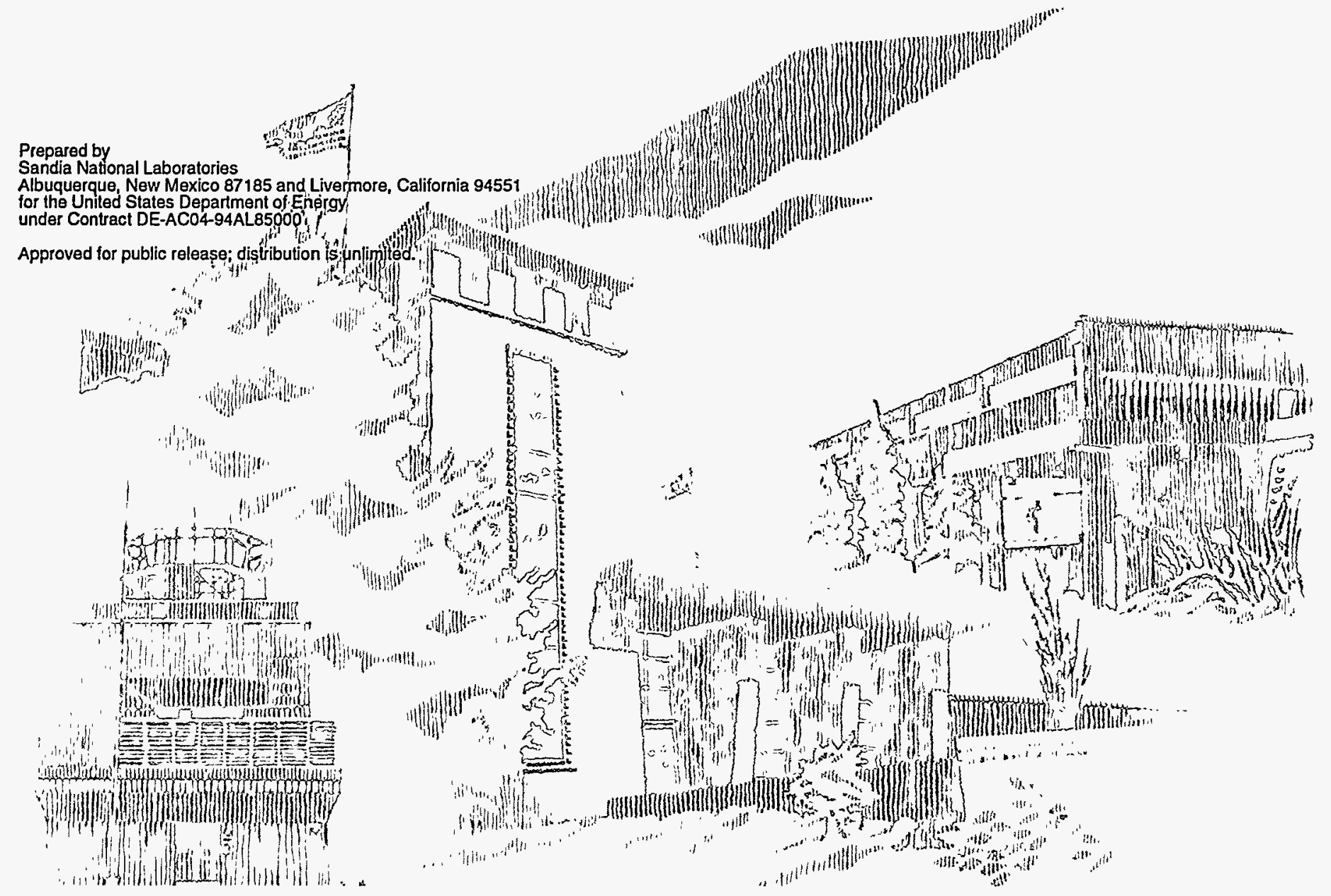




\begin{abstract}
Issued by Sandia National Laboratories, operated for the United States Department of Energy by Sandia Corporation.

NOTICE: This report was prepared as an account of work sponsored by an agency of the United States Government. Neither the United States Government nor any agency thereof, nor any of their employees, nor any of the contractors, subcontractors, or their employees, makes any warranty, express or implied, or assumes any legal liability or responsibility for the accuracy, completeness, or usefulness of any information, apparatus, product, or process disclosed, or represents that its use would not infringe privately owned rights. Reference herein to any specific commercial product, process, or service by trade name, trademark, manufacturer, or otherwise, does not necessarily constitute or imply its endorsement, recommendation, or favoring by the United States Government, any agency thereof or any of their contractors or subconractors. The views and opinions expressed herein do not necessarily state or reflect those of the United States Government, any agency thereof or any of their contractors or subcontractors.
\end{abstract}

This report has been reproduced from the best available copy.

\title{
Available to DOE and DOE contractors from:
}

Office of Scientific and Technical Information

P. O. Box 62

Oak Ridge, TN 37831

Prices available from (615) 576-8401, FTS 626-8401

Available to the public from:

National Technical Information Service

U.S. Department of Commerce

5285 Port Royal Rd.

Springfield, VA 22161 


\section{DISCLAIMER}

Portions of this document may be illegible in electronic image products. Images are produced from the best available original document. 


\title{
PARTICLE SIZE REDUCTION OF PROPELLANTS BY CRYOCYCLING ${ }^{\dagger}$
}

\author{
LeRoy Whinnery \\ Stewart Griffiths \\ Joel Lipkin \\ Bob Nilson \\ Steve Goods \\ Dan Dawson \\ Harold Radloff \\ Rich Larson \\ Bruce Long \\ Jack Swearengen \\ Jill Hruby \\ Sandia National Laboratories \\ Livermore, California 94551-0969
}

\begin{abstract}
Repeated exposure of a propellant to liquid nitrogen causes thermal stress gradients within the material resulting in cracking and particle size reduction. This process is termed cryocycling. We conducted a feasibility study, combining experiments on both inert and live propellants with three modeling approaches. These models provided optimized cycle times, predicted ultimate particle size, and allowed crack behavior to be explored. Process safety evaluations conducted separately indicated that cryocycling does not increase the sensitivity of the propellants examined. The results of this study suggest that cryocycling is a promising technology for the demilitarization of tactical rocket motors.
\end{abstract}

$\dagger$ This research was sponsored by DOE contract DE- C04-94AL85000 through the Laboratory Directed Research and Development Program and the Joint DoD/DOE MOU on Advanced Munitions Technology. 


\section{ACKNOWLEDGMENT}

The authors would like to thank Bill Melvin, James Graham, Jeffrey Wright, and Chuck Freeman from the US Army MICOM, Huntsville, Alabama for conducting the cryocycling demonstration on the N5 propellant in the Mighty Mouse rocket motor. We are also grateful to Pat Oyler of Global Environmental Solutions, Inc. and Bruce Isom of Hercules, Inc. for conducting the cryocycling experiments with the $\mathrm{CMDB}, \mathrm{XLDB}$, and composite propellants and for providing the thermal and mechanical property data. We would also like to thank Bill Munson and Lou Canizzo of Thiokol, Inc., Brigham City, Utah, for many helpful conversations and advice in the initial phase of this project. Carl Schoenfelder also provided enthusiastic guidance during the initial phase. We would also like to acknowledge John Scola and Andy Gardea for polishing the polystyrene samples. 


\section{TABLE OF CONTENTS}

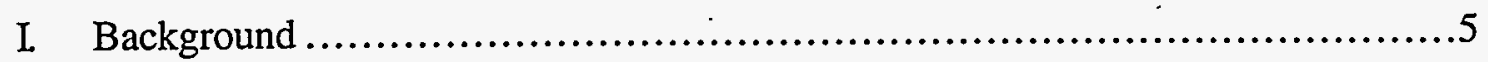

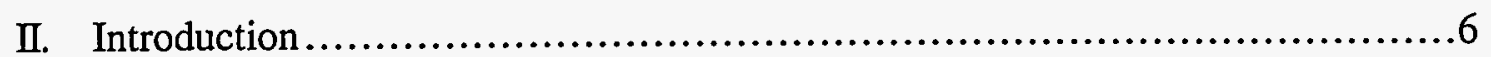

III. Experimental Demonstrations ............................................8

IV. Material Property Measurements ...........................................15

V. Modeling Activities............................................................

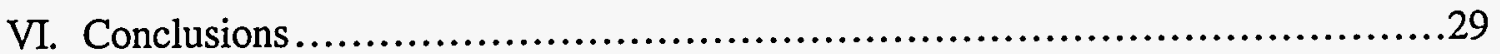

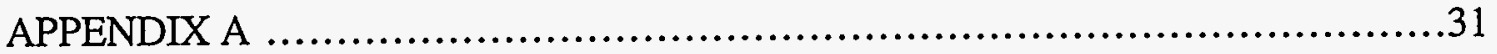

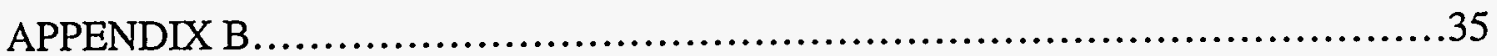

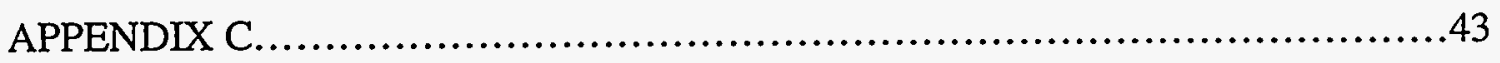

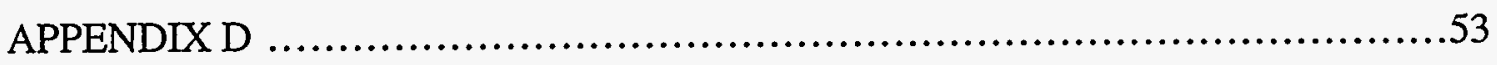




\section{PARTICLE SIZE REDUCTION OF PROPELLANTS BY CRYOCYCLING}

\section{Background}

The military services in the U.S., as well as in many foreign nations, possess large numbers of relatively small rocket motors (i.e., motors containing $100 \mathrm{~kg}$, or less, of energetic materials). These motors were developed to deliver munitions in tactical battlefield operations. Many of the motors contain highly energetic propellant based on hazardous nitrate ester compounds. Some also contain toxic heavy metals, such as lead, used to control propellant burn rate. Depending on its chemical formulation, each propellant has a finite shelf life that dictates the limits of useful rocket motor performance. Once its shelf life is exceeded, a motor is withdrawn from the stockpile and goes into storage while awaiting disposition options.

The United States has accumulated large quantities of aging tactical rocket motors and conventional munitions. As these items are declared excess, a pressing need has developed to identify environmentally conscious disposal options. The current Department of Defense inventory of excess conventional munitions is approximately $3.1 \times 10^{8} \mathrm{~kg} .{ }^{1}$ In the DOE, Sandia's rocket motor inventory includes 16,000 units (containing about 1 million pounds of propellant); and waste energetic material is currently generated at a rate of roughly $6.8 \times 10^{4} \mathrm{~kg}$ per year at Pantex, Mound, and the weapon design laboratories. Clearly, a disposal technology that enables viable recycle/reuse options for the energetic materials in these inventories provides a valuable asset to the economy both by minimizing the generation of hazardous waste streams and by reducing uncontrolled atmospheric emissions from continued open burning/open detonation (OB/OD).

Thermal cycling between ambient and cryogenic temperatures (cryocycling) is a process we developed to remove propellants from rocket motors. Removal is a first step in a complete recovery, reclamation, reapplication $\left(\mathrm{R}^{3}\right)$ methodology. Subsequent steps might include using the material as a commercial explosive or employing other technologies for ingredient recovery such as liquid ammonia, biodispersion, or dissolution/recovery processes.

In addition to conducting feasibility studies on inert and live propellants, we developed numerical models to gain a better understanding of the cryocycling process. These models allow us to predict the extents of the susceptibility of the various propellant compositions and initial geometries. They also help us simulate the cryocycling process so that issues such as process optimization, scale-up, and commercialization can be addressed.

'I. Byrd, Jr., Keynote Address, Energetic Materials Waste Management Colloquium, San Ramon, CA, June 15-18, 1992. 


\section{Introduction}

\section{Alternate Technologies}

Increasing environmental regulations are expected to put an end to OB/OD of solid rocket motors. A replacement demilitarization process will have to take into account: removal of the propellant from the case, size reduction, decomposition or recovery of the energetic components, and identification of all waste streams. Although much work has been directed at decomposition or recovery of the energetic ingredients, comparatively less effort has been aimed at propellant removal or particle size reduction. ${ }^{2-5}$ Several alternative technologies for demilitarization of solid rocket motors have been established including machining, confined burn, and washout methods using either high pressure water, ammonia, or liquid nitrogen.

The best demonstrated available technology (BDAT) that is currently in use to dispose of such motors is $\mathrm{OB} / \mathrm{OD}$. As the name suggests, $\mathrm{OB} / \mathrm{OD}$ is a largely uncontrolled process from the standpoint of atmospheric emissions. Current and pending environmental regulations will almost certainly limit the use of this option in the near future. Indeed, the U.S. DoD has assumed that OB/OD will not be permitted after 1996. All the US military services are thus actively seeking alternative disposal methods for energetic materials. The methods under consideration principally involve controlled destruction of the propellant by thermal techniques including some related to incineration. As a result, the inherent energetic content of the material is wasted. In contrast, the cryocycling process proposed here preserves the energetic value of the material, and thus allows us to pursue relatively straightforward recycle/reuse options with the commercial explosives industry.

Two alternative technologies being considered for Hazard Class 1.1 (HC 1.1) large rocket motor demilitarization appears to be confined burning and liquid ammonia extraction. Confined burning is a straightforward modification of well-established technologies (incineration and $\mathrm{OB} / \mathrm{OD})$. However, it suffers from many of the same problems and drawbacks as incineration and OB/OD. Although confined burning was established to address concerns about emission regulations, these regulations continue to be increasingly restrictive. The waste stream associated with any incineration-like process is significant and disposal costs are high. This waste stream includes corrosive hydrogen chloride gas and large quantities of solid residue such that filters will have to be used to scrub toxic emissions and particulates from the gaseous effluent. The cooling water will have to be filtered occasionally also. Another disadvantage of confined burning is that it does not make productive use of the propellant's inherent energy.

Liquid ammonia extraction involves a high pressure ammonia jet impinging on the propellant surface to mechanically erode the material, followed by selective dissolution of some components and decomposition of others. While this method recovers some of the components, it suffers from safety concerns over adding energy (high pressure jet) to the propellant, degradation of several components requiring an additional disposal step, moving metal parts within the motor case, limited throughput, and economics.

\section{Cryocycling}

The concept behind cryocycling is straightforward. Contact with liquid nitrogen induces thermal gradients in the bulk of a propellant grain. These temperature gradients produce a characteristic stress pattern within the propellant. Stress relieving cracks are formed when internal stresses exceed the strength of the propellant. Additional cracking may also occur upon warming to ambient temperature. The network of cracks may not be sufficient at this point to allow the

2 S. Yosim, L. Grantham, D. Huber, "Non-Polluting Disposal of Explosives and Propellants," U.S. Patent 3778320, 1973. 
propellant to fall out of the metal case in the form of rubble, requiring repeated exposure to liquid nitrogen to enhance cracking. The cycling is continued until the average particle size does not decrease significantly. Cryocycling a rocket motor is thus a potentially efficient process for both removal and sizing of a propellant grain.

There is a distinction between cryocycling, cryofracture, ${ }^{3}$ and cryogenic washout/erosion. ${ }^{4}$ Currently, cryofracture refers to single freezing of a munition in liquid nitrogen to desensitize it, followed by crushing and incineration. Cryofracture is primarily being considered for demilitarization of chemical weapons where toxic hazards are present. In contrast, cryogenic washout/erosion uses a high pressure liquid nitrogen jet to spall off small chunks of propellant and is subject to the same safety risks as high pressure water or ammonia washout.

Cryocycling removes the propellant in a form that can be reused as a bulk material or the individual chemical ingredients can be recovered. Potential reuse applications include: explosive welding of dissimilar metals, booster charges for the mining industry, vehicle airbags, re-manufactured/re-qualified military explosives and propellants, combining with energetic emulsions for use as commercial explosives, and energy conversion.

Cryocycling has been successfully demonstrated on several classes of propellants including composite, double-base (DB), composite modified double-base (CMDB), and cross-linked double-base (XLDB). After three to five thermal cycles most propellant compositions are reduced to less than one centimeter particle size. This particle size is in the right range for many reuse applications. Representatives from ICI Explosives, Valley Forge, Pennsylvania, indicates that a particle size of less than $1 \mathrm{~cm}$ of double-base propellants can be combined with energetic emulsions to produce a very effective commercial explosive for the mining industry. ${ }^{5} \mathrm{TPL}$, Inc., Albuquerque, NM, is looking at reformulating propellants for use in the explosive welding of dissimilar metals ${ }^{6}$.

There are a number of operational advantages we can associate with the application of cryocycling to hazardous energetic materials. Although several of these advantages are shared by competing technologies, no other removal/size reduction process offers as comprehensive a list of benefits as cryocycling. First, cryocycling uses nitrogen, one of the least reactive, cheapest and safest elements known, to enhance propellant removal. Because of this there are no current or anticipated emissions regulations. Second, monitoring requirements on the cryocycling process are limited. During the cryocycling process, only the particle size needs to be monitored and, prior to personnel entering the site, the nitrogen level must be measured. Third, tests indicate the sensitivity of propellants does not increase as a result of the cryocycling process. Fourth, cryocycling does not alter the composition of the propellant, thus allowing all the inherent energy of the propellant to be recycled, reused, or reformulated. Fifth, the cryocycling process is very simple and requires no moving parts within the motor, which is expected to increase safety and lower costs. Sixth, cryocycling induces only the amount of stress into the propellant required to form cracks and does not add energy from an external source to the propellant. Seventh, cryocycling has been successfully demonstrated on five types of propellants including composite, double-base, composite modified double-base, cross-linked double-base, and gun propellant. Eighth, there is no waste stream if the propellant is reprocessed and reused. The ninth benefit of cryocycling is that it can easily be combined with other

\footnotetext{
${ }^{3}$ G. Lumas, D. Osborne, and M. Ancho, "Executive Summary of the Cryofracture Demonstration Program," Informal Report No. EGG-WTD-9916, September 1991.

${ }^{4}$ M. Spritzer, "Method and Apparatus for Cryogenic Removal of Solid Materials," US Patent No. 5,025,632, June $25,1991$.

5 Private communication with Robert Morhard, Karlsruhe, Germany, July 1, 1993.

${ }^{6} \mathrm{H}$. Stoller, Life Cycles of Energetic Materials, Santa Fe, NM, Oct. 24-29, 1993.
} 
technologies, especially those that would benefit from a large increase in surface area and/or small particle sizes.

A simple economic analysis of a conceptual disposal/recycle facility indicates that market entry is feasible. As a conservative starting point, we can assume that the market target is limited to propellant from the existing conventional stockpile slated for disposal. The available material thus amounts to roughly $3.1 \times 10^{7} \mathrm{~kg}$. If we further assume that $25 \%$ can be processed using a cryocycle/recycle facility, the available material becomes $7.7 \times 10^{6} \mathrm{~kg}$. Using a current disposal fee of $\$ 2$ per $\mathrm{kg}$, and a recycle value of $\$ 0.10$ per $\mathrm{kg}$, the available revenue is $\$ 17.85 \mathrm{M}$. Current estimates suggest that construction of a facility capable of processing $4.5 \times 10^{3} \mathrm{~kg} /$ day of propellant could begin with a cost of roughly $\$ 10 \mathrm{M}$. Such a facility would employ an estimated 20 personnel and could be in operation for 5 years (to handle $7.7 \times 10^{6} \mathrm{~kg}$ ) with a revenue stream of about $\$ 1.6 \mathrm{M}$ per year. Going beyond the conservative nature of this model, the economics suggest that an expanded facility capable of handling increased quantities of energetic material from other sources is also feasible.

\section{Experimental Demonstrations}

Both inert and live propellants were thermally cycled in a variety of initial geometries including solid and hollow right circular cylinders, cubes, plates, sheets, and disks. The compositions of the inert and live propellants used are shown in Tables I and II, respectively. The inert propellant LWCYH was formulated at Sandia to simulate the physical properties of live HC 1.1 composite modified double-base (CMDB) propellants, specifically CYH. H-19 is a product of Thiokol Corporation and was formulated to simulate the mass properties of an HC 1.3 composite propellant. Polystyrene was used because of known thermal and mechanical properties and because newly formed cracks could be seen.

Ultimate particle size was used as the criterion to rank the susceptibility of each of the propellants to the cryocycling process. The experimentally observed trend from largest ultimate particle size to smallest is: $\mathrm{H}-19>$ polystyrene $>$ composite $>\mathrm{LWCYH} \approx \mathrm{XLDB} \approx \mathrm{N} 5 \approx$ CMDB.

During the initial experiments, samples were immersed in liquid nitrogen for times much longer than required to achieve complete cracking. Scoping calculations discussed in the modeling section suggest that cracking is complete at a time two orders of magnitude sooner than that required to achieve thermal equilibrium. 
Table I. Inert Propellant Compositions

\begin{tabular}{|l|c|c|c|}
\hline & LWCYH (\%) & H-19(\%) & Polystyrene (\%) \\
\hline Potassium Chloride & 7 & $50-70$ & \\
\hline $\begin{array}{l}\text { Powdered } \\
\text { Aluminum }\end{array}$ & 12 & $15-35$ & \\
\hline $\begin{array}{l}\text { Hydroxyl } \\
\text { Terminated } \\
\text { Polybutadiene }\end{array}$ & & 10 & \\
\hline $\begin{array}{l}\text { Ammonium } \\
\text { Perchlorate }\end{array}$ & & & \\
\hline Dioctyl Adipate & & 5 & \\
\hline $\begin{array}{l}\text { Isophorone } \\
\text { Disocyanate }\end{array}$ & & 2 & \\
\hline $\begin{array}{l}\text { Cyanoethylated } \\
\text { Polyamine }\end{array}$ & & $<1$ & \\
\hline Cellulose Acetate & 14 & $<1$ & \\
\hline Cyanuric Acid & 7 & & \\
\hline Triacetin & 21 & & \\
\hline Shell Epon 815 & 24 & & \\
\hline Versamid 140 & 15 & & \\
\hline Polystyrene & & & \\
\hline
\end{tabular}

Table II. Live propellant compositions.

\begin{tabular}{|l|c|c|}
\hline & N5 (\%) & CYH (\%) \\
\hline Nitrocellulose & 50.0 & 21.6 \\
\hline Nitroglycerin & 34.9 & 29.6 \\
\hline Diethylphthalate & 10.5 & \\
\hline 2-Nitrodiphenylamine & 2.0 & 1.0 \\
\hline Lead Salicylate & 1.2 & \\
\hline Lead 2-ethylhexoate & 1.2 & \\
\hline Candelilla Wax & 0.2 & 19.8 \\
\hline Aluminum & & 10.8 \\
\hline HMX & & 10.8 \\
\hline Ammonium Perchlorate & & 5.3 \\
\hline Triacetin & & 1.1 \\
\hline Resorcinol & & \\
\hline
\end{tabular}

\section{Inert Propellants}

Disks ( $7.5 \mathrm{~cm}$ dia. $\times 1.3 \mathrm{~cm}$ thick) of LWCYH were placed in a tight fitting screen and thermally cycled six times by dipping into a Dewar containing liquid nitrogen. Pictures were taken after each warming cycle. The results are shown in Figure 1. 


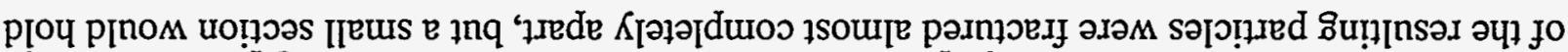
KuRIN 'ssəวoId ôu!

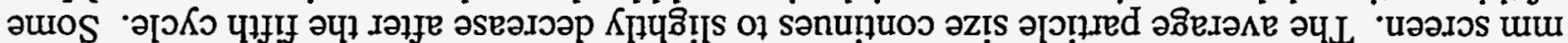

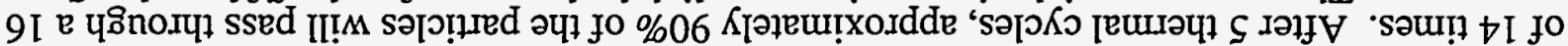

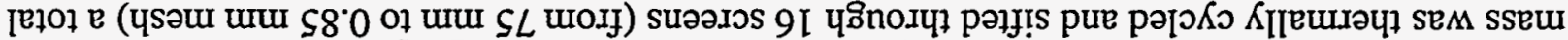

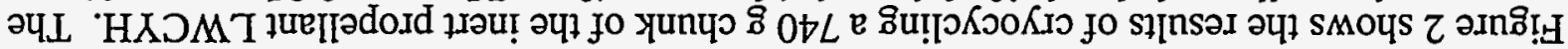

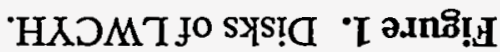
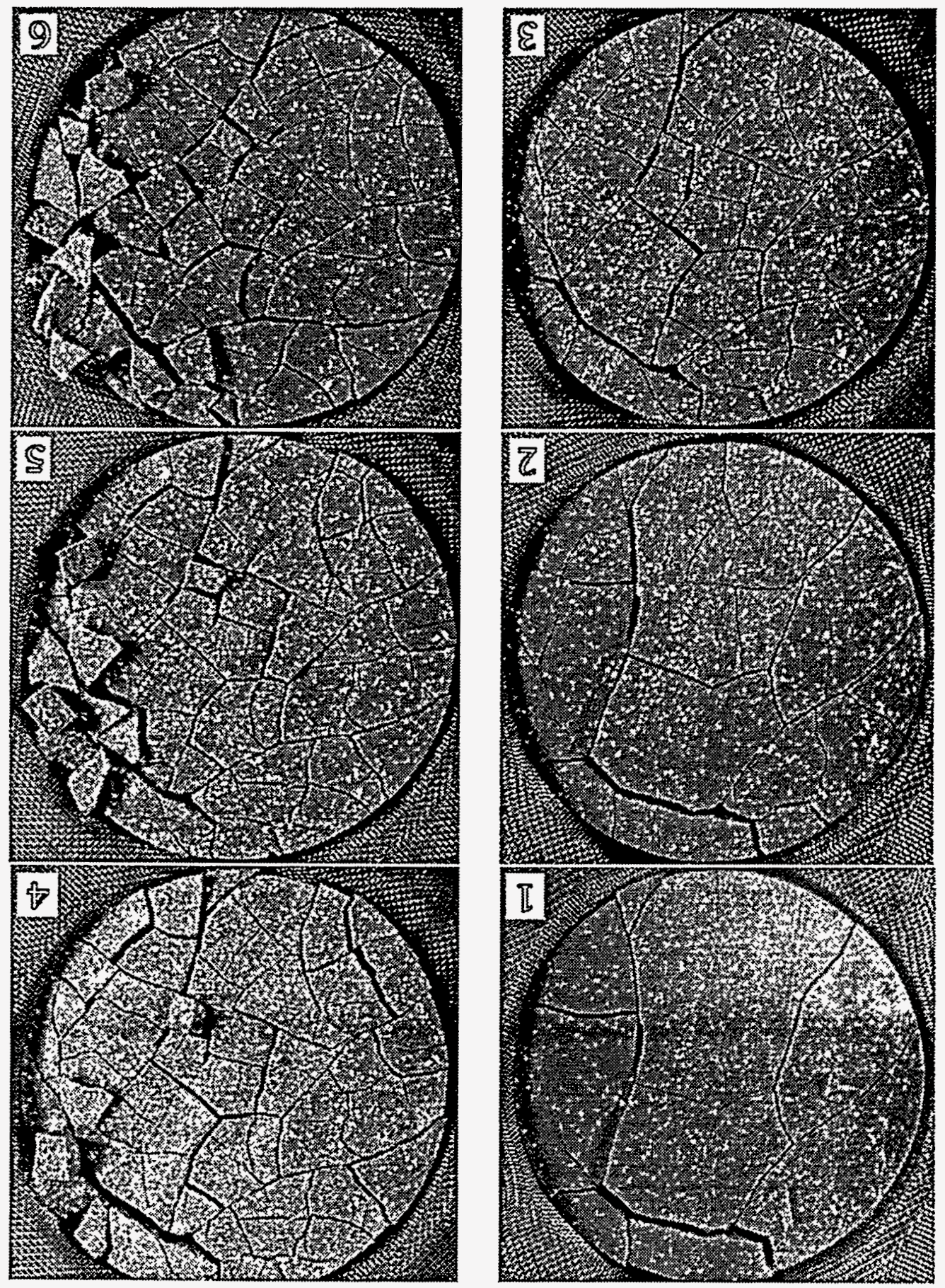
the two pieces together. Often these pieces would separate easily while picking them up to look at them. The question then arises, "is this one particle or two?" We decided that if the screening procedure separated the pieces into two distinct particles, then it should be counted as two particles.

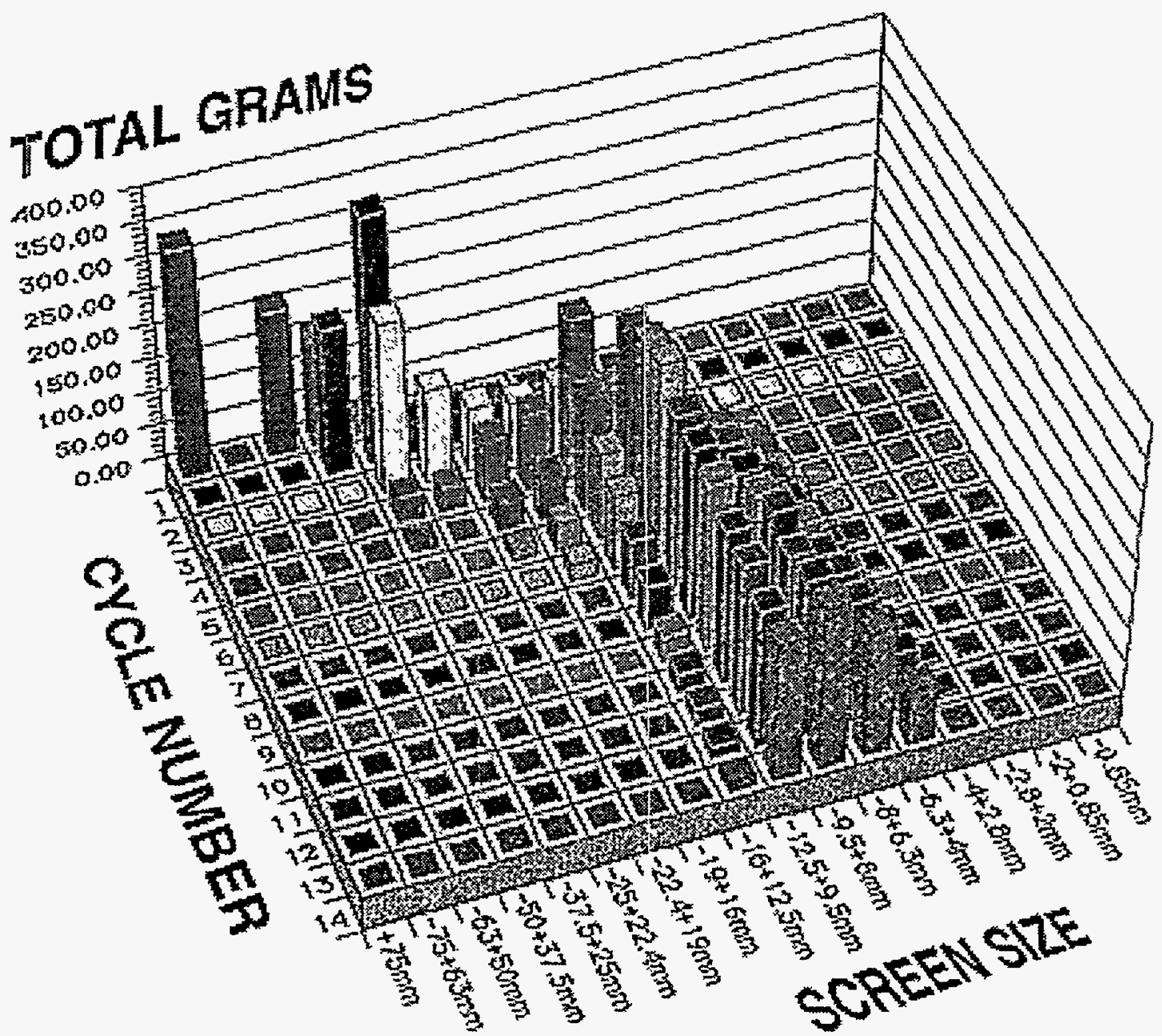

Figure 2. Particle size distribution of cryocycling LWCYH.

Next, a right circular hollow cylinder kevlar/epoxy case containing $\mathrm{H}-19^{7}$ inert propellant with the geometry shown in Figure 3 and dimensions of $O D=45 \mathrm{~cm}, \mathrm{ID}=22 \mathrm{~cm}$, and $\mathrm{L}=45 \mathrm{~cm}$ was cryocycled inside a 250 liter drum with no lid by pouring liquid nitrogen inside the motor case. No attempt was made to optimize heat transfer. An organic insulator (EPDM) was located between the inert propellant and the case. The inert motor was frozen in liquid nitrogen for approximately 2 hours and then allowed to warm to ambient temperature in air. The motor was cryocycled over 10 times with no noticeable increase in the number of cracks after approximately the fifth cycle. The average spacing between cracks was roughly $6 \mathrm{~cm}$. The interlocking nature of the chunks prevented them from falling out of the motor case. Since no attempt was made to optimize the heat transfer in this experiment, we don't know if it would be possible to obtain an ultimate particle size small enough to allow the propellant to fall out of the case.

${ }^{7} \mathrm{H}-19$ is a product of Thiokol Corporation. 


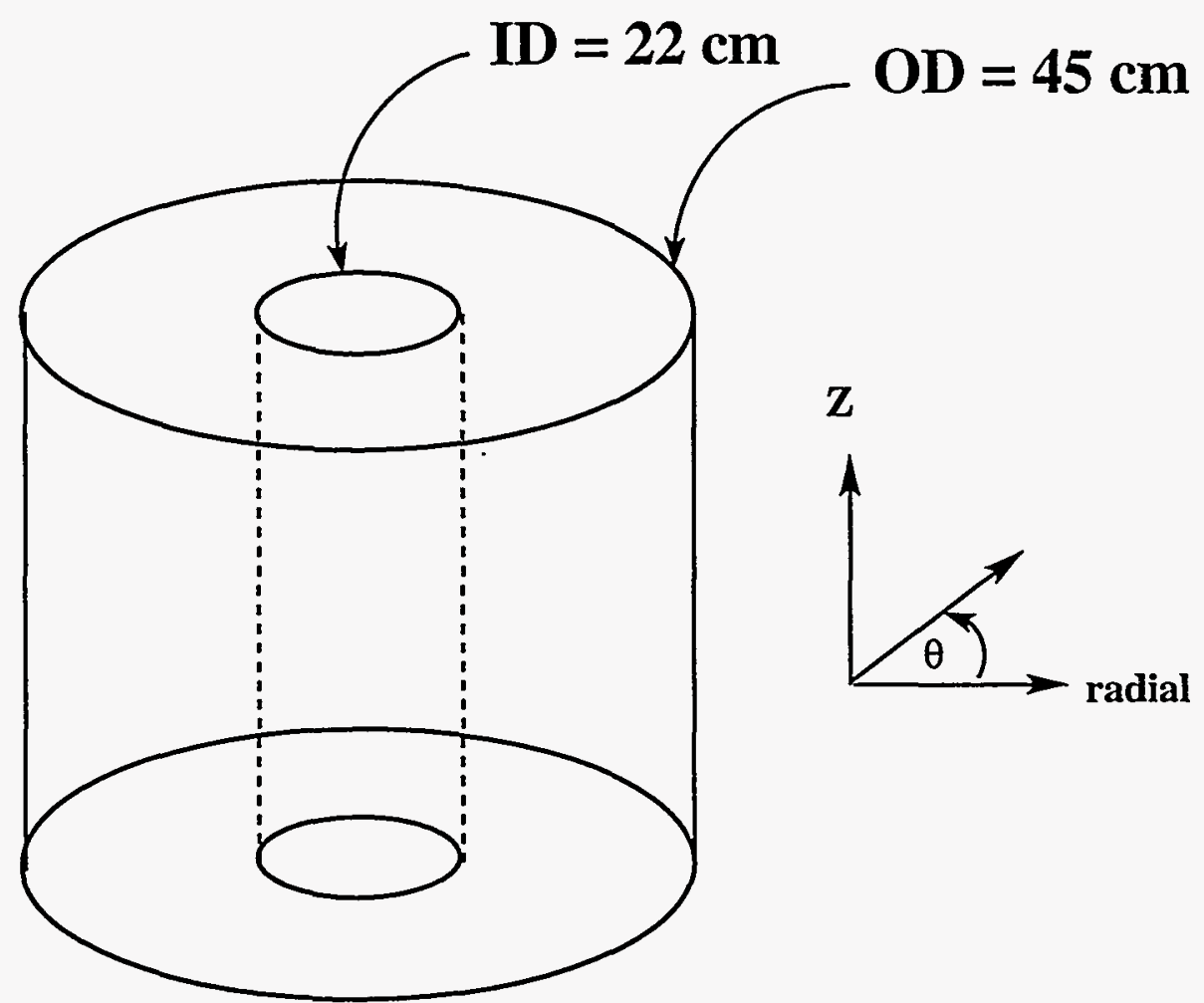

Figure 3. Geometry of $\mathrm{H}-19$ inert propellant grain.

The next experiment was conducted on polystyrene blocks. Polystyrene is a clear, homogeneous polymer that usually cracks when submerged in liquid nitrogen. However, several plates did not crack in our thermal cycling tests. We attribute this behavior to batch-to-batch differences in polystyrene from the manufacturer. This also demonstrates that the ratio of the stress induced upon cryocycling to the stress to failure for polystyrene is very close to unity. Since the glass transition temperature $(\mathrm{Tg})$ of polystyrene is $100^{\circ} \mathrm{C}$, we cannot heat the samples much above room temperature in an attempt to increase the induced stresses. These polystyrene experiments allowed us to watch the cracks grow into the material. Several layers of cracks were observed ranging from microscopic to approximately $60 \%$ of the distance to the center of the sample. Almost all the cracking of the polystyrene was complete on the first cooling cycle and in general did not increase the number of pieces. Accelerated warm-up resulted in driving the fractures completely through the piece yielding several smaller pieces. As shown in Figure 4, a $2 \mathrm{~cm} \times 10$ $\mathrm{cm} \mathrm{x} 10 \mathrm{~cm}$ plate of polystyrene was removed at several time intervals allowing us to monitor crack propagation. The times shown are the total time the piece was in the liquid nitrogen. Since it was removed and warmed to room temperature several times, the exact times required to induce the cracking shown would be less if the plate were left in liquid nitrogen. 


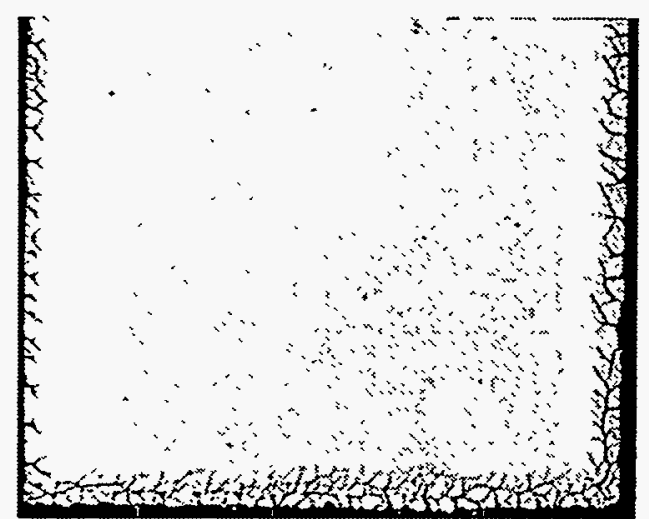

3 seconds

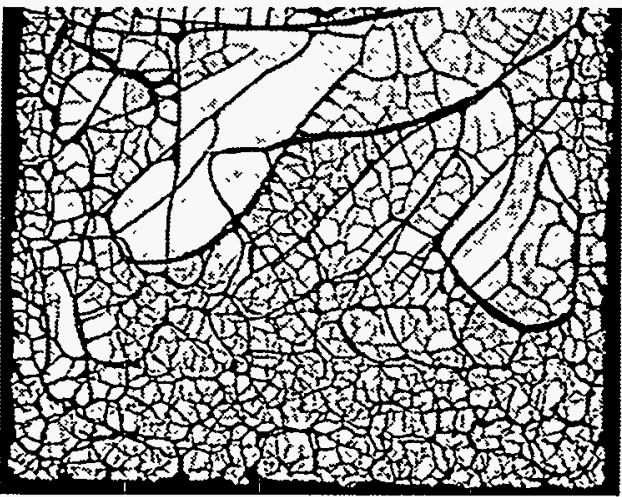

12 seconds

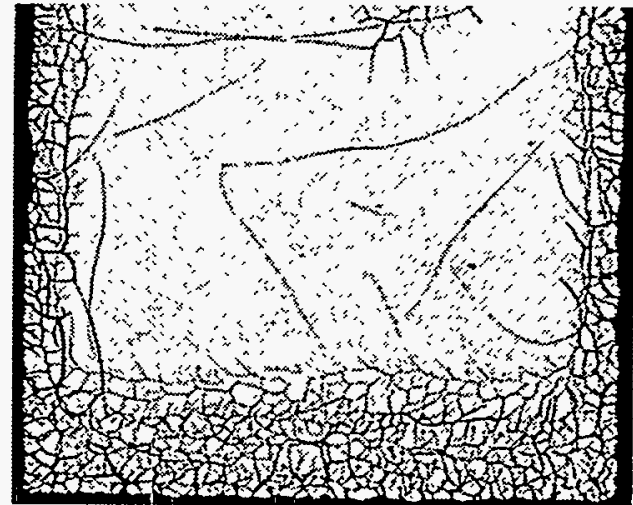

7 seconds

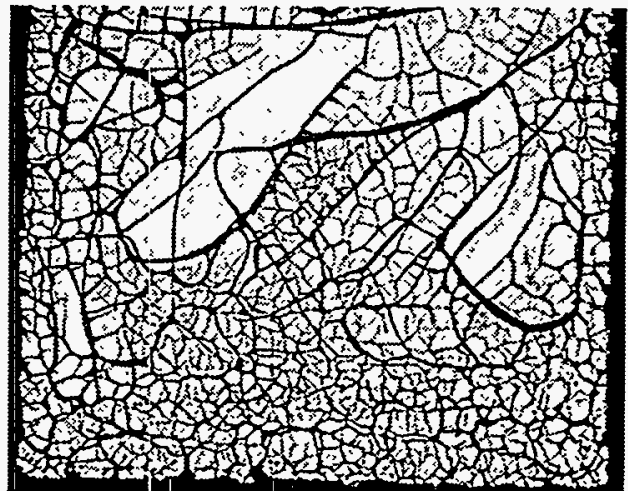

19 seconds

Figure 4. Crack propagation in polystyrene (initial temperature was $86^{\circ} \mathrm{C}$ ).

In an attempt to see the effect of altering the thermal boundary conditions, a $2 \mathrm{~cm}$ thick plate of polystyrene was fitted into a piece of closed cell polyethylene foam, insulating one face and four edges of the plate. The edges were sealed with RTV silicone. Thermal cycling resulted in cracking on the insulated face, but not on the face exposed to the liquid nitrogen. This can be explained by the plate attempting to flex when the cold side contracts, putting the insulated side into tension. Lower strength on the warmer side allows cracking at lower stresses. Hollow cylinders ( $5 \mathrm{~cm}$ dia. by $25 \mathrm{~cm}$ long) with a $1.5 \mathrm{~cm}$ dia. by $18 \mathrm{~cm}$ long hollow core were also cryocycled. Three different boundary conditions were examined: 1) exposure of both the inside and the outside to liquid nitrogen by submerging the cylinder with the open end up, 2) exposure of only the outside to liquid nitrogen by submerging the cylinder with the open end down, and 3) exposure of only the inside to liquid nitrogen by pouring the liquid nitrogen into the open end of the cylinder. The first two cases had similar results with the exception of no cracks on the inside of case \#2. However, case \#3 resulted in axial cracks that went all the way through the sides of the cylinder early in the thermal cycle.

\section{Live Propellants}

As a demonstration of the effectiveness of cryocycling, a $20 \mathrm{~cm}$ length section of a double-based Mighty Mouse rocket motor was thermally cycled at the U.S. Army MICOM in Huntsville, Alabama. The propellant, designated N5, was removed from the metal motor case but still had a tough ethylcellulose wrap around the outside. This sample was placed in a screened box attached to a pulley system so that it could be remotely lowered into a bath of liquid nitrogen. 
The section of propellant broke into 430 pieces after the first cryocycle. Two additional cryocycles resulted in approximately 3,000 and 10,000 total particles, respectively. Almost all the particles were less than $1 \mathrm{~cm}$ in their largest dimension. The roughly 50 pieces somewhat larger than $1 \mathrm{~cm}$ all had part of the ethylcellulose wrap attached. Further size reduction was not attempted.

With Sandia's guidance, Hercules Corporation, Magna, UT, has demonstrated cryocycling on several propellant compositions. Experiments include cryocycling $5 \mathrm{~cm}$ by $5 \mathrm{~cm}$ squares of propellant with several thicknesses ranging from $0.6 \mathrm{~cm}$ to $5 \mathrm{~cm}$. These results are listed in Appendix A. Particles with mass larger than $1 \mathrm{~g}$ were segregated into particles larger than $3 \mathrm{~g}$ $(+3 g)$ and particles less than $3 \mathrm{~g}(-3 g+1 g)$. These particles were then counted and weighed. Particles with less than $1 \mathrm{~g}$ mass were placed in a 4 mesh screen. Particles remaining in the screen $(-1 g+4$ mesh) were counted and weighed. Particles passing through a \#4 mesh screen $(-4$ mesh) were not individually counted, but the mass of particles in the screen was recorded. Data for the $5 \mathrm{~cm}$ cubes is graphed in Figure 5. Accelerated warm-ups were conducted by placing the frozen propellant in front of a forced air heat gun. The specific propellants were: QDT, composite; EJC, composite modified double-base, CMDB; and VTG, cross liknked double-base, XLDB. The headings: composite; CMDB, and XLDB are general propellant composition categories for the three propellants discussed here.

\section{Particle Size Distributions}

As shown previously in Figure 2, particle size distributions of several propellants were obtained as a function of thermal cycle. There are several factors that can affect this distribution including initial temperature and rate of warm-up. A higher initial temperature will result in a larger change in temperature and should induce a larger stress in the material upon immersion. However, this increase can be mitigated by the temperature dependent physical properties. The magnitude of the induced stress may actually decrease with a higher initial temperature if the modulus or volume decreases substantially, such as a phase transition. Conceptually, an increased rate of warm-up should increase crack propagation because the inside of the particle goes into tension on warm-up and should result in more complete cracking. Our data, however, (Figure 5) show that this is not always the case. We do not have an explanation for this phenomenon at this time. It should be noted that this data is from a single experiment on each of the propellants and needs to be reproduced.

Breakage ratios (Figure 5) are a useful way of looking at the number of particles that will result from a given thermal cycle. Breakage ratio is the ratio of the number of particles produced from a thermal cycle to the number of particles at the start of the cycle. This ratio should never be less than one because the pieces will not go back together. For the CMDB propellant, $94 \%$ of the mass had passed through the 4 mesh screen after the seventh cycle. In Figure 5 , it appears that some of the propellants have a breakage ratio of less than one because particles falling through the smallest screen ( 4 mesh) were not counted. Breakage ratios are dependent upon the size of the initial particle and geometry. For example, if the initial piece of N5 had a mass of $250 \mathrm{~g}$ (similar to the other propellants shown) instead of approximately $900 \mathrm{~g}$, the breakage ratio of the first cycle would have been lower. 


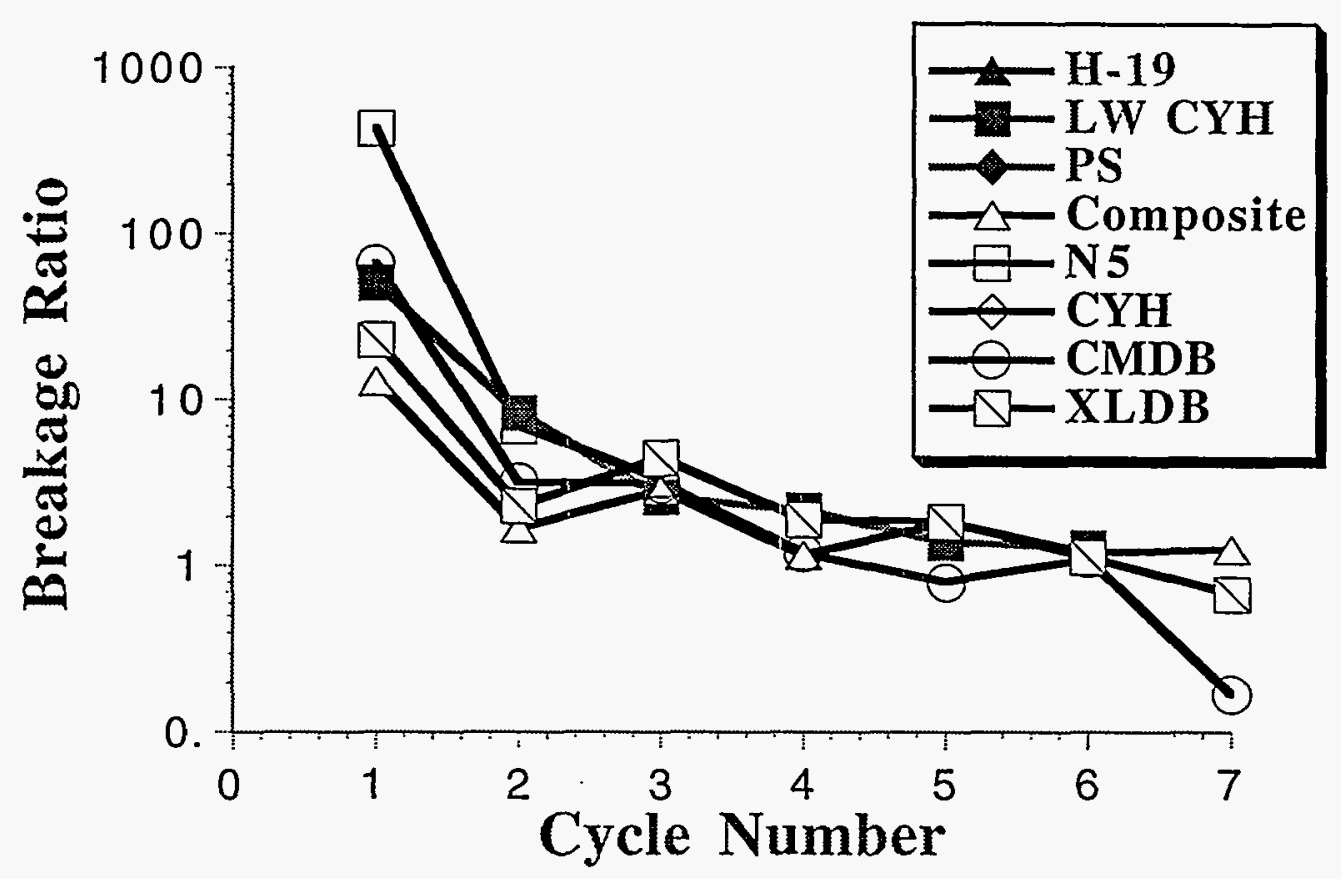

Figure 5. Breakage ratios.

\section{Material Property Measurements}

Since one of our cryocycling process development objectives was to model the process, the thermal and mechanical properties of the materials used for testing were required. In this section the material testing techniques and data gathered are reported.

The modulus, ductility, and strength are summarized in Figures 6,7, and 8 for all inert and live propellants used in our experiments. The data were obtained from several sources. The temperature dependence of the mechanical properties of H-19 and LWCYH was investigated at Sandia National Laboratories with data discussed in Appendices B and C.8 Mechanical properties of polystyrene were obtained from the Encyclopedia of Polymer Science and Engineering. Data for N5 and CYH was obtained from the CPIA/M2 Manual. ${ }^{9}$ Additional mechanical data for CYH was obtained by Thiokol Corporation under contract with Sandia National Laboratories. All the data for the composite, CMDB, and XLDB propellants were supplied by Hercules, Inc.

\footnotetext{
${ }^{8}$ Mechanical properties for H-19 and LWCYH were determined in both tension and compression. Tensile specimens with a $1.2 \mathrm{~cm}$ gage length were pulled to failure at several crosshead rates at several temperatures between room temperature and $77 \mathrm{~K}$. Compression samples were $1 \mathrm{~cm}$ diameter by $1 \mathrm{~cm}$ in height right circular cylinders. Displacement measurements in compression resulted in more consistant predictions with our model. ${ }^{9}$ Chemical Propulsion Information Agengy/M2 Manual.
} 


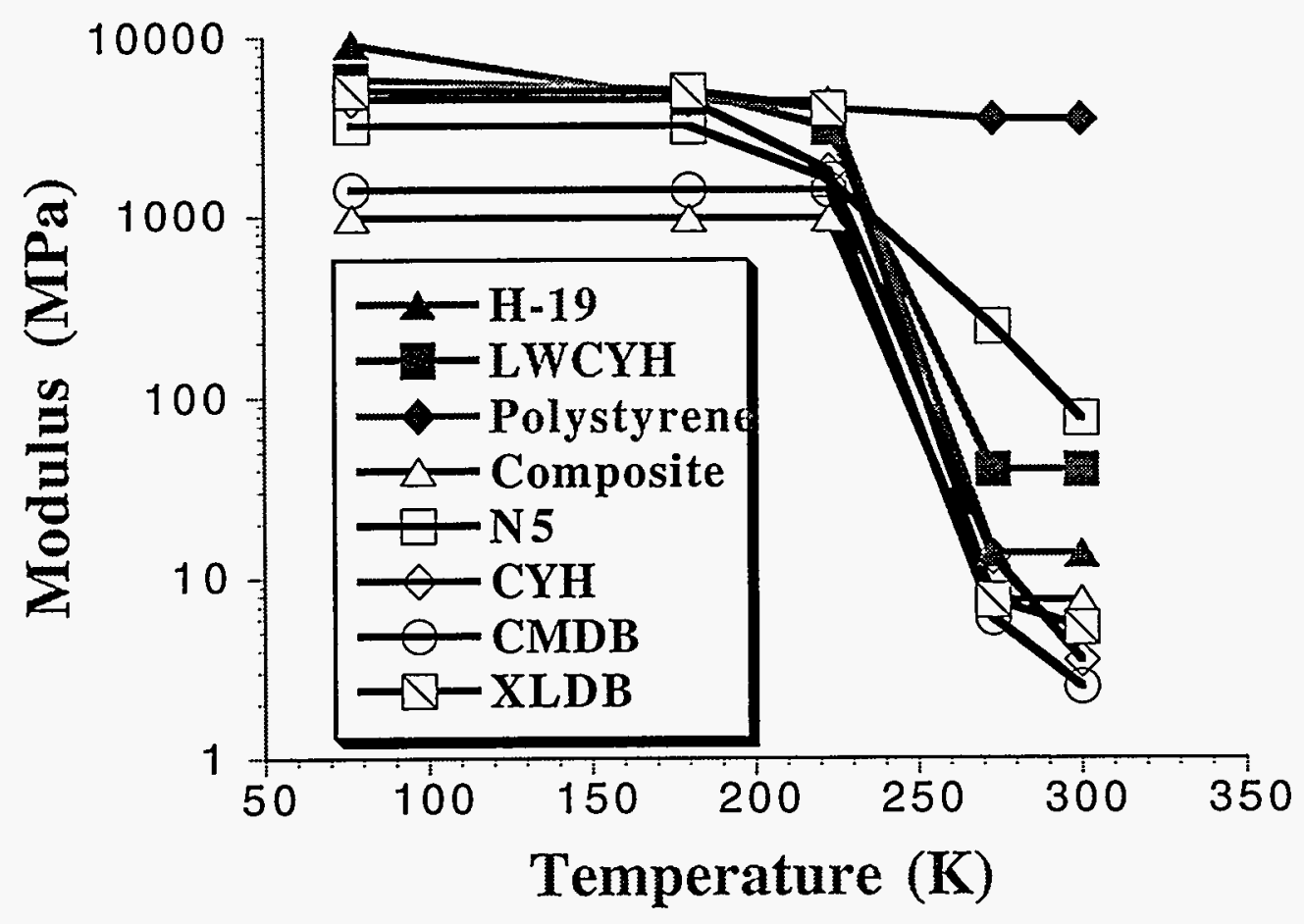

Figure 6. Compilation of modulus data.

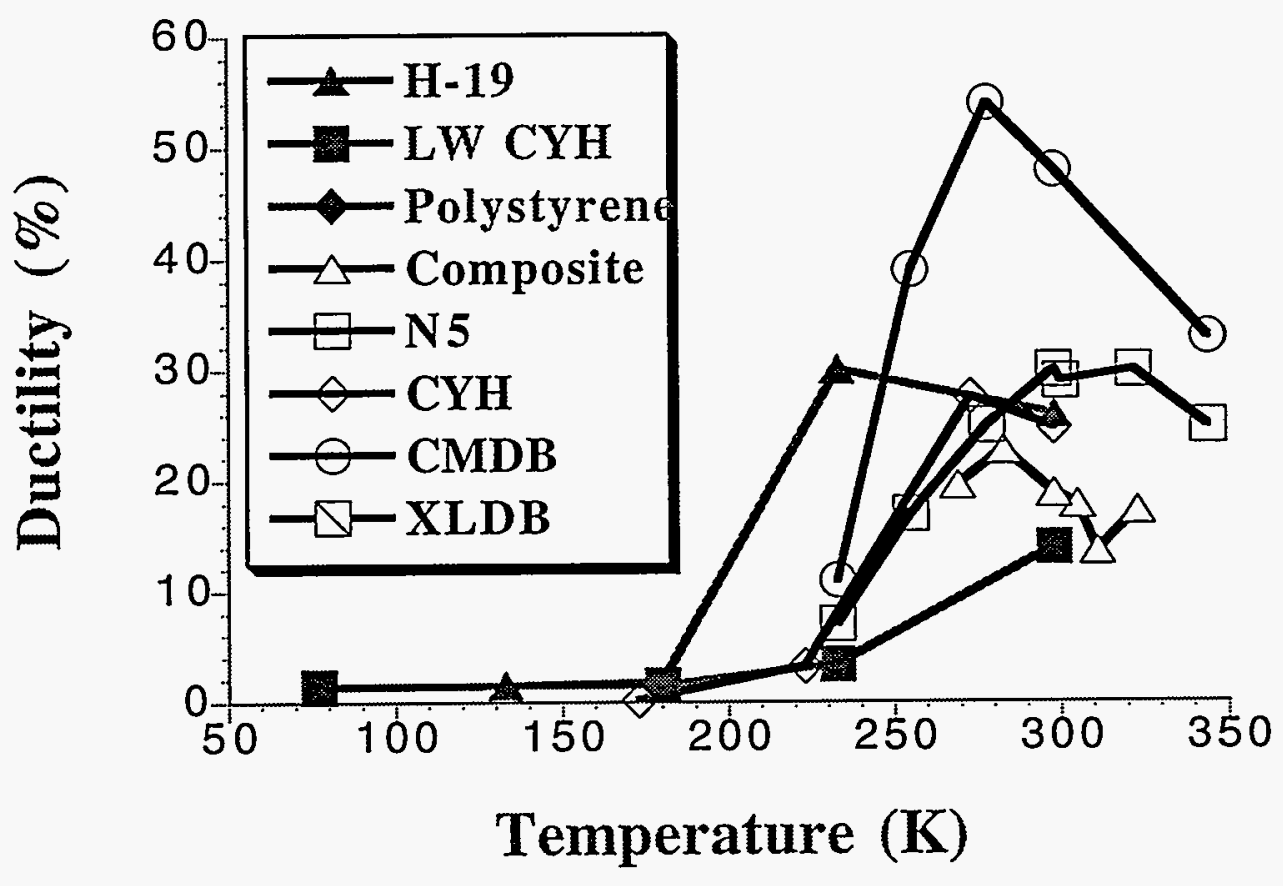

Figure 7. Compilation of ductility data. 


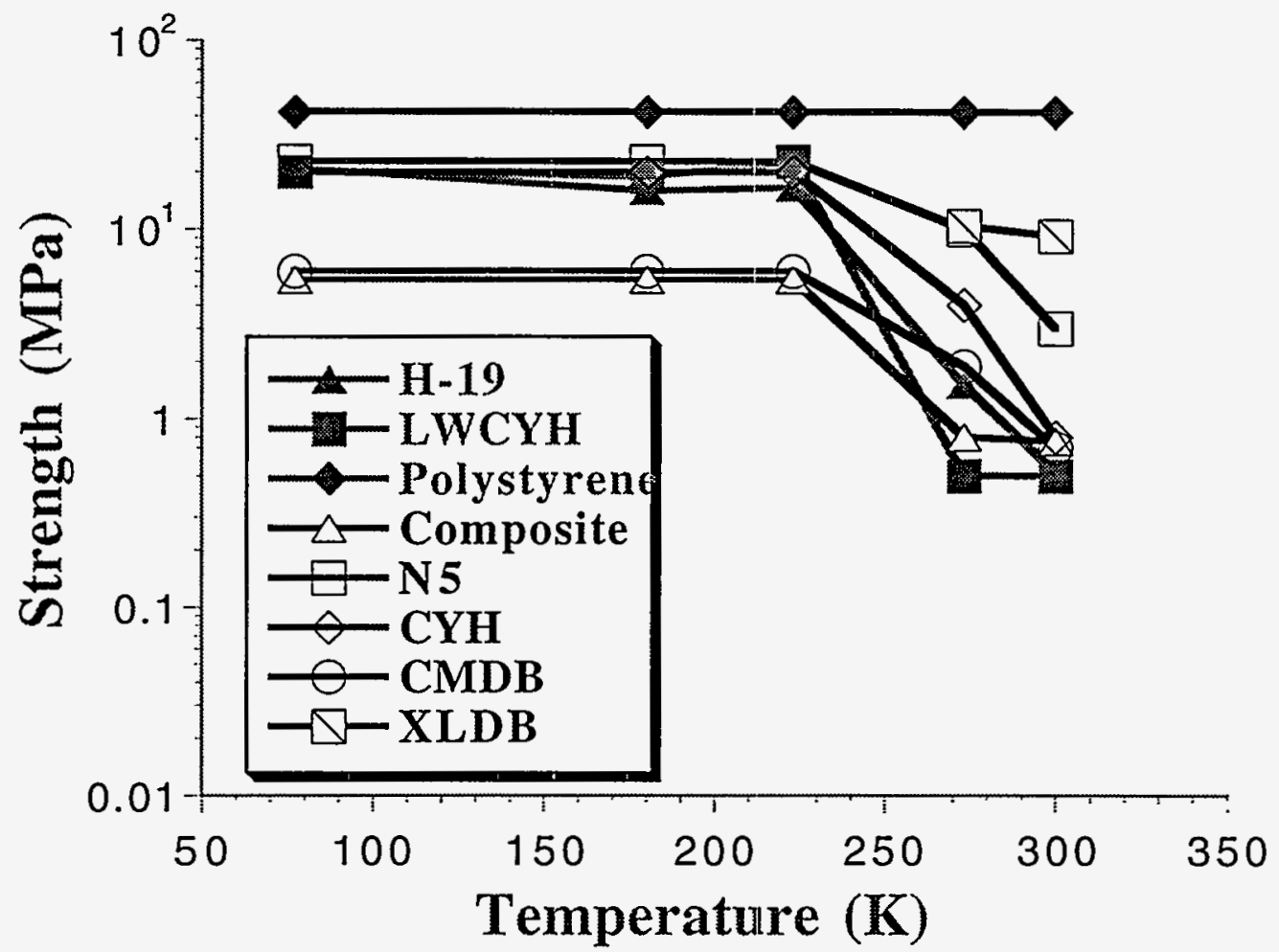

Figure 8. Compilation of strength data.

\section{Thermal}

Thermophysical properties of LWCYH and H-19 were determined under contact with R.E. Taylor, J.B. Henderson, and H. Groot of the Thermophysical Properties Research Laboratory at Purdue University. Thermal data for CYH were obtained under contract with Thiokol, Inc. Thermal data for N5, were obtained from the CPIA/M2 Manual. Hercules, Inc. provided the data for the composite, CMDB, and XLDB propellants. Linear thermal expansion, thermal conductivity, specific heat, and thermal diffusivity are shown in Figures 9-12.

The thermophysical properties of the propellants appear to follow similar trends over the temperatures measured. There are several cases where the range of values for a given property, thermal conductivity for example, are very different for each material, but each generally decreases approximately $40 \%$ from $-100^{\circ} \mathrm{C}$ to $50^{\circ} \mathrm{C}$.

While it is straightforward to predict the effects of variations in a given physical property, it is much more difficult to predict which set of physical properties, that change with temperature, will make a material more or less susceptible to the cryocycling process. For example, we know that a low thermal conductivity should result in steeper thermal gradients. But, a material with a low conductivity and a low expansion coefficient may not break up as well as a material with a high conductivity and a high expansion coefficient. Since no single physical property exhibits the same trend with temperature variation for the series of ultimate particle sizes discussed previously, we can conclude that no single physical property is dominant in determining the effectiveness of cryocycling. The relative importance and interaction between all the thermal and mechanical properties have not been determined. 
Thermal Conductivity $(\mathrm{W} / \mathrm{cm} \cdot \mathrm{K})$

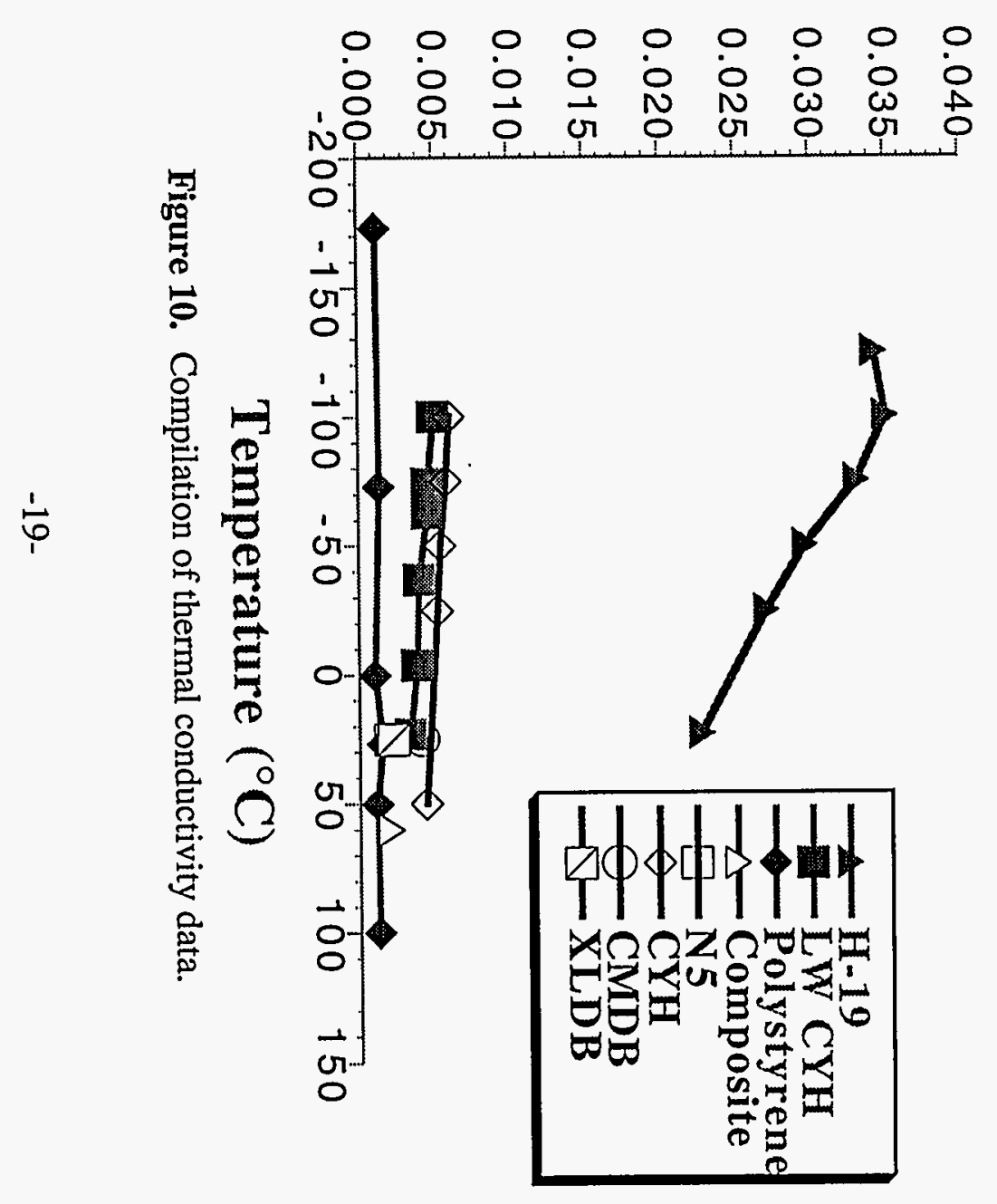

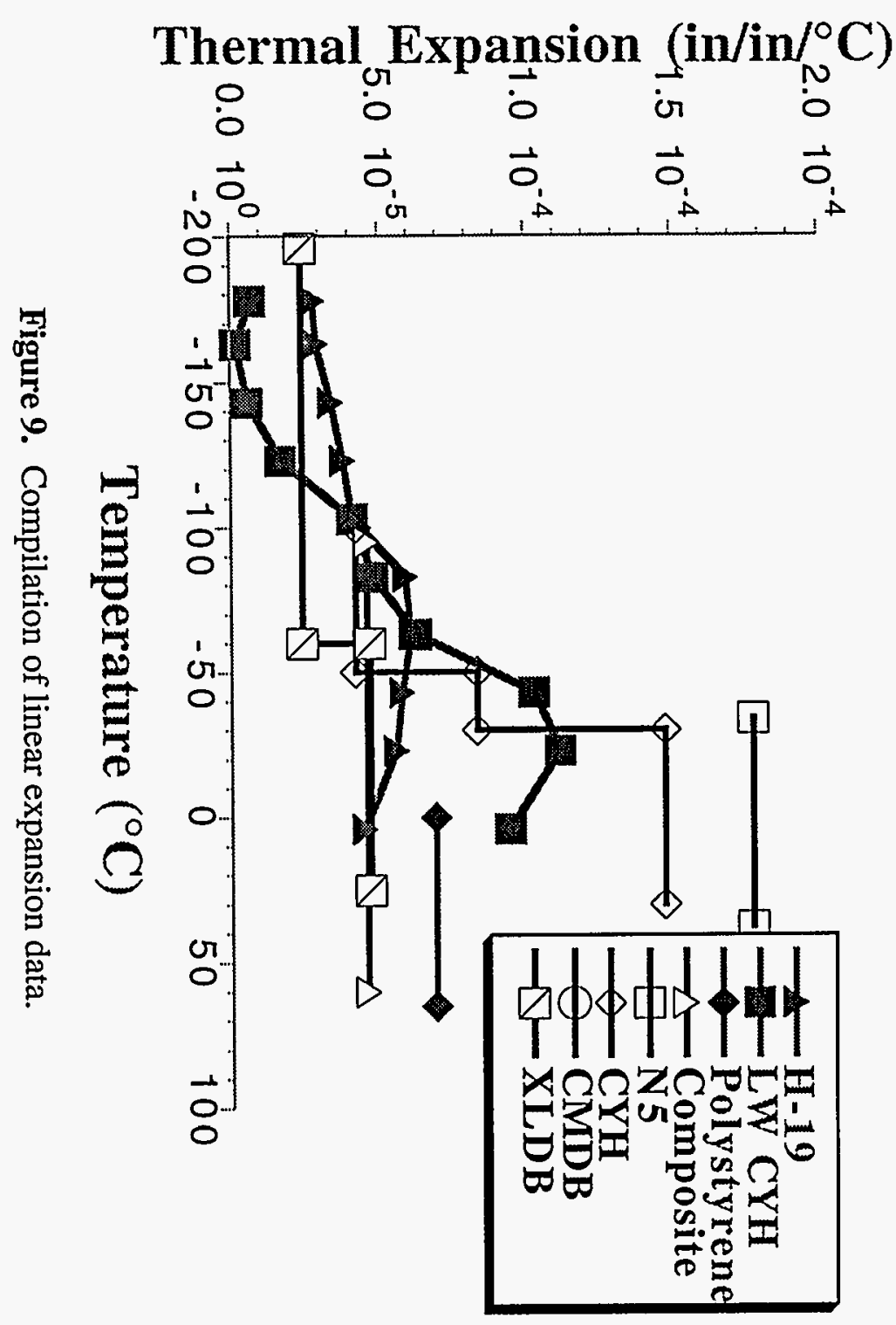




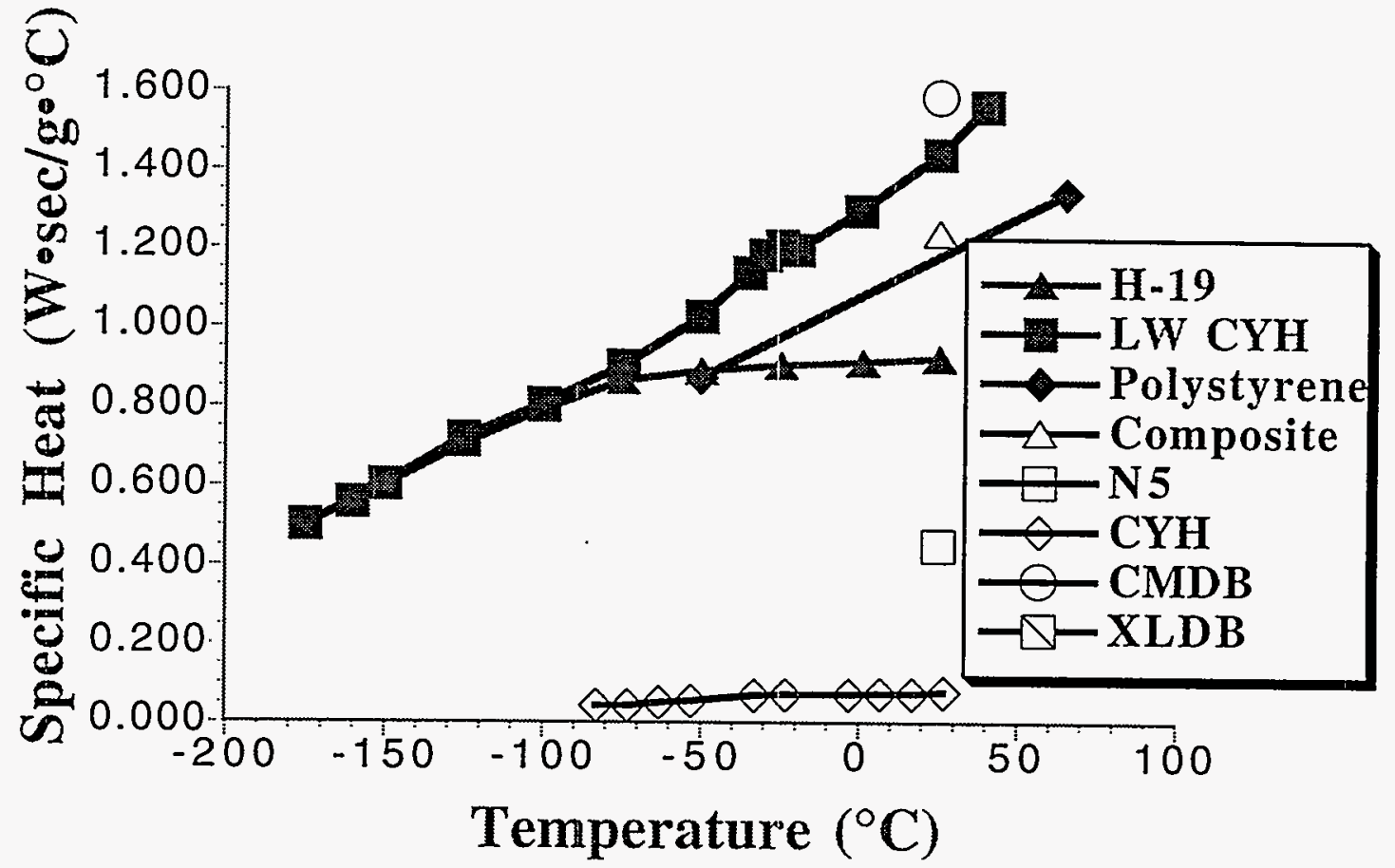

Figure 11. Compilation of specific heat data.

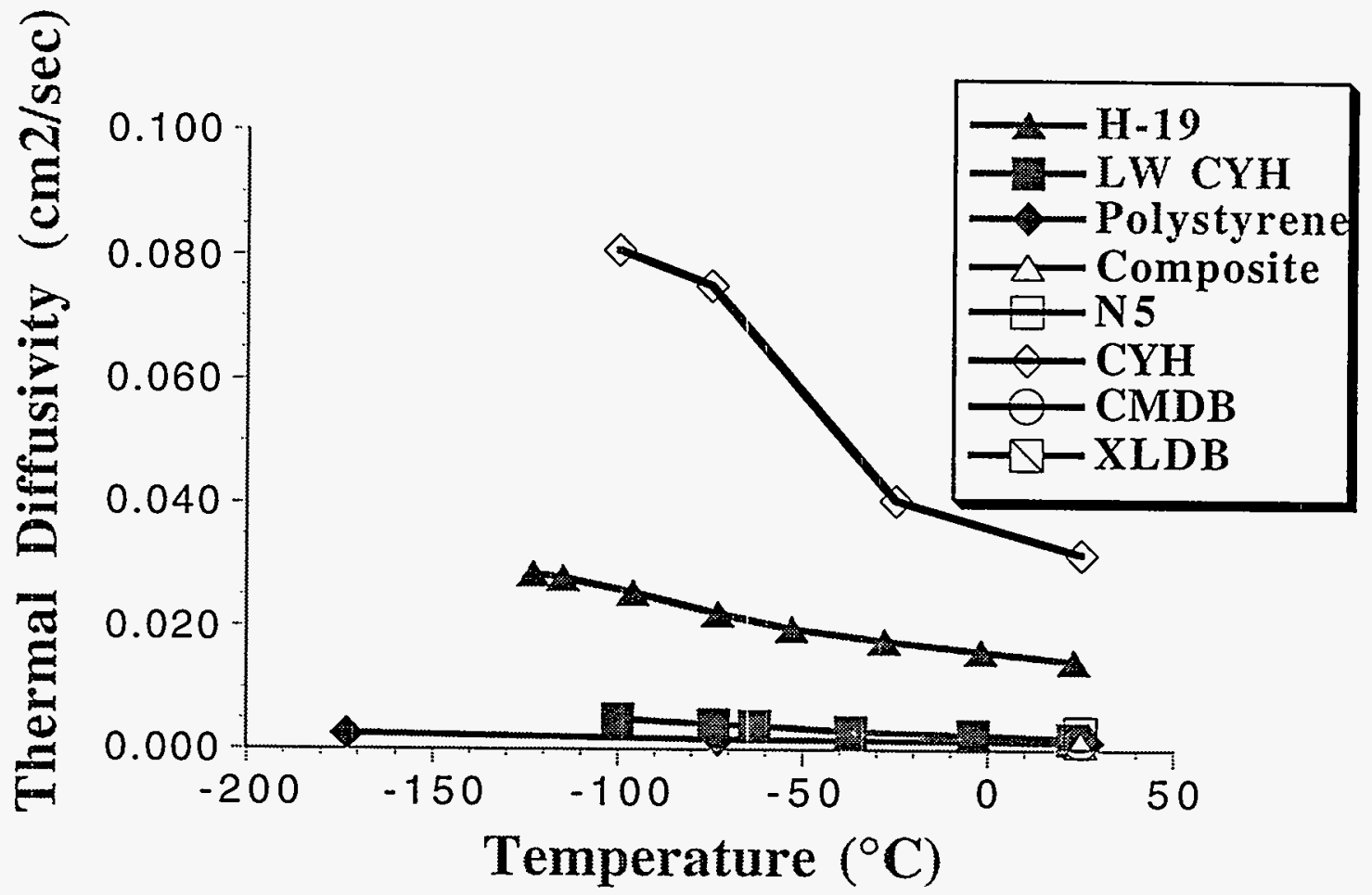

Figure 12. Compilation of diffusivity data. 
Safety

Safety is a concern with any propellant removal or size reduction technology. Thiokol conducted a safety evaluation of $\mathrm{CYH}$ and WAK $\Pi^{10}$ propellants at cryogenic temperatures and several temperature cycles. Safety tests included: ABL impact, ${ }^{11} \mathrm{ABL}$ friction, ${ }^{12}$ electrostatic discharge (ESD), ${ }^{13}$ wrench test, ${ }^{14}$ and DOT impact. ${ }^{15} \mathrm{CYH}$ and WAK II propellants were shown to have roughly the same sensitivity at cryogenic temperatures as at room temperature and no effect due to temperature cycling was observed.

We have accumulated substantial safety data associated with propellants and cryogenic fluids. The tests include $\mathrm{ABL}$ impact, $\mathrm{ABL}$ friction, TC ESD, wrench, and DOT impact of materials at $196^{\circ} \mathrm{C}, 25^{\circ} \mathrm{C}$ after freezing in liquid nitrogen, and $25^{\circ} \mathrm{C}$ after five thermal cycles. Results are summarized in Table III. The conclusions from these safety evaluations are: (1) lower temperatures requires larger impacts to induce failure in bulk propellants, (2) thin wafers are more sensitive to impact at lower temperature because they cannot diffuse the impact effectively, (3) no apparent ESD problem exists at cryogenic temperatures, and (4) five cycles of temperature caused no detectable increase in the sensitivity of the propellant.

\begin{tabular}{|l|c|c|c|c|}
\hline Propellant & Temp $\left({ }^{\circ} \mathrm{C}\right)$ & $\begin{array}{c}\text { ABL Impact } \\
\text { T.I.L. }(\mathrm{cm})\end{array}$ & $\begin{array}{c}\text { TCESD } \\
\text { (joules) }\end{array}$ & $\begin{array}{c}\text { DOT Impact } \\
\text { Pass/Fail }\end{array}$ \\
\hline CYH & 25 & 13 & $>8$ & Pass \\
\hline CYH & -40 & 17 & $>8$ & Fail \\
\hline CYH & -151 & 26 & $>8$ & Fail \\
\hline & & & & \\
\hline WAK 2 & 25 & 33 & $>8$ & Pass \\
\hline WAK 2 & -40 & 21 & $>8$ & N/A \\
\hline WAK 2 & -151 & 33 & $>8$ & Fail \\
\hline
\end{tabular}

Table III. Low Temperature Safety Evaluation of CYH and WAK IIPropellants.

\footnotetext{
${ }^{a} \mathrm{~A}$ mass of $2 \mathrm{~kg}$ was dropped at $\mathrm{X} \mathrm{cm}$ having a striker of $1 \mathrm{~cm}$ diameter. The piece of material was $1 \mathrm{~cm}$ in diameter and $1 \mathrm{~mm}$ thick. The anvil for impact was $2 \mathrm{~cm}$.

b The propellant samples were $2.5 \mathrm{~cm}^{3}$ cubes and $5 \mathrm{~cm}^{3}$ cubes. A $11.3 \mathrm{~kg}$ weight was dropped $\approx 2$ meters onto the propellant cubes. The striker was $7 \mathrm{~cm}$ in diameter and the anvil had an area of $35.6 \mathrm{~cm}^{2}$.
}

\footnotetext{
${ }^{10}$ Due to a limited supply of CYH at Thiokol, WAK II (similar composition to CYH) was used for some of the initial safety tests.

${ }^{11} \mathrm{ABL}$ Impact evaluations were conducted on an ABL F-255-0203 impact testing machine.

${ }^{12} \mathrm{ABL}$ friction evaluations were conducted on an ABL F-255-0203 sliding friction tester.

${ }^{13}$ The Thiokol Corporation Electrostatic Discharge Sensitivity Tester was employed for the electrostatic testing.

${ }^{14} \mathrm{~A}$ single operator performed all wrench tests with a hammer as the friction source.

${ }^{15}$ This is a modification of the DOT drop test. An $11.34 \mathrm{~kg}$ mass was lowered at $30.5 \mathrm{~cm}$ increments until no reports occurred.
} 


\section{Modeling Activities}

The laboratory and demonstration portions of the project are guided by modeling activities which employ three complementary approaches. In the first, closed-form analytical solutions are used to investigate the growth of a single fracture induced by rapid cooling of a propellant slab or sphere. The second modeling approach uses a two dimensional network model to simulate the initiation and growth of a large number of interacting fractures. These two models are currently limited to simple geometries such as the outer slab-like surface of a bare propellant cartridge or the sphere-like fragments which are reprocessed on successive cryocycles. In contrast, the third modeling approach, using finite-difference and finite-element methods, is specifically aimed at more complex grain geometries and boundary conditions. These grain geometries and boundary conditions are particularly important during the first cooling cycle of a case-bonded propellant.

The remainder of this section will describe the formulation and application of the analytical and network models. Finite difference modeling is discussed in Appendix D. Finally, a separate presentation will illustrate the use of finite element modeling to predict thermal and stress histories for complex case-bonded rocket motors such as the Zuni. ${ }^{16}$ This model is currently being extended to explicitly account for the initiation and growth of a multiplicity of interacting fractures.

\section{Analytical Modeling}

The temperature and stress histories induced by cryocycling may be well approximated by onedimensional analytical solutions to the governing equations. These solutions illustrate the role of material properties and process parameters in determining:

- the potential of a material to fracture during cryocycling,

- the time required to complete cryocycling, and

- the ultimate fragment size a material can achieve under cryocycling conditions.

Following a brief description of the analytical model, its predictions are compared with the experimental observations presented earlier. Although generally encouraging, these comparisons underscore the importance of having reliable data for the mechanical properties of candidate materials at liquid nitrogen temperatures.

The analytical model describes fracture initiation in a slab of thickness $2 a$ that is suddenly plunged into a liquid nitrogen bath having a temperature $T_{b}$ colder than the initial slab temperature $T_{o}$. The temperature distribution within the slab is given by a well known series solution that satisfies the one dimensional cartesian conduction equation subject to a convective boundary condition of the form $-k d T / d x=h\left(T-T_{b}\right) .{ }^{17}$

$$
\frac{T-T_{b}}{T_{o}-T_{b}}=\sum_{n=1}^{\infty} \frac{2 B i \sec \lambda_{n}}{B i(1+B i)+\lambda_{n}^{2}} \cos \left(\lambda_{n} x^{*}\right) e^{-\lambda_{n}^{2} F_{o}}
$$

${ }^{16}$ P. Oyler, Farnsworth, J. Lipkin, J. Handrock, L. Weingarten, "Tactical Rocket Motor Demilitarization-The Complete Process Including $\mathrm{R}^{3}$," to be presented at the 1995 Global Demilitarization Symposium and Exhibition, St. Louis, May 15-18, 1995

${ }^{17}$ H.S. Carslaw and J. C. Jaeger, Conduction of Heat in Solids, Oxford University Press, 1976. 
The temperature depends on the fractional distance from the center of the slab, $x^{*}=(x-a) / a$, the normalized time or Fourier number, $F_{o}=\alpha t / a^{2}$, and the Biot number, $B i=h a / k$ in which $k$ and $\alpha$ are the thermal conductivity and thermal diffusivity of the solid. The series summation extends over the discrete eigenvalues, $\lambda_{n}$, which are roots of the characteristic equation $\lambda_{n} \tan \lambda_{n}=B i$.

Since many solid propellants behave elastically at moderate strains $(<1 \%)$ and low temperature, the thermally induced tensile stress, $\sigma$, parallel to the cooled surface is related to the temperature distribution through the following integral equations:

$$
\sigma=\phi-\frac{E}{\bar{E}} \bar{\phi} \quad \text { where } \phi=\frac{E}{1-v_{T_{g}}} \int_{T}^{T} \beta d T, \bar{\phi}=\frac{1}{2 a} \int_{0}^{2 a} \phi d x \text {, and } \bar{E}=\frac{1}{2 a} \int_{0}^{2 a} E d x
$$

These are derived from the theory of elasticity ${ }^{18}$, taking into account temperature variations in the elastic modulus $E$ and thermal expansion coefficient $\beta$. Poisson's ratio $v$ is assumed constant.

Time histories of $T$ and $\sigma$ are generated by evaluating these expressions for sequential choices of the Fourier number, Fo. The Biot number is first determined for particular values of $k, a$, and the convective heat transfer coefficient, $h$. Since the initial propellant temperature is well above the $77 \mathrm{~K}$ boiling point of liquid nitrogen, the convection coefficient is estimated from an analytic function 19,20 which smoothly transitions between a pair of data correlations which separately describe the film and nucleate boiling regimes. Once the Biot number has been established, the temperature profile $T\left(x_{i}\right)$ is calculated by summing the series solution at a discrete set of points

$x_{i}$. The corresponding stress profiles $\sigma\left(x_{i}\right)$ are next generated by numerical quadrature.

A typical family of temperature profiles is shown in Figure 13 for a $50 \mathrm{~mm}$ slab of CYH. At $\mathrm{Fo}=10^{-2}$ the slab surface temperature has just fallen below the glass transition temperature of $225 \mathrm{~K}$. Thereafter, in the time window between $\mathrm{F}_{0}=3 \times 10^{-2}$ and $10^{-1}$, the transition from film to nucleate boiling occurs, causing a considerable increase in the heat transfer coefficient and a corresponding reduction of the surface temperature. $\mathrm{By} \mathrm{FO}=1$, the slab temperature is nearly uniform and in equilibrium with that of the liquid nitrogen bath.

\footnotetext{
18B. A. Boley and J. H. Weiner, Theory of Thermal Stresses, John Wiley, 1960.

19 Haselden, G.G. (ed.), Cryogenic Fundamentals, Academic Press, London, 1971. Chapter 3

"Heat Transfer", Clark, J.A. and Thorogood, R.M.

20Larson, R.S., Ltr to Distribution, "Calculation of Thermal Stress Profiles During Cryocycling", January 17, 1994.
} 


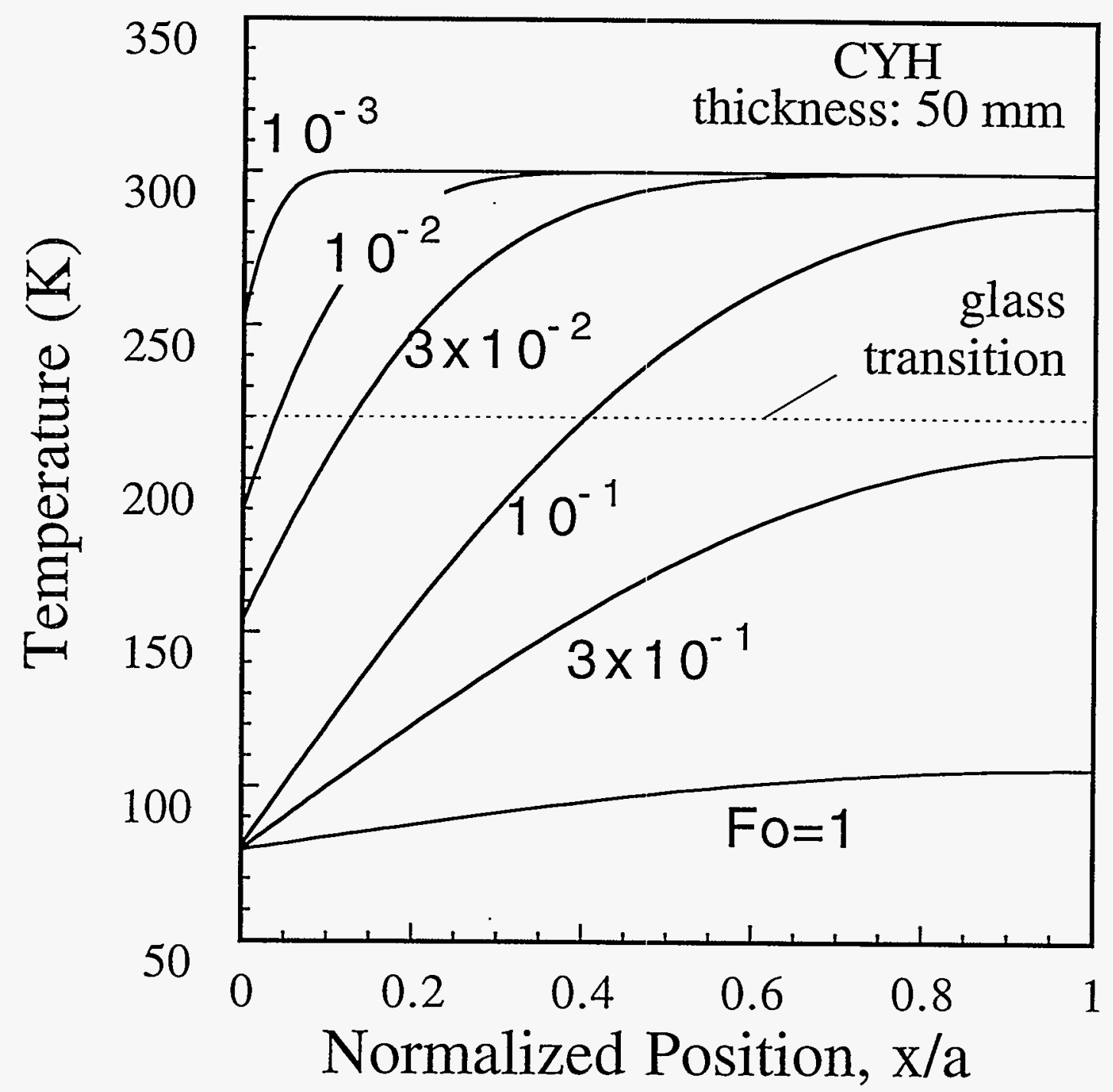

Figure 13. Predicted temperature profiles in a $50 \mathrm{~mm}$ slab of $\mathrm{CYH}$.

The corresponding stress distributions presented in Figure 14 are strongly influenced by the thousand-fold increase in elastic modulus that occurs as the material passes through its glass transition at $225 \mathrm{~K}$. Prior to $\mathrm{Fo}=10^{-2}$, nearly all of the material remains warmer than the transition temperature, $\mathrm{T}_{\mathrm{g}}$. For that time, the propellant's modulus is so small that thermally induced stresses are negligible. As cooling proceeds beyond $\mathrm{Fo}=10^{-2}$, the glass transition front sweeps inward from the surface to the interior. $\mathrm{By} F \mathrm{Fo}=10^{-1}$, the outer $40 \%$ of the slab has been cooled below $\mathrm{T}_{\mathrm{g}}$, as apparent in the stress profiles which indicate significant stresses over the interval $0<x / a<0.4$. It is apparent from these results that surface tensile stresses are balanced by internal compressive stresses, and that this balance must be maintained entirely within the highmodulus material. This restriction of stresses to the thermally influenced region reduces the maximum tensile stresses to less than $1 / 4$ of the maximum attainable stress, $\sigma_{0}=\phi\left(\mathrm{T}_{\mathrm{b}}\right)$, which is used as a reference stress in scaling the vertical axis of Figure 14. 


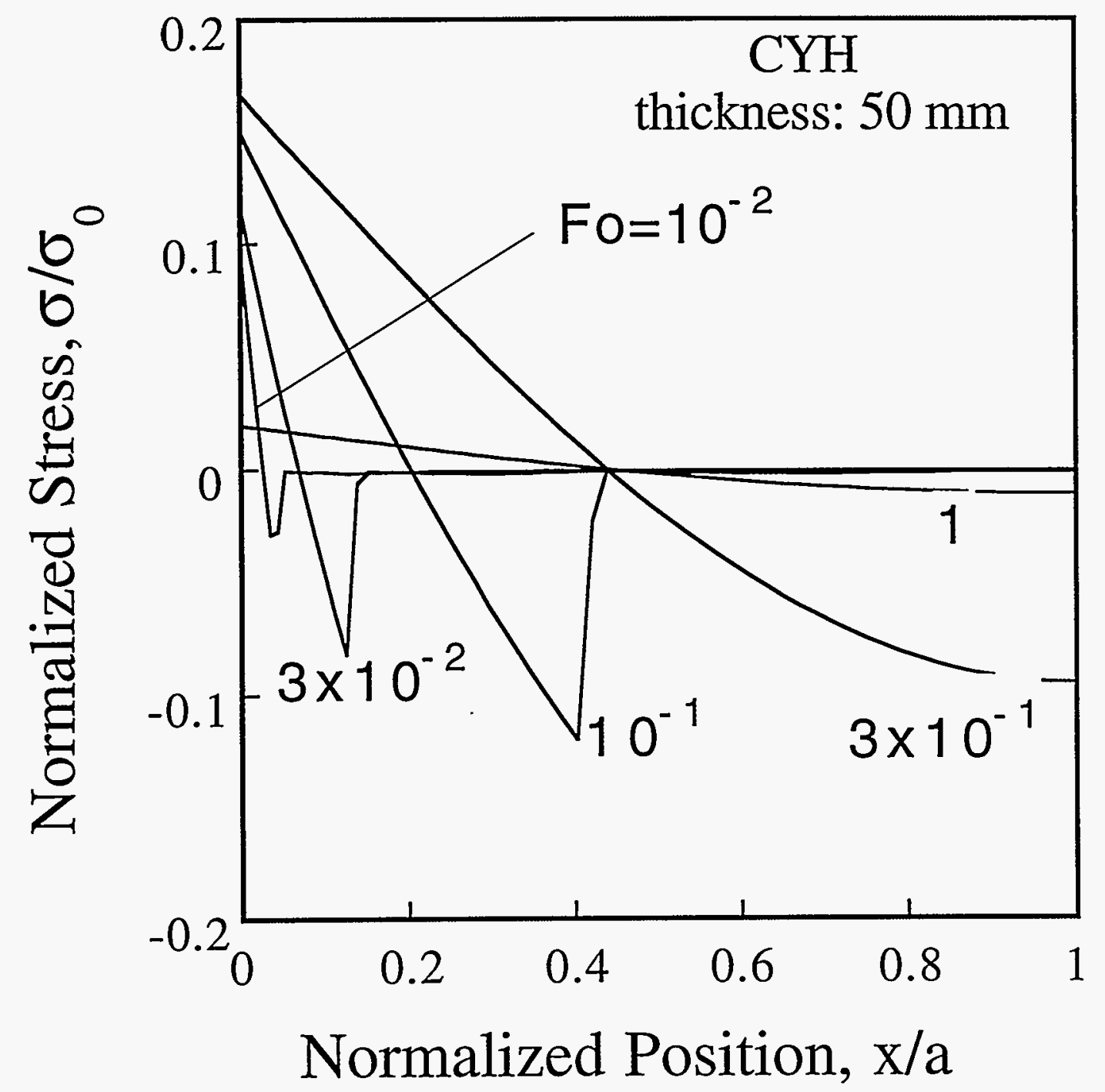

Figure 14. Predicted stress profiles in a $50 \mathrm{~mm}$ slab of CYH.

Figure 14 illustrates two important aspects of cryocycling that are generally valid regardless of process parameters. First, the maximum stress occurs in a time range from $\mathrm{Fo}=0.1-0.3$, a time much shorter than the thermal equilibration time of $F o=1.0$. Cooling beyond $F o=0.3$ thus provides no added benefit and needlessly extends both the cooling and warming phases of the cycle. The second general observation is that stresses always remain compressive in the central region of the slab, indicating that the fractures produced on cooling cannot penetrate more than about $50-70 \%$ of the distance from the surface to the center. It is, however, possible to extend fractures through the center of the slab by subsequently heating the exterior, thereby producing compressive stresses at the surface and tensile stresses in the interior. Accordingly, sequential cycles of rapid cooling and heating should be particularly effective in breaking a material.

The occurrence of fracturing can be predicted by comparing the local time-dependent stress at the surface with the temperature-dependent strength at the same location. Before stresses become significant, the strength of the surface material typically increases by about one order of 
magnitude during the glass transition. Thereafter, the ratio of stress to strength grows for a while, reaches a maximum, and then subsides as temperatures equilibrate and stresses diminish.

Figure 15 displays the calculated maximum ratio of stress to strength for four propellants, one plastic bonded explosive (PBX), two propellant simulants (LWCYH and H-19), and the polystyrene which was used in cryocycling experiments. The order from left to right is based on the experimental ranking of "best" to "worst" susceptibility to cryocycling. CYH is the only exception to this ranking. Since it has not yet been subjected to cryocycling experiments, it was placed between the two most similar materials, CMDB and LWCYH. The calculated ratio of stress to strength is clearly greatest at the left, falling gradually to the right, in keeping with the experimental ranking. The ratio of stress to strength is greater than unity for all materials (except $\mathrm{H}-19$ ), indicating that a $25 \mathrm{~mm}$ slab of any one (except $\mathrm{H}-19)$ should fracture.

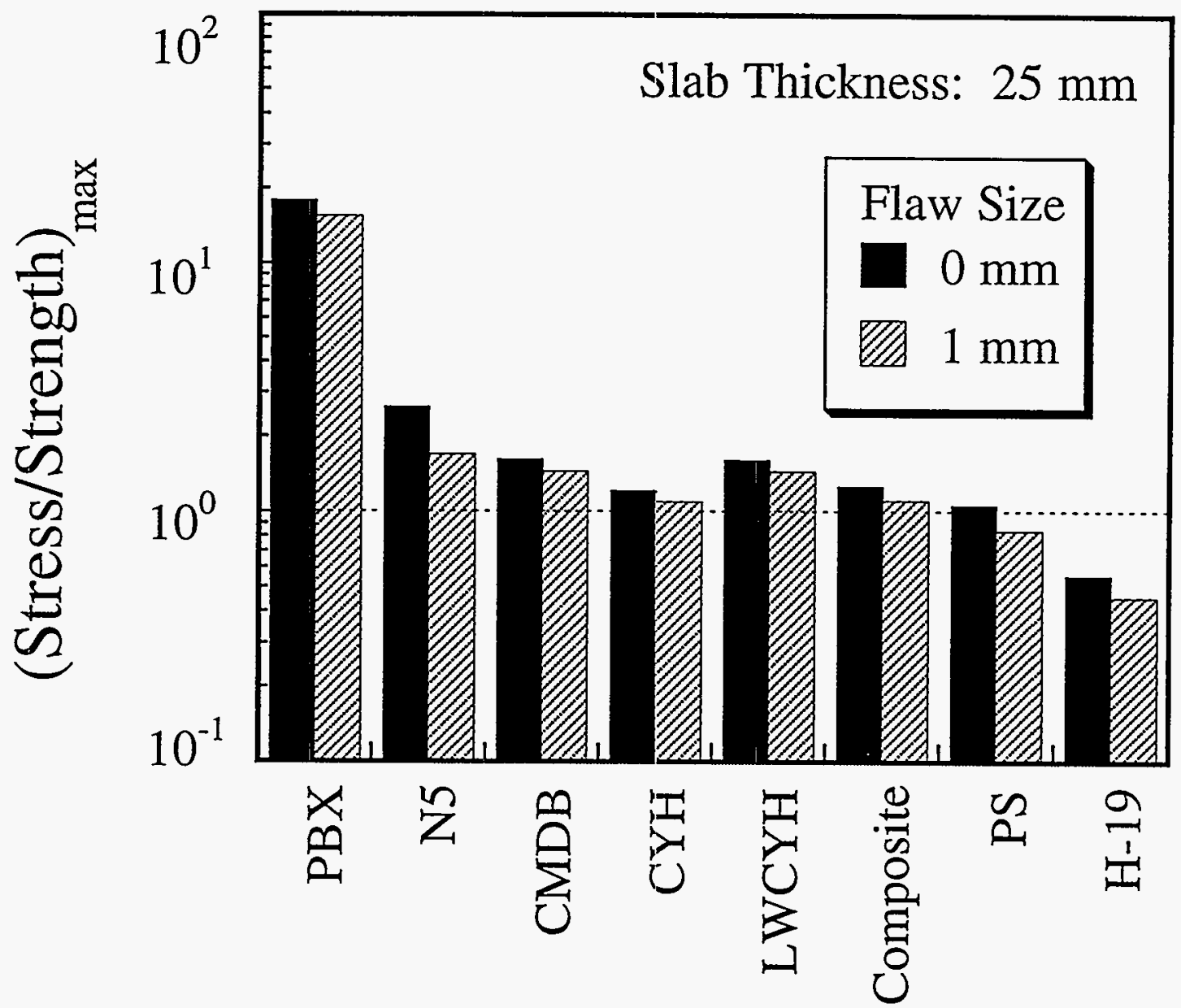

Figure 15. Maximum ratio of stress to strength; comparison of analytical predictions (bar height) with experimental observations (horizontal ranking).

The minimum fragment size obtainable by cryocycling can be estimated by calculating the maximum ratio of stress to strength for successively smaller slab thicknesses. As the thickness decreases, heat conduction becomes more effective in reducing the temperature difference and, hence, thermal stress within the slab. The minimum fragment sizes shown in Figure 16 are the slab thicknesses which resulted in a unit ratio of stress to strength. Presumably a slightly thicker slab would break in two, while a slightly thinner slab would remain in one piece. So the minimum particle size should be as displayed in Figure 16 or, perhaps, one half that large. The 
smallest sizes are predicted for the leftmost materials that were, in fact, deemed "best" in cryocycling experiments because they yielded the smallest fragment sizes.

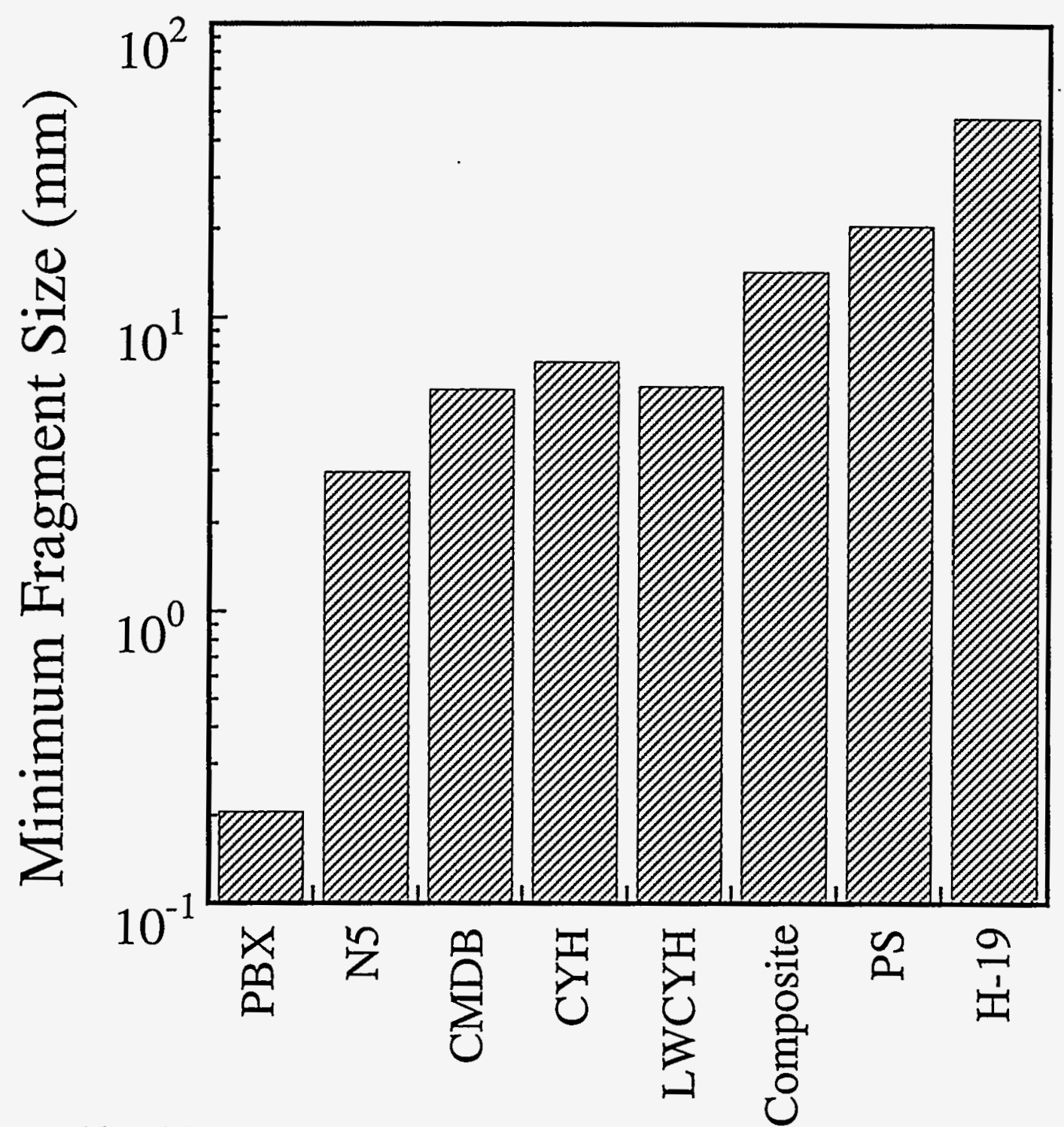

Figure 16. Minimum particle size obtainable by cryocycling; comparison of analytical predictions (bar height) with experimental observations (horizontal ranking).

The predicted fragment sizes shown in Figure 16 agree reasonably well with those observed experimentally. For example, cryocycling of $\mathrm{H}-19$ resulted in an average particle size of $60 \mathrm{~mm}$, in remarkable agreement with predictions. In the middle of the spectrum, LWCYH broke down to an average particle size of roughly $8 \mathrm{~mm}$, as compared with a prediction of $6 \mathrm{~mm}$; composite and $\mathrm{CMDB}$ produced similar particle sizes, in general agreement with the model. Cryocycling of PBX produced many small fragments $(<5 \mathrm{~mm})$ which were themselves severely cracked and so friable that the ultimate particle size was expected to be less than $1 \mathrm{~mm}$. Indeed, the predictions suggest that a considerably smaller size $(0.2 \mathrm{~mm})$ would be obtained if the material behaved as a continuum at length scales of less than $1 \mathrm{~mm}$.

While these comparisons of analytical and experimental results are generally encouraging, they nevertheless illustrate the importance of obtaining reliable measurements of strength and 
modulus, especially at liquid nitrogen temperature. For example, a 50\% uncertainty in either of these quantities can result in an order of magnitude uncertainty in predicting the ultimate particle size, since the maximum attainable stress rarely exceeds the cryogenic strength by more than $50 \%$ to $100 \%$. Among the materials considered here, polystyrene and PBX are probably the best characterized, since they experience glass transition above or near room temperature. The properties of composite and CMDB have been carefully measured by Hercules at liquid nitrogen temperature but are lacking at intermediate temperatures. Conversely, the temperature dependence is known for CYH and N5 from 173 to $300 \mathrm{~K}$, but the low temperature behavior must be extrapolated. Finally, although the properties of the inert propellant simulants, LWCYH and $\mathrm{H}-19$, were measured over the full temperature range, the two different experimental techniques used in these measurements produced different values for the low temperature modulus; we chose to use the larger values for the sake of consistency with other materials.

Ongoing analytical work is focused upon the derivation of scaling laws and engineering formulas relating the required processing time, fragmentation history, and minimum particle size to material properties and process parameters. The usefulness of this approach is illustrated by our earlier observation that the cooling phase of cryofracture should be terminated when the dimensionless time, or Fourier number, is roughly 0.2 . Since $F o=\alpha t / a^{2}$, it follows that the cooling time should decrease as the square of the fragment size, a, on successive cryocycles in order to avoid unnecessary warming time between cycles. In a similar fashion, we are seeking to derive a closed-form approximation for the minimum fragment size in terms of the maximum attainable thermal stress (for large fragment size), the cryogenic strength, and the associated Biot number at which maximum thermal stress barely exceeds strength. Prediction of the number of fragments produced on a given cryocycle-will, however, require consideration of interactions between neighboring fractures. Although this issue may eventually yield to analytical techniques, it is first being studied through the application of network modeling.

\section{Network Modeling}

Network models represent a solid body of interest by a triangular lattice of breakable elastic bonds joining neighboring nodes of material. In contrast to previous network models which have utilized regular hexagonal grids, our calculational grids are constructed in a random fashion which avoids the introduction of preferential cracking directions. Nodal point locations are sequentially selected by a random number generator, rejecting any which fall too close to existing points. When repeated to saturation, this procedure generates a randomly oriented network having a fairly regular zone size comparable to the preselected minimum spacing. Figure 17 shows a typical array of nodal points with bonds joining nearest neighbors represented with thin lines. The corresponding zone boundaries, shown in Figure 17 with thicker lines, are the Voronoi polygons obtained by assigning to each nodal point the region closer to it than to any other point. 


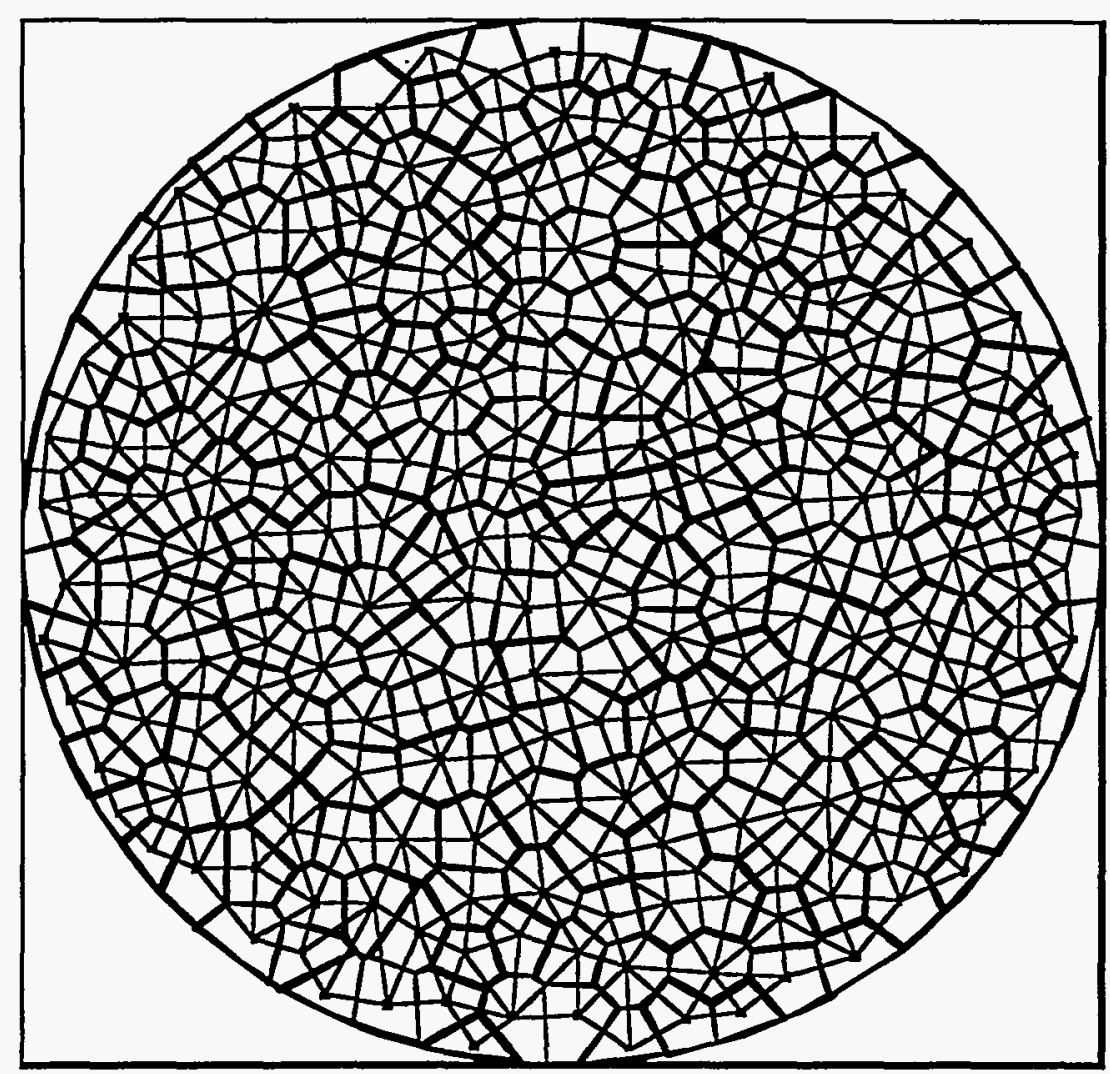

Figure 17. Randomly generated network model. Nodal points and bonds represented with thin lines and zone boundaries with thick lines.

The response of the network to imposed stresses or strains is determined by solving the twodimensional equations of momentum conservation using a time-marching implicit/explicit algorithim. The new position of each nodal point is written in terms of its old position, old velocity, and a weighted average of old and new accelerations. Those accelerations are then expressed in terms of nodal masses and the applied forces which are proportional to the axial strains in the bonds. Finally, by relating the new strains to the new nodal positions, we obtain a coupled system of algebraic equations which is iteratively solved for the new positions. If the stress in any bond should exceed its preassigned strength, the bond is broken and the corresponding force on the ruptured cell face is thereafter set to zero. The same algorithm can also be applied to quasistatic problems by simply omitting the inertial terms and relaxing the network to equilibrium after each time step.

The non-deterministic nature of the fracturing process is incorporated through probabalistic mesh generation and by assigning small random variations to the modulus and ultimate strength of each bond. For these reasons, repeated simulations of a given cryocycling process will differ in detail, as do cryocycling experiments, even though the size distribution of fragments will be quite similar for all.

A two-dimensional cryocycling simulation may be performed in either the plane of the cooled surface or in a perpendicular cross section. In the latter case, temperature varies with time and with distance from the cooled surface in accordance with the analytical solution given earlier. At each time step, the mean temperature of each bond is used to determine its thermal strain.

Contraction of surface bonds produces tensile stresses which may grow large enough to break surface bonds, giving rise to fractures that propagate into the material. Conversely, two- 
dimensional calculations performed in the surface plane depict propagation of fractures across the cooled face of the material. In either instance, the spacing between fractures and related fragment size is then determined as a function of the time or, equivalently, thermal strain.

Figure 18 compares the results of network modeling with photographs of inert propellant samples taken after 1,2 , and 3 exposures to liquid nitrogen. The calculated fracture pattern in the upper frames are obtained by connecting the perpendicular bisectors of broken bonds. Surface fracturing of this type proceeds in a discrete manner as the surface strain increases. After reaching the threshold strain required to rupture the weakest bond, very little additional strain is needed to subdivide the disc into three to five pieces of comparable size. From that point, the additional surface strain required to subdivide a fragment is inversely proportional to the square of the current fragment size.

Comparisons like these clearly illustrate the ability of the model to reproduce qualitative features of the cryocycling process. Work in this area is presently focused on quantitative comparisons with exact analytical solutions describing fracture propagation and interaction. Ultimately, a combination of analytical and network modeling may prove useful in dealing with inherently three-dimensional aspects of the cryocycling process.
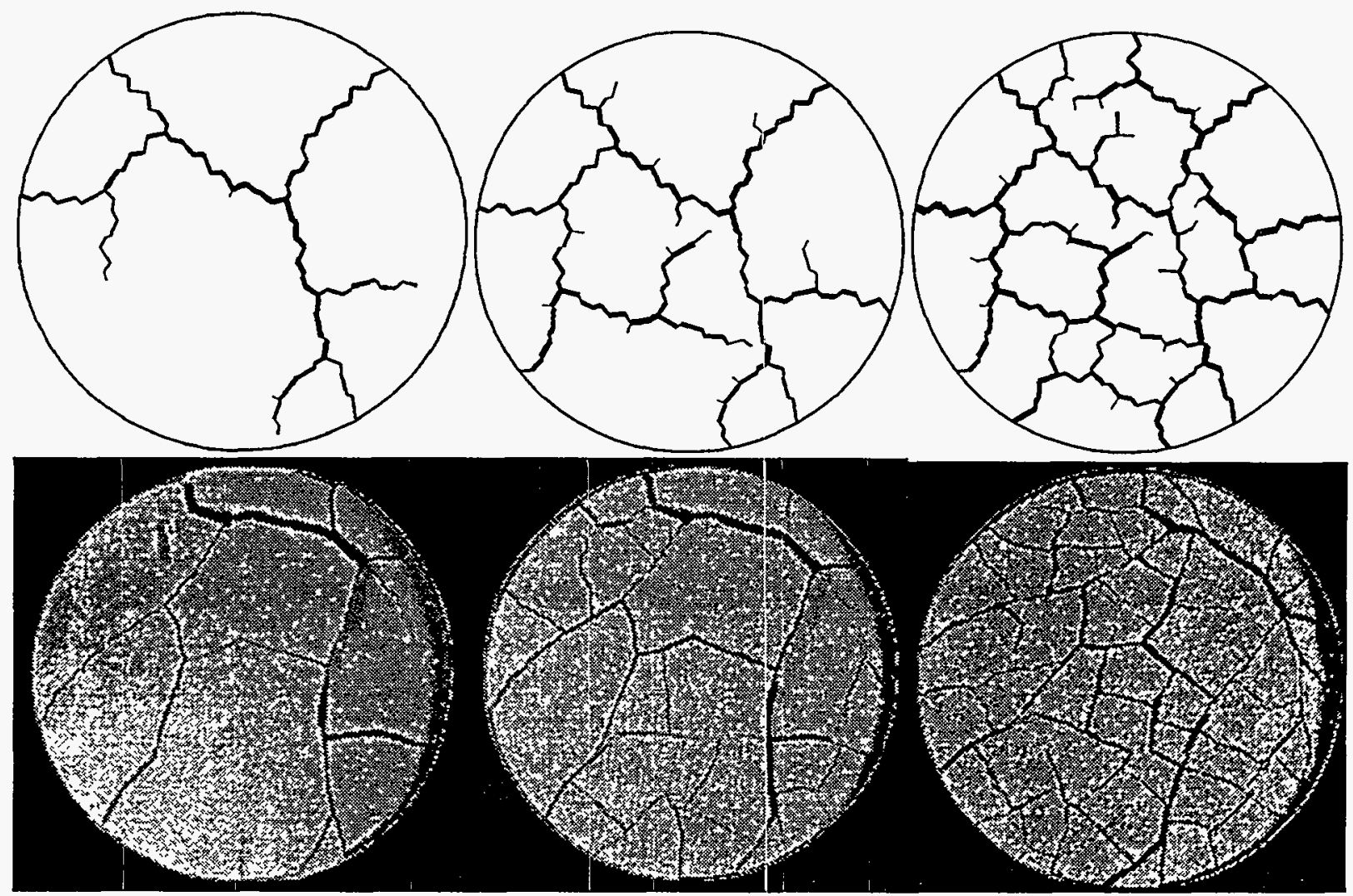

Figure 18. Comparison of network model with experiment. Disks were initially $75 \mathrm{~mm}$ dia. and $10 \mathrm{~mm}$ thick.

\section{Conclusions}

Cryocycling has been demonstrated on several inert propellant compositions with a range of physical properties. These experiments were useful in demonstrating cryocycling as an effective 
propellant size reduction technology that results in particle sizes small enough for reuse applications. Homogeneous and translucent materials allowed us to observe crack propagation and determine crack depth as a function of time. Breaking ratios were also obtained for each inert propellant with a given initial particle size, temperature, and cycle number.

Four live propellants were successfully cryocycled. A $20 \mathrm{~cm}$ length section $(7 \mathrm{~cm}$ diameter) of a double-base propellant grain from a Mighty Mouse tactical rocket motor was cracked into approximately 10,000 pieces of less than $1 \mathrm{~cm}$ in size after only three thermal cycles. A series of experiments were conducted with three propellants, including a composite modified double-base (CMDB), a cross-linked double-base (XLDB), and a composite propellant. Initial sizes of $5 \mathrm{~cm}$ by $5 \mathrm{~cm}$ by $X$, where $X$ was varied from 0.7 to $5 \mathrm{~cm}$. All three of the compositions broke up with the CMDB propellant having the smallest ultimate particle size, followed by XLDB and the composite.

Although cryocycling is simple in concept, it is difficult to predict the degree of fragmentation that will occur. The controlling physical mechanisms include boiling heat transfer, heat conduction, thermally induced stresses, and fracture propagation. The material also experiences variations of modulus and strength spanning two or three orders of magnitude during cooling to liquid nitrogen temperatures. A one dimensional analytical modeling of these coupled processes was formulated and used to predict the occurrence of fracturing, the time require for its completion, and the smallest fragment sizes which can be produced. Although predicted fragment sizes are consistent with experimental observations, the predictions are strongly dependent upon the material strength and modulus at liquid nitrogen temperature, data which are sometime unavailable or unreliable. The analytical model further indicated that fracturing should be complete in a dimensionless time, or Fourier modulus, of $0.1-0.3$, thus providing a simple guideline for process optimization. In addition to these analytical results, a network model was used to simulate the processes of fracture initiation, interaction, and intersection which determine the evolution of fragment sizes on successive cryocycles. The qualitative behavior of this model is in remarkable agreement with experimental observations, lending encouragement to further quantitative development and evaluation. In addition to the analytical and network modeling activities described here, finite difference and finite element analyses have also been performed with the latter modeling capability now reaching a level of sophistication which will allow explicit simulations of the initiation and growth of a multitude of cryofractures in complex rocket motor geometries.

We have successfully demonstrated cryocycling on a variety of propellant compositions. Based on our results, tactical rocket motors (especially cartridge loaded) can be effectively size reduced by cryocycling for several reuse applications. While the applicability of cryocycling to a given rocket motor is not limited by size in principle, some of the economic benefits are diminished, compared to competitive technologies, for larger motors. We currently feel cryocycling is most advantageous for propellant grains up to approximately $30 \mathrm{~cm}$ in diameter. Cryocycling has successfully and safely reduced the particle size of every live propellant attempted including several compositions not discussed in this paper. We do not know the limits of cryocycling on case bonded propellants. The propellant grains in these motors usually crack significantly, but remain inside the case as a three dimensional interlocking puzzle. Cryocycling may still be successful on some case bonded compositions and geometries.

We are concentrating on combining cryocycling with reuse and recovery technologies rather than destruction technologies. Environmental and economic analysis dictate that the inherent energy of the millions of pounds of propellant in the stockpile, and being more produced daily, should be viewed as a resource, rather than a waste. 


\section{APPENDIX A}

Particle Size Distributions of Live Propellants from Hercules Experiments

\begin{tabular}{|c|c|c|c|c|c|}
\hline $\begin{array}{l}\text { Propellant/ } \\
\text { Thickness }(\mathrm{cm})\end{array}$ & $\begin{array}{c}\text { \# of } \\
\text { Cycles }\end{array}$ & -4 Mesh & $\begin{array}{c}-1 \mathrm{~g}+4 \mathrm{Mesh} \\
\text { \# of } \\
\text { particles/mass }\end{array}$ & $\begin{array}{c}-3 g+1 g \\
\# \text { of } \\
\text { particles/mass }\end{array}$ & $\begin{array}{c}+3 \mathrm{~g} \\
\# \text { of } \\
\text { particles/mass }\end{array}$ \\
\hline \multirow{8}{*}{ CMDB-0.6 } & 0 & 0.0 & $0 / 0.0$ & 00.0 & $1 / 34.5$ \\
\hline & 1 & 0.35 & $26 / 14.6$ & $1 / 1.6$ & $3 / 17.9$ \\
\hline & 2 & 0.35 & $57 / 20.8$ & $7 / 8.25$ & $1 / 3.4$ \\
\hline & 3 & 6.78 & $117 / 26.9$ & $0 / 0.0$ & $0 / 0.0$ \\
\hline & 4 & 14.4 & $125 / 19.2$ & $0 / 0.0$ & $0 / 0.0$ \\
\hline & 5 & 29.9 & $39 / 3.7$ & $0 / 0.0$ & $0 / 0.0$ \\
\hline & 6 & 31.3 & $26 / 2.2$ & $0 / 0.0$ & $0 / 0.0$ \\
\hline & 7 & 32.2 & $14 / 1.26$ & $0 / 0.0$ & $0 / 0.0$ \\
\hline \multirow{6}{*}{$\begin{array}{l}\text { CMDB-0.6 } \\
\text { theat } \\
\end{array}$} & & & & & \\
\hline & 0 & 0.0 & $0 / 0.0$ & $\overline{0 / 0.0}$ & $1 / 33.3$ \\
\hline & 1 & 0.14 & $5 / 2.6$ & $8 / 13.4$ & $4 / 17.2$ \\
\hline & 2 & 0.85 & $25 / 10.3$ & $14 / 22.2$ & $0 / 0.0$ \\
\hline & 3 & 2.14 & $87 / 28.6$ & $2 / 2.7$ & $0 / 0.0$ \\
\hline & 4 & 13.1 & $120 / 20.4$ & $0 / 0.0$ & $0 / 0.0$ \\
\hline \multirow{9}{*}{ CMDB-0.6 } & & & & & \\
\hline & 0 & 0.0 & $0 / 0.0$ & $0 / 0.0$ & $1 / 31.5$ \\
\hline & 1 & 0.02 & $15 / 9.1$ & $7 / 16.7$ & $1 / 5.7$ \\
\hline & 2 & 0.92 & $67 / 24.1$ & $4 / 5.8$ & $0 / 0.0$ \\
\hline & 3 & 8.04 & $128 / 22.6$ & $0 / 0.0$ & $0 / 0.0$ \\
\hline & 4 & 18.9 & $95 / 11.6$ & $0 / 0.0$ & $0 / 0.0$ \\
\hline & 5 & 28.1 & $27 / 2.4$ & $0 / 0.0$ & $0 / 0.0$ \\
\hline & 6 & 29.4 & $11 / 1.1$ & $0 / 0.0$ & $0 / 0.0$ \\
\hline & 7 & 30.1 & $1 / 1.0$ & $0 / 0.0$ & $0 / 0.0$ \\
\hline \multirow{9}{*}{ CMDB-1.2 } & & & & & \\
\hline & 0 & 0.0 & $0 / 0.0$ & $0 / 0.0$ & $1 / 54.8$ \\
\hline & 1 & 0.25 & $3 / 1.45$ & $4 / 6.2$ & $5 / 46.9$ \\
\hline & 2 & 0.79 & $13 / 3.7$ & $12 / 23.2$ & $5 / 27.1$ \\
\hline & 3 & 0.88 & $20 / 6.4$ & $14 / 24.5$ & $5 / 22.9$ \\
\hline & 4 & 3.4 & $98 / 34.0$ & $12 / 17.3$ & $0 / 0.0$ \\
\hline & 5 & 20.3 & $196 / 34.3$ & $0 / 0.0$ & $0 / 0.0$ \\
\hline & 6 & 25.7 & $180 / 28.9$ & $0 / 0.0$ & $0 / 0.0$ \\
\hline & 7 & 48.0 & $65 / 6.8$ & $0 / 0.0$ & $0 / 0.0$ \\
\hline \multirow{8}{*}{ CMDB-2.5 } & $\overline{0}$ & 00 & $0 \overline{00}$ & 000 & $7 / 1255$ \\
\hline & $\frac{0}{1}$ & 0.6 & 0.0 .0 & $33 / 28.6$ & $7 / 96.3$ \\
\hline & 2 & 2.76 & $59 / 15.2$ & $42 / 65.8$ & $8 / 40.9$ \\
\hline & 3 & 14.6 & $314 / 88.7$ & $16 / 21.3$ & $0 / 0.0$ \\
\hline & 4 & 35.5 & $403 / 87.8$ & $1 / 1.1$ & $0 / 0.0$ \\
\hline & 5 & \begin{tabular}{l|l}
93.0 \\
\end{tabular} & $229 / 31.4$ & $0 / 0.0$ & $0 / 0.0$ \\
\hline & 6 & 102.2 & $207 / 22.3$ & $0 / 0.0$ & $0 / 0.0$ \\
\hline & 7 & 118.5 & $64 / 5.9$ & $0 / 0.0$ & $0 / 0.0$ \\
\hline & & & & & \\
\hline
\end{tabular}




\begin{tabular}{|c|c|c|c|c|c|}
\hline CMDB-5.0 & 0 & $0 / 0.0$ & $0 / 0.0$ & $0 / 0.0$ & $1 / 244.3$ \\
\hline & 1 & 1.4 & & $48 / 31.7$ & $18 / 211.2$ \\
\hline & 2 & 8.2 & $110 / 27.3$ & $84 / 115.4$ & $17 / 93.1$ \\
\hline & 3 & 33.3 & $648 / 185.2$ & $16 / 22.8$ & $1 / 3.3$ \\
\hline & 4 & 68.6 & $787 / 172.5$ & $2 / 2.2$ & $0 / 0.0$ \\
\hline & 5 & 152.2 & $632 / 91.7$ & $0 / 0.0$ & $0 / 0.0$ \\
\hline & 6 & 162.1 & $702 / 81.4$ & $0 / 0.0$ & $0 / 0.0$ \\
\hline & 7 & 229.7 & $120 / 13.7$ & $0 / 0.0$ & $0 / 0.0$ \\
\hline \multirow{6}{*}{$\begin{array}{l}\text { CMDB-5.0 } \\
\text { theat } \\
\end{array}$} & 0 & 0 & $0 / 0.0$ & $0 / 0.0$ & $1 / 254.1$ \\
\hline & & & & & \\
\hline & 1 & 0.52 & $16 / 6.3$ & $5 / 10.6$ & $17 / 236.7$ \\
\hline & 2 & 7.33 & $138 / 50.2$ & $69 / 122.4$ & $19 / 73.8$ \\
\hline & 3 & 19.9 & $436 / 145.8$ & $55 / 80.4$ & $2 / 7.3$ \\
\hline & 4 & 73.3 & $881 / 179.1$ & $1 / 1.0$ & $0 / 0.0$ \\
\hline & & & & & \\
\hline \multirow[t]{8}{*}{ Composite- 0.6} & 0 & 0 & $0 / 0.0$ & $0 / 0.0$ & $1 / 26.6$ \\
\hline & 1 & 0 & $0 / 0.0$ & $1 / 1.4$ & $1 / 25.2$ \\
\hline & 2 & 0 & $2 / 1.35$ & $2 / 3.1$ & $2 / 22.1$ \\
\hline & 3 & 0.005 & $2 / 1.35$ & $6 / 8.5$ & $3 / 16.7$ \\
\hline & 4 & 0.005 & $2 / 1.35$ & $6 / 8.5$ & $3 / 16.7$ \\
\hline & 5 & 0.005 & $13 / 6.88$ & $8 / 13.8$ & $1 / 5.9$ \\
\hline & 6 & 0.005 & $14 / 6.88$ & $8 / 13.8$ & $1 / 5.9$ \\
\hline & 7 & 0.005 & $20 / 9.9$ & $8 / 10.8$ & $1 / 5.9$ \\
\hline \multirow{6}{*}{$\begin{array}{l}\text { Composite- } 0.6 \\
\text { theat }\end{array}$} & & & & & \\
\hline & 0 & $\overline{0}$ & $0 / 0.0$ & 0/0.0 & $1 / 25.05$ \\
\hline & 1 & 0 & $2 / 1.35$ & $2 / 4.8$ & $1 / 18.9$ \\
\hline & 2 & 0.01 & $2 / 1.34$ & $2 / 4.8$ & $1 / 18.9$ \\
\hline & 3 & 0.01 & $2 / 1.34$ & $2 / 4.8$ & $1 / 18.9$ \\
\hline & 4 & 0.01 & $3 / 1.9$ & $12 / 23.2$ & 0 \\
\hline \multirow{9}{*}{ Composite-1.2 } & & & & & \\
\hline & 요 & 0 & $0 / 0.0$ & $0 / 0.0$ & $1 / 67.1$ \\
\hline & 1 & 0 & $0 / 0.0$ & $0 / 0.0$ & $4 / 67.1$ \\
\hline & 2 & 0 & $0 / 0.0$ & $1 / 2$ & $6 / 65.1$ \\
\hline & 3 & 0.05 & $0 / 0.0$ & $4 / 8.9$ & $12 / 58.1$ \\
\hline & 4 & 0.05 & $2 / 1.0$ & $10 / 18.6$ & $11 / 47.4$ \\
\hline & 5 & 0.09 & $31 / 18.7$ & $28 / 45.2$ & $1 / 3.1$ \\
\hline & 6 & 0.16 & $32 / 19.2$ & $28 / 44.6$ & $1 / 3.1$ \\
\hline & 7 & 0.16 & $46 / 26.8$ & $28 / 40.1$ & $0 / 0.0$ \\
\hline \multirow{9}{*}{\begin{tabular}{|l|} 
Composite- 2.5 \\
\end{tabular}} & & & & & \\
\hline & 0 & $\frac{0}{n}$ & $0 / 0.0$ & $\frac{0 / 0.0}{1 / 2}$ & $1 / 128.7$ \\
\hline & 1 & 0 & $0 / 0.0$ & $1 / 1.2$ & $4 / 127.5$ \\
\hline & 2 & 0 & $0 / 0.0$ & $2 / 4.3$ & $13 / 124.2$ \\
\hline & 3 & 0.03 & $3 / 1.7$ & $9 / 19.3$ & $21 / 107.5$ \\
\hline & 4 & 0.05 & $9 / 6.14$ & $16 / 30.0$ & $20 / 92.3$ \\
\hline & 5 & 0.08 & $30 / 20.4$ & $61 / 97.0$ & $3 / 11.1$ \\
\hline & 6 & 0.07 & $54 / 36.9$ & $57 / 89.1$ & $1 / 3.35$ \\
\hline & 7 & 0.09 & $89 / 56.3$ & $51 / 72.1$ & $0 / 0.0$ \\
\hline
\end{tabular}




\begin{tabular}{|c|c|c|c|c|c|}
\hline & & & & & \\
\hline \multirow[t]{8}{*}{ Composite-5.0 } & 0 & 0 & $0 / 0.0$ & $0 / 0.0$ & $1 / 216.7$ \\
\hline & 1 & 0.04 & $4 / 1.5$ & $2 / 5.2$ & $7 / 209.6$ \\
\hline & 2 & 0.08 & $8 / 3.65$ & $2 / 5.2$ & $12 / 207.3$ \\
\hline & 3 & 0.13 & $18 / 9.3$ & $13 / 26.2$ & $32 / 180.4$ \\
\hline & 4 & 0.16 & $24 / 11.4$ & $21 / 41.3$ & $29 / 163.0$ \\
\hline & 5 & 0.39 & $55 / 29.2$ & $65 / 117.5$ & $16 / 68.7$ \\
\hline & 6 & 0.29 & $85 / 45.4$ & $66 / 115.3$ & $12 / 54.08$ \\
\hline & 7 & 0.44 & $124 / 66.1$ & $75 / 118.4$ & $8 / 30.7$ \\
\hline \multirow{6}{*}{$\begin{array}{l}\text { Composite-5.0 } \\
\text { theat }\end{array}$} & & & & & \\
\hline & 0 & 0 & $\overline{0} / 0.0$ & $0 / 0.0$ & $1 / 261.1$ \\
\hline & 1 & 0.14 & $0 / 0.0$ & $1 / 2.0$ & $11 / 259.0$ \\
\hline & 2 & 0.31 & $2 / 0.84$ & $3 / 4.7$ & $17 / 255.4$ \\
\hline & 3 & 0.41 & $12 / 4.6$ & $4 / 6.4$ & $35 / 250.0$ \\
\hline & 4 & 0.56 & $25 / 12.4$ & $52 / 96.4$ & $35 / 151.7$ \\
\hline & & & & & \\
\hline \multirow[t]{8}{*}{ XLDB-0.6 } & 0 & 0 & $0 / 0.0$ & $0 / 0.0$ & $1 / 33.07$ \\
\hline & 1 & 0.07 & $3 / 1.6$ & $4 / 7.3$ & $3 / 24.1$ \\
\hline & 2 & 0.42 & $11 / 6.1$ & $10 / 16.8$ & $2 / 9.9$ \\
\hline & 3 & 1.65 & $53 / 21.9$ & $7 / 9.7$ & $0 / 0.0$ \\
\hline & 4 & 4.7 & $78 / 27.2$ & $1 / 1.2$ & $0 / 0.0$ \\
\hline & 5 & 12.9 & $103 / 20.2$ & $0 / 0.0$ & $0 / 0.0$ \\
\hline & 6 & 14.9 & $95 / 18.2$ & $0 / 0.0$ & $0 / 0.0$ \\
\hline & 7 & 28.0 & $41 / 5.0$ & $0 / 0.0$ & $0 / 0.0$ \\
\hline \multirow{6}{*}{$\begin{array}{l}\text { XLDB-0.6 } \\
\text { theat }\end{array}$} & 0 & 0 & $0 / 0.0$ & $0 / 0.0$ & $1 / 33.87$ \\
\hline & 0 & & $0 / 0.0$ & $0 / 0.0$ & \\
\hline & 1 & 0.07 & $4 / 2.7$ & $11 / 18.8$ & $2 / 12.3$ \\
\hline & 2 & 0.5 & $55 / 20.8$ & $8 / 12.5$ & $0 / 0.0$ \\
\hline & 3 & 2.9 & $73 / 23.2$ & $6 / 7.8$ & $0 / 0.0$ \\
\hline & 4 & 7.1 & $92 / 22.7$ & $3 / 4.0$ & $0 / 0.0$ \\
\hline \multirow{8}{*}{ XLDB-1.2 } & 0 & 0 & $0 / 0.0$ & $0 / 0.0$ & $1 / 66.93$ \\
\hline & 1 & 0.13 & $1 / 0.1$ & $8 / 15.1$ & $5 / 51.6$ \\
\hline & 2 & 0.44 & $14 / 6.4$ & $11 / 20$ & $6 / 40.1$ \\
\hline & 3 & 2.19 & $64 / 23.4$ & $24 / 33.4$ & $2 / 7.7$ \\
\hline & 4 & 7.54 & $107 / 32.5$ & $14 / 18.9$ & $2 / 7.7$ \\
\hline & 5 & 16.8 & $197 / 47.4$ & $2 / 2.5$ & $0 / 0.0$ \\
\hline & 6 & 19.8 & $216 / 45.8$ & $1 / 1.0$ & $0 / 0.0$ \\
\hline & 7 & 37.5 & $169 / 129.1$ & $0 / 0.0$ & $0 / 0.0$ \\
\hline \multirow{8}{*}{ XLDB-2.5 } & & & & & \\
\hline & 0 & 0 & $0 / 0.0$ & $0 / 0.0$ & $1 / 122.77$ \\
\hline & 1 & 0.27 & $6 / 3.9$ & $13 / 18.5$ & $7 / 103.1$ \\
\hline & 2 & 1.39 & $34 / 12.7$ & $7 / 13.3$ & $12 / 98.3$ \\
\hline & 3 & 4.3 & $148 / 64.1$ & $26 / 42.9$ & $3 / 14.4$ \\
\hline & 4 & 14.0 & $257 / 82.3$ & $20 / 29.2$ & $0 / 0.0$ \\
\hline & 5 & 37.8 & $327 / 70.4$ & $12 / 17.1$ & $0 / 0.0$ \\
\hline & 6 & 44.3 & $349 / 64.8$ & $11 / 16.1$ & $0 / 0.0$ \\
\hline
\end{tabular}




\begin{tabular}{|r|r|r|r|r|r|}
\hline & 7 & 71.8 & $265 / 49.7$ & $2 / 3.6$ & $0 / 0.0$ \\
\hline & & & & & \\
\hline XLDB-5.0 & 0 & 0 & $0 / 0.0$ & $0 / 0.0$ & $1 / 258.39$ \\
\hline & 1 & 1.19 & $3 / 1.4$ & $7 / 15.8$ & $13 / 240.0$ \\
\hline & 2 & 2.28 & $25 / 8.6$ & $13 / 24.1$ & $15 / 223.6$ \\
\hline & 3 & 6.88 & $139 / 62.0$ & $80 / 133.3$ & $16 / 56.0$ \\
\hline & 4 & 17.1 & $387 / 141.9$ & $57 / 88.6$ & $3 / 10.2$ \\
\hline & 5 & 69.4 & $831 / 186.1$ & $2 / 2.26$ & $0 / 0.0$ \\
\hline & 6 & 74.5 & $941 / 182.0$ & $1 / 1.2$ & $0 / 0.0$ \\
\hline & 7 & 145.6 & $642 / 110.7$ & $1 / 1.2$ & $0 / 0.0$ \\
\hline & & & & & \\
\hline $\begin{array}{l}\text { XLDB-5.0 } \\
\text { +heat }\end{array}$ & 0 & 0 & $0 / 0.0$ & $0 / 0.0$ & $1 / 253.43$ \\
\hline & 1 & 0.88 & $21 / 4.65$ & $3 / 4.5$ & $19 / 243.4$ \\
\hline & 2 & 3.45 & $96 / 42.7$ & $66 / 122.2$ & $19 / 84.9$ \\
\hline & 3 & 8.33 & $174 / 71.7$ & $67 / 122.4$ & $13 / 50.6$ \\
\hline & 4 & 15.3 & $344 / 111.1$ & $54 / 95.2$ & $8 / 31.4$ \\
\hline
\end{tabular}




\section{APPENDIX B}

\section{Uniaxial Tensile Testing of H-19 and LWCYH}

\section{Mechanical Properties of $\mathrm{H}-19$}

Uniaxial mechanical properties of the $\mathrm{H}-19$ propellant as a function of temperature were measured at Sandia. The specific properties measured were: modulus, tensile strength, ductility and toughness. All properties, with the exception of toughness, were measured at a number of temperatures between $77 \mathrm{~K}$ and $298 \mathrm{~K}$ and at initial strain rates of $1.3 \times 10^{-4}, 1.3 \times 10^{-3}$, and 1.3 $\times 10^{-2} \mathrm{sec}^{-1}$. Since the material exhibits little linear elastic behavior except at the lowest temperatures measured, toughness was only measured at $77 \mathrm{~K}$ and $133 \mathrm{~K}$.

Tensile specimens with rectangular cross sections were machined from blocks of the mock material. The specimens had a reduced gage section measuring $3.18 \times 6.36 \mathrm{~mm}$ with a gage length of $15.88 \mathrm{~mm}$. Toughness measurements were performed on notched bend specimens. These specimens were $63.5 \mathrm{~mm}$ long and had a square cross-section measuring $11.18 \mathrm{~mm}$. Specimen preparation and toughness testing were performed according to ASTM Standard E 399-83. 21 While strictly valid only for materials exhibiting linear elastic behavior, the test was considered adequate for the $\mathrm{H}-19$ at low temperatures.

Properties were measured at five different temperatures. Low temperatures were achieved by immersing the specimens in low temperature "slush baths" using various organic liquids cooled with liquid nitrogen. The temperatures and fluids used are indicated in Table IV. Specimen temperature varied by less than $1 \mathrm{~K}$ during testing. Prior to testing, the mock propellant was exposed to these liquids at room temperature for extended periods of time to insure that the material did not degrade or suffer loss in properties due to interactions with the liquids. No measurable effects were observed on the room temperature mechanical properties as the result of prolonged exposure of the mock material to any of the fluids.

\begin{tabular}{|c|c|}
\hline Temperature, $\mathrm{K}$ & Fluid \\
\hline \hline 77 & Liquid Nitrogen \\
\hline 133 & Isopentane \\
\hline 180 & Methanol \\
\hline 233 & $\begin{array}{c}70 \% \text { Ethanol, } \\
30 \% \mathrm{H}_{20} 0\end{array}$ \\
\hline 298 & Air \\
\hline
\end{tabular}

Table IV. Test Temperatures and Temperature Baths

Figure 19 shows the results for the room temperature testing at all three strain rates studied. The results reveal that the material is quite sensitive to the imposed rate of deformation, exhibiting a 3-fold increase in the apparent modulus when comparing the lowest strain rate test to highest strain rate test. This sensitivity to the imposed strain rate reflects the relaxation characteristics of the material. Figure 20 shows a room temperature stress relaxation curve for the mock propellant tested at an initial strain rate of $1.3 \times 10^{-3} \mathrm{sec}^{-1}$. The specimen was loaded to approximately $70 \%$ of the ultimate tensile strength, UTS. The curve reveals that the material relaxes by more than half of the peak load in just a few minutes. It follows then, that tensile

${ }^{21}$ ASTM Standard E 399-83 
specimens tested at high strain rates, where this relaxation behavior is suppressed, will exhibit higher apparent moduli.

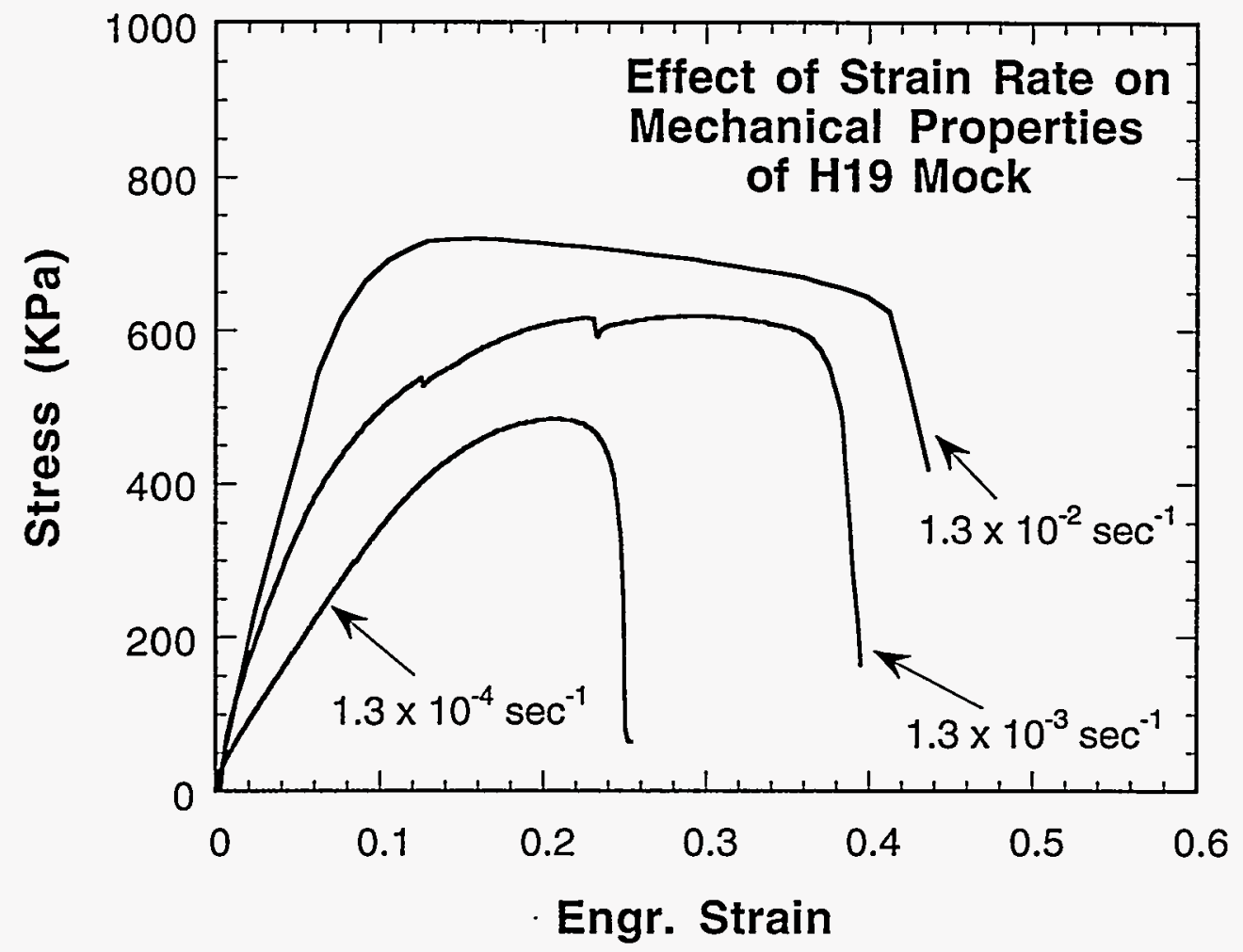

Figure 19. Tensile curves for $\mathrm{H}-19$ at three different strain rates at $25^{\circ} \mathrm{C}$. 


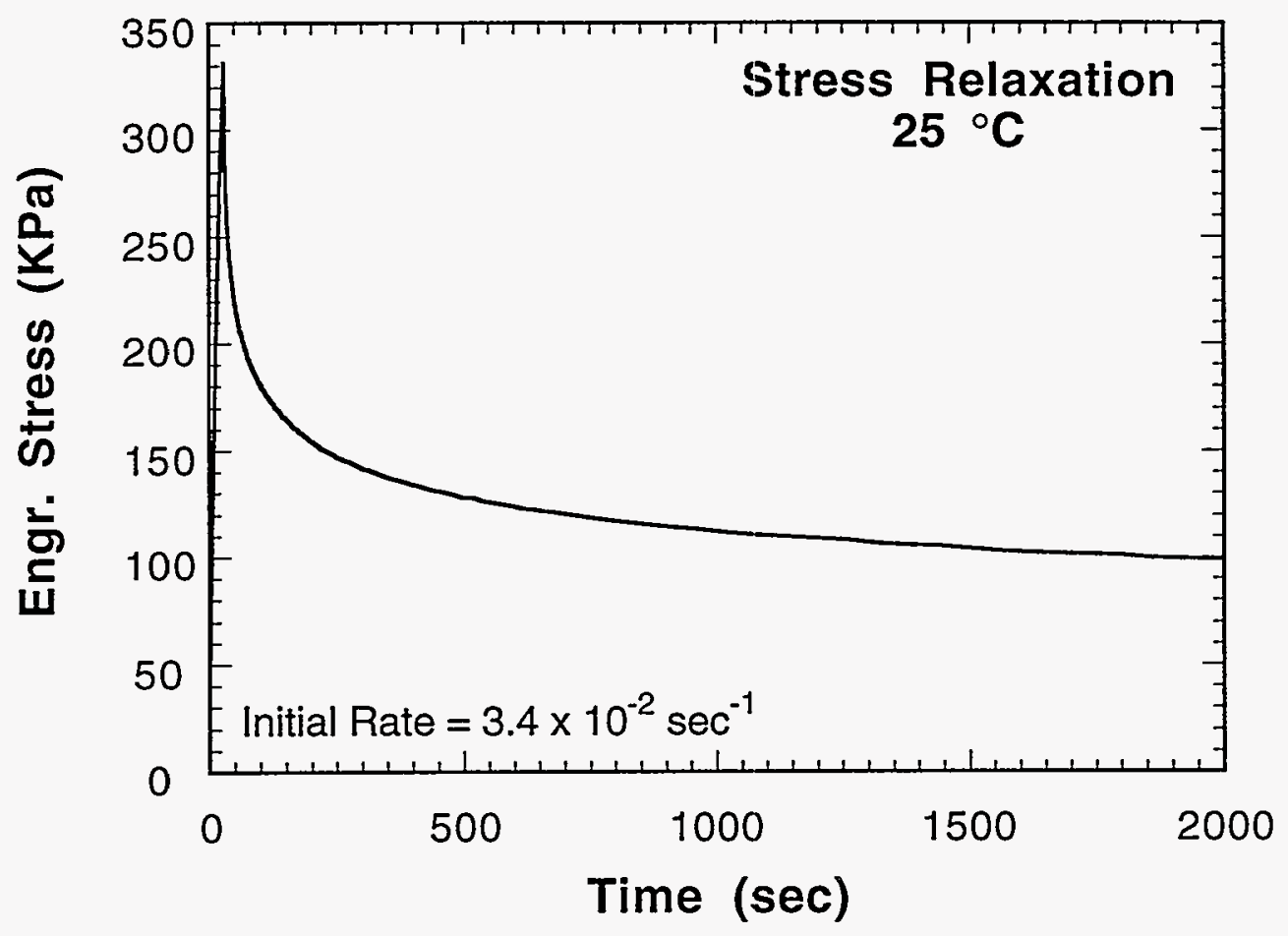

Figure 20. Stress relaxation of the mock propellant. Initial rate $=1.3 \times 10^{-3} \mathrm{sec}^{-1}$.

We observe that the sensitivity of the material decreases at lower test temperatures until at $77 \mathrm{~K}$, the tensile behavior of the material was essentially unaffected by strain rate.

Figure 21 shows the tensile response curves for the material tested at all five temperatures and at a strain rate of $1.3 \times 10^{-4} \mathrm{sec}^{-1}$. Clearly the mechanical properties of the material are sensitive to the test temperature, with the strength of the material increasing with decreasing temperature. The figure reveals that there is an abrupt increase in strength between $233 \mathrm{~K}$ and $180 \mathrm{~K}$.

Coincident with this abrupt increase in strength is an equally dramatic decrease in ductility. At the lowest temperatures, the material was quite brittle, so that fracture stress is equal to the tensile strength. Strength as a function of temperature is summarized in Figure 22. Figure 22 also summarizes the temperature dependence of the ductility. At temperatures above $233 \mathrm{~K}$, the material exhibited approximately $25-30 \%$ strain to failure. Below $233 \mathrm{~K}$, the abrupt change in strength and ductility is apparent. 


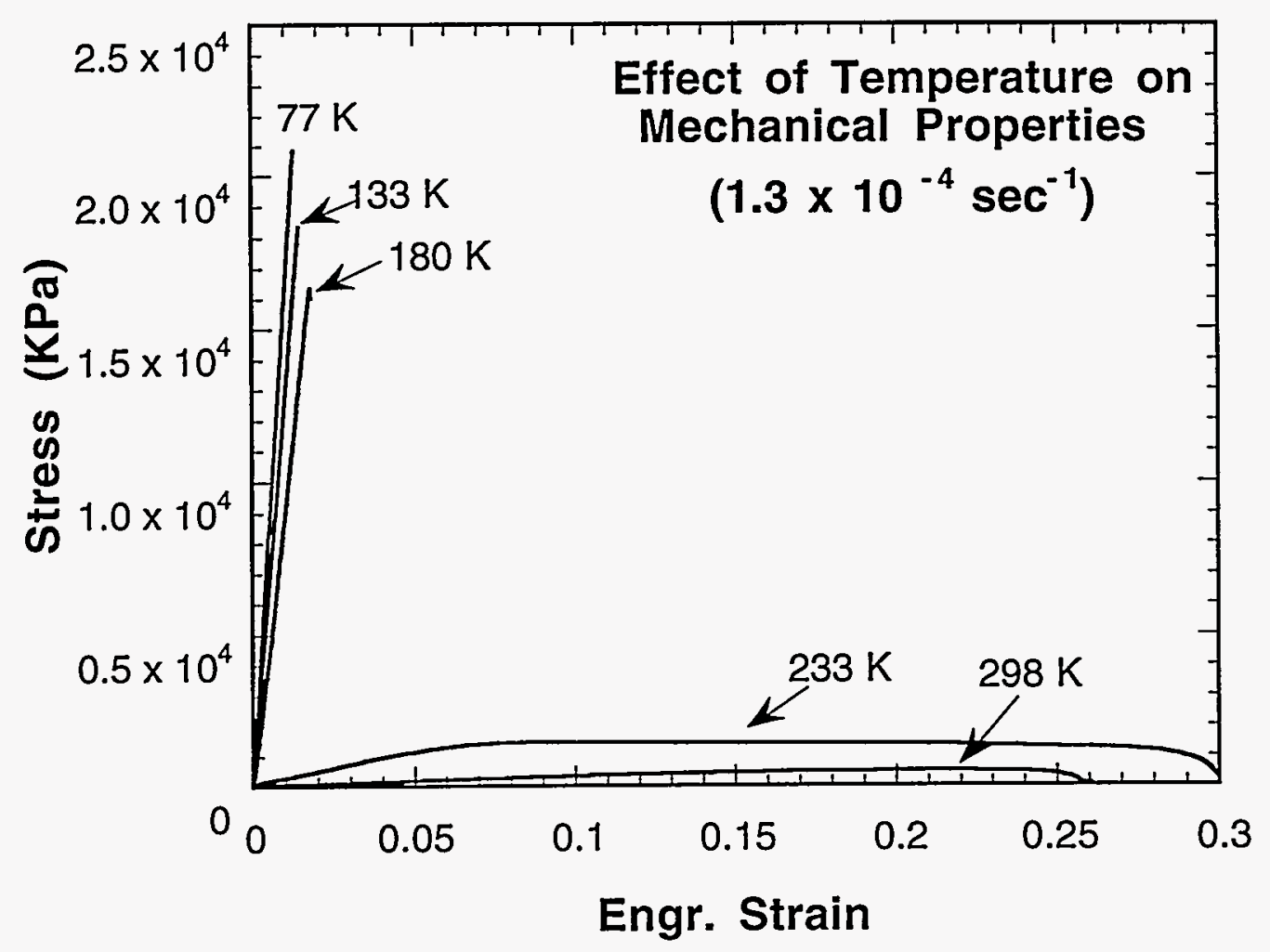

Figure 21. Temperature effects on tensile behavior of $\mathrm{H}-19$.

Modulus was also found to increase with decreasing test temperature. At room temperature, the material exhibits little elastic response. Modulus measurement via the kind of quasi-static testing presented here is difficult. Our best measure of the room temperature modulus is approximately $2.5 \mathrm{MPa}$. As with strength, there was an abrupt increase in modulus between 233 and $180 \mathrm{~K}$. At $77 \mathrm{~K}$ the modulus is well defined and equal to $2350 \mathrm{MPa}$, a nearly hundred-fold increase between the lowest and highest temperatures. The temperature dependence of the modulus is shown in Figure 23. 


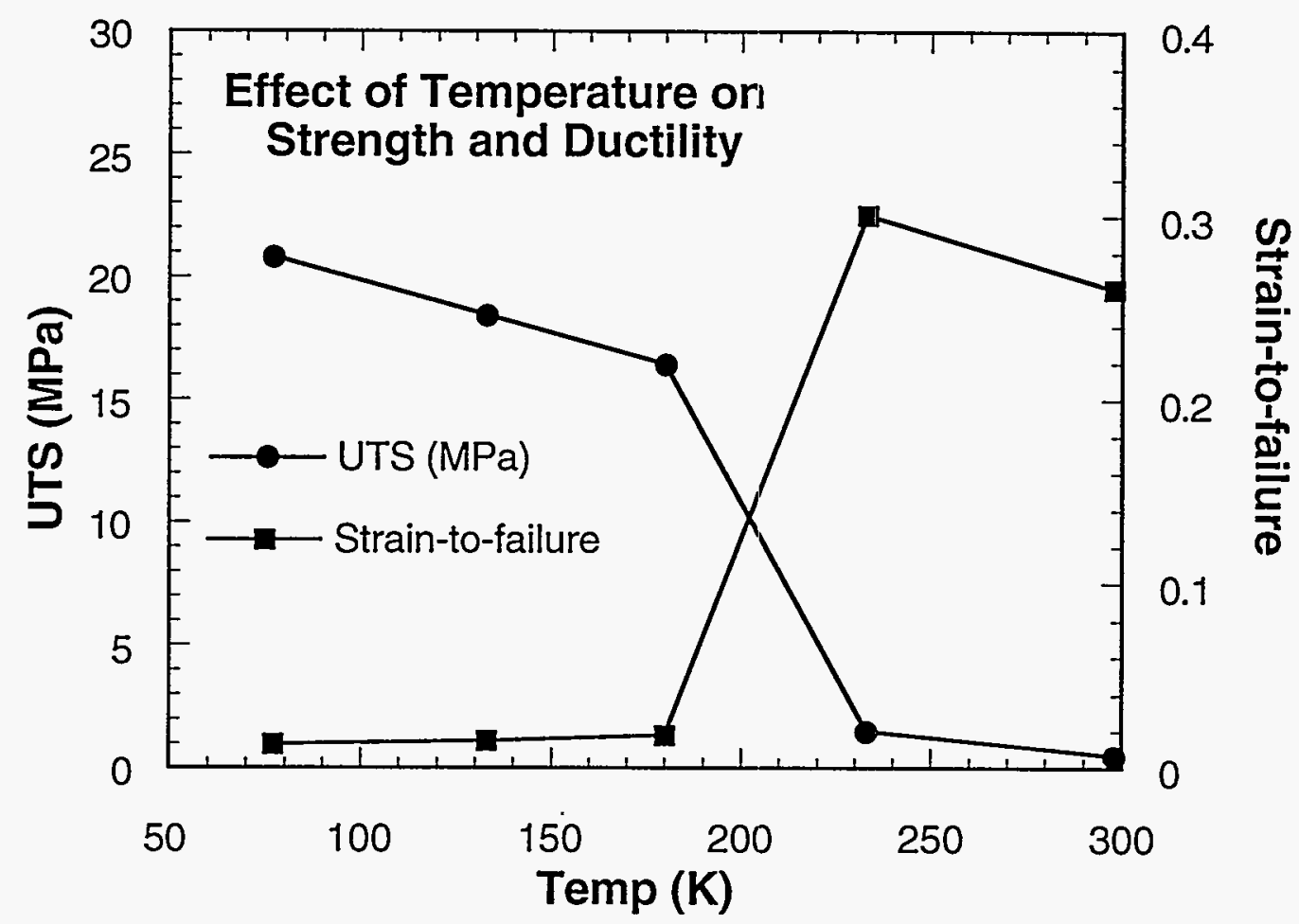

Figure 22. Effect of test temperature on strength and ductility.

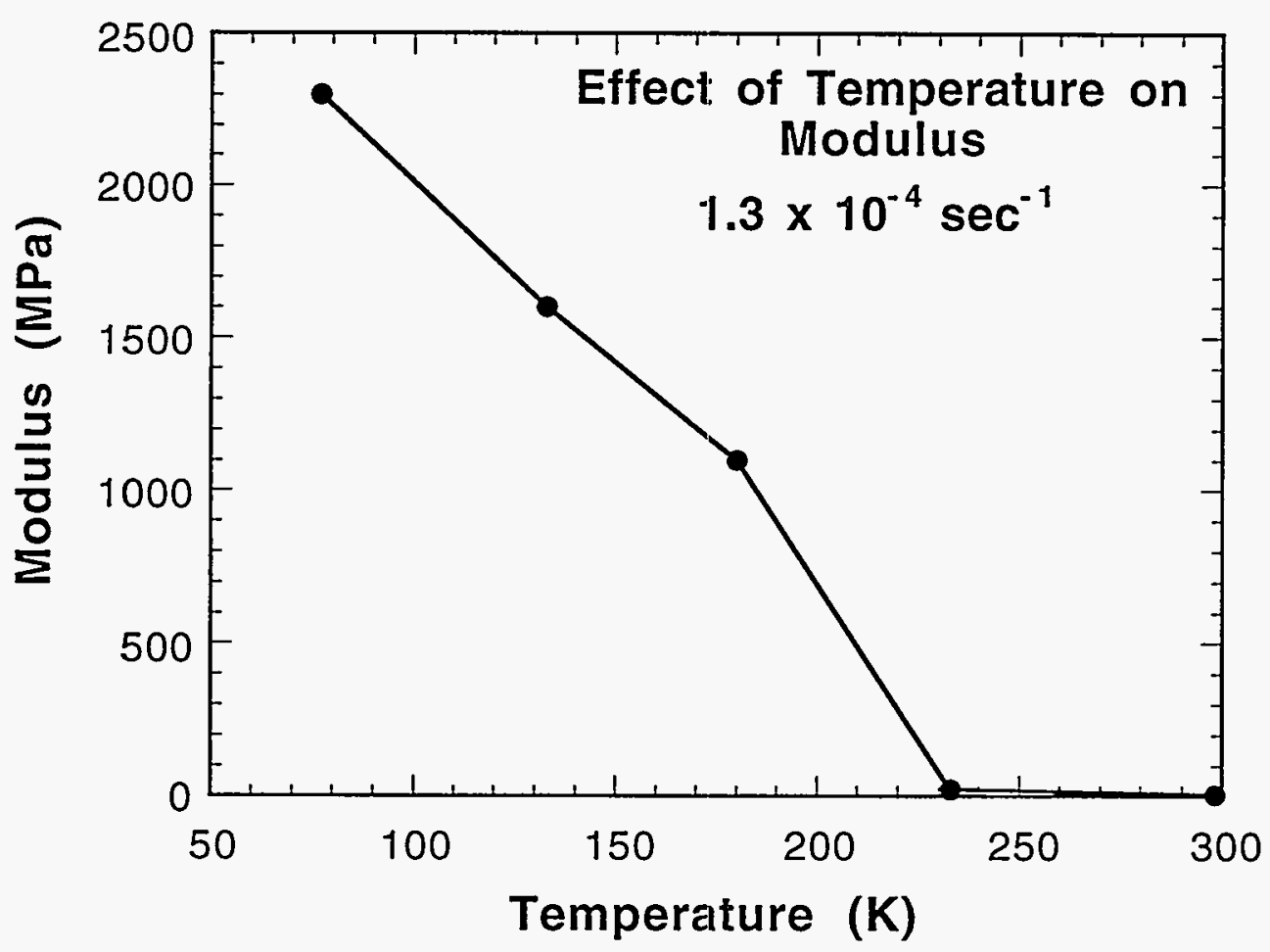

Figure 23. Modulus of H-19 propellant vs. test temperature. 


\section{Mechanical Properties of LWCYH}

Figure 24 shows the room temperature stress-strain curves of the LWCYH at the three different strain rates. The results reveal that the UTS of the material is even more sensitive to the imposed rate of deformation than $\mathrm{H}-19$. In this case, the material exhibited a 4-fold increase in strength when tested at the highest strain rate compared to the lowest strain rate. Ductility, however, was considerably less affected.

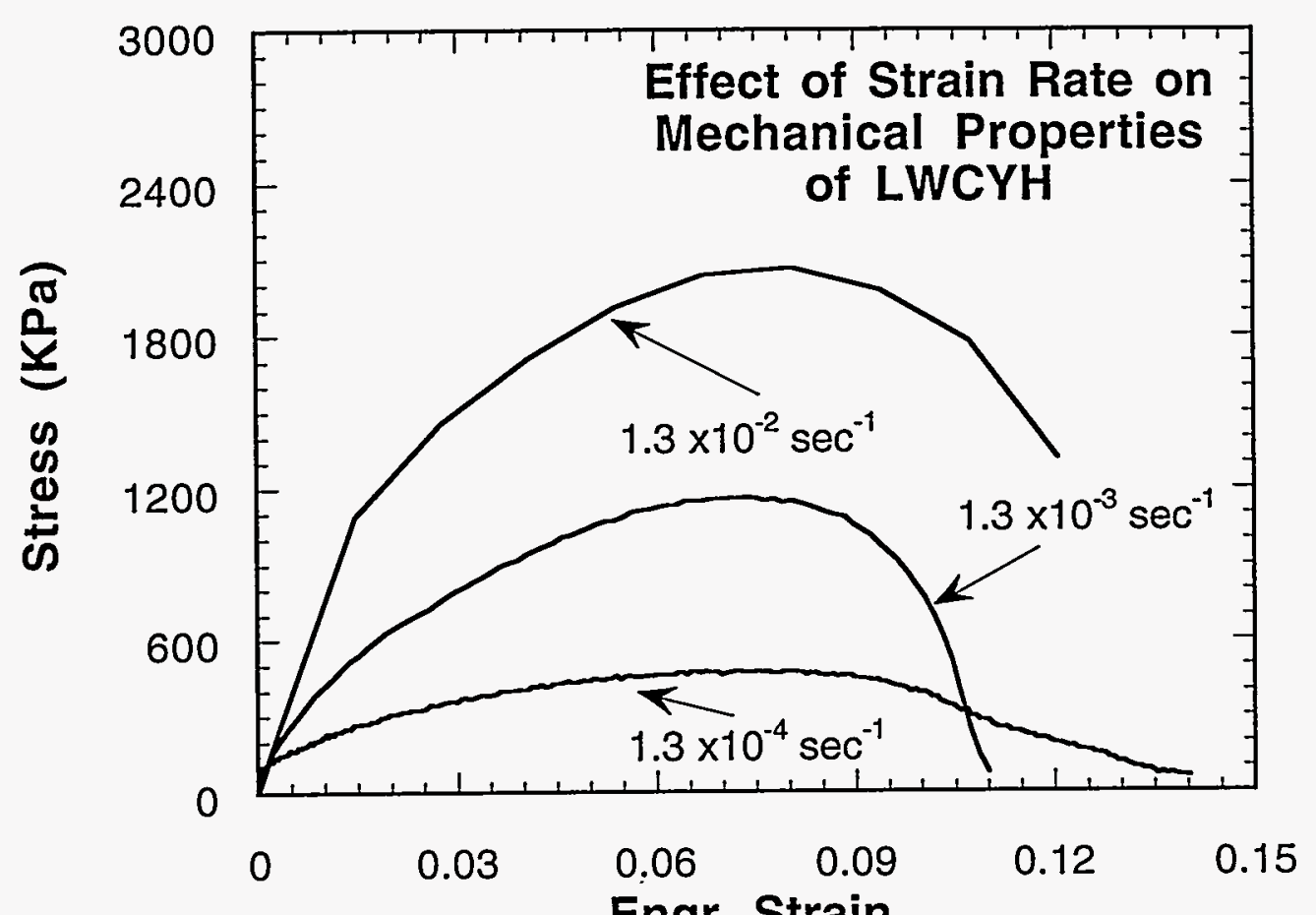

Figure 24. Mechanical properties of LWCYH tested at three different strain rates at $25^{\circ} \mathrm{C}$.

Figure 25 shows the tensile curves for the LWCYH material tested at four different temperatures and at a strain rate of $1.3 \times 10^{-4} \mathrm{sec}^{-1}$. Similar to the $\mathrm{H}-19$, the mechanical properties of the material are highly dependent on the test temperature, with the strength of the material increasing with decreasing temperature. Here, the abrupt increase in strength occurs between $298 \mathrm{~K}$ and $233 \mathrm{~K}$. Once again, coincident with the abrupt increase in strength is a decrease in ductility. At the lowest temperatures the material was quite brittle so that fracture stress is equal to the tensile strength. Strength as a function of temperature is summarized in Figure 26. Figure 26 also summarizes the temperature dependence of the ductility. At room temperature the material exhibited $12 \%$ strain to failure. Below room temperature the abrupt change in strength and ductility is apparent. 


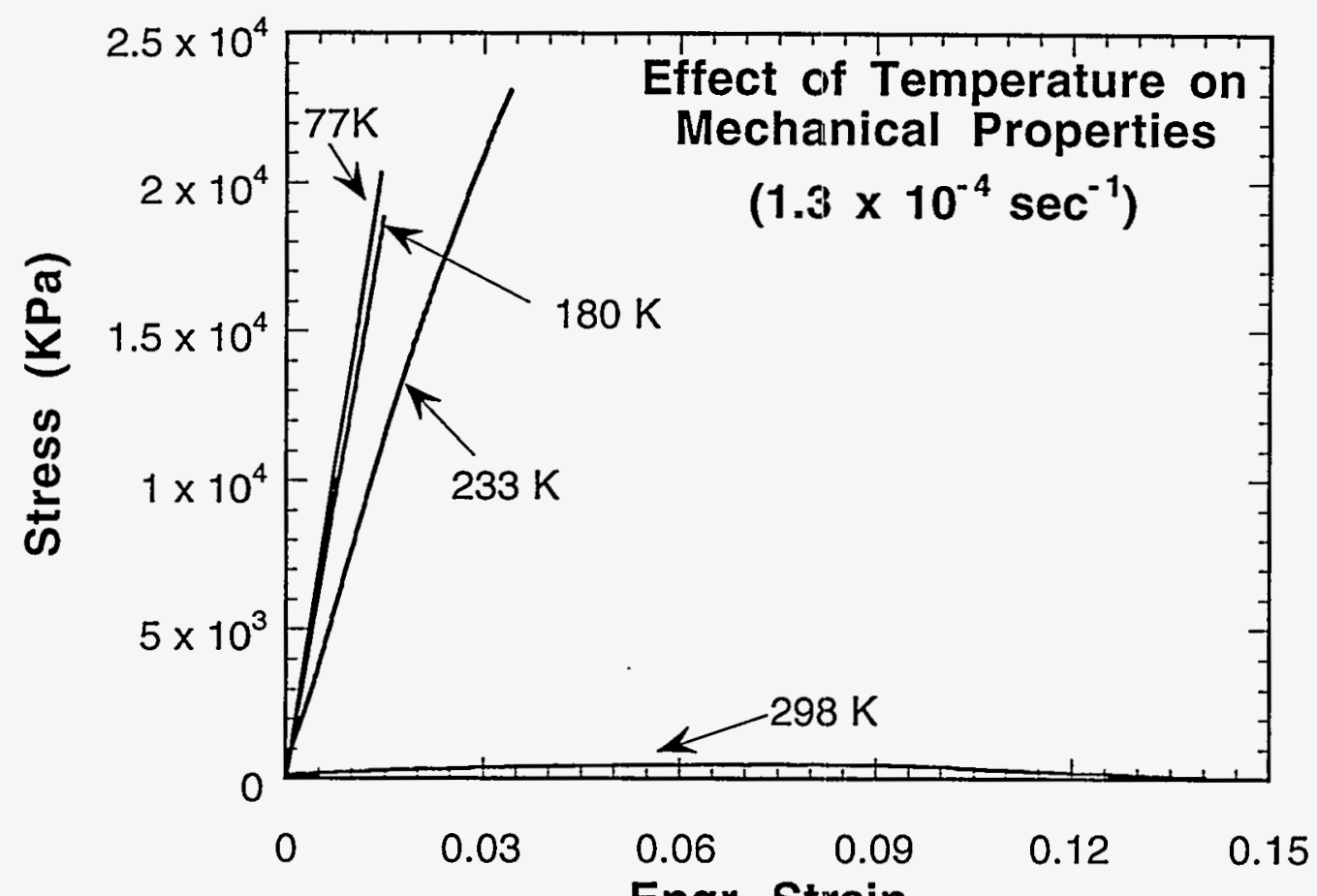

Engr. Strain

Figure 25. Temperature effects on tensile behavior of LWCYH.

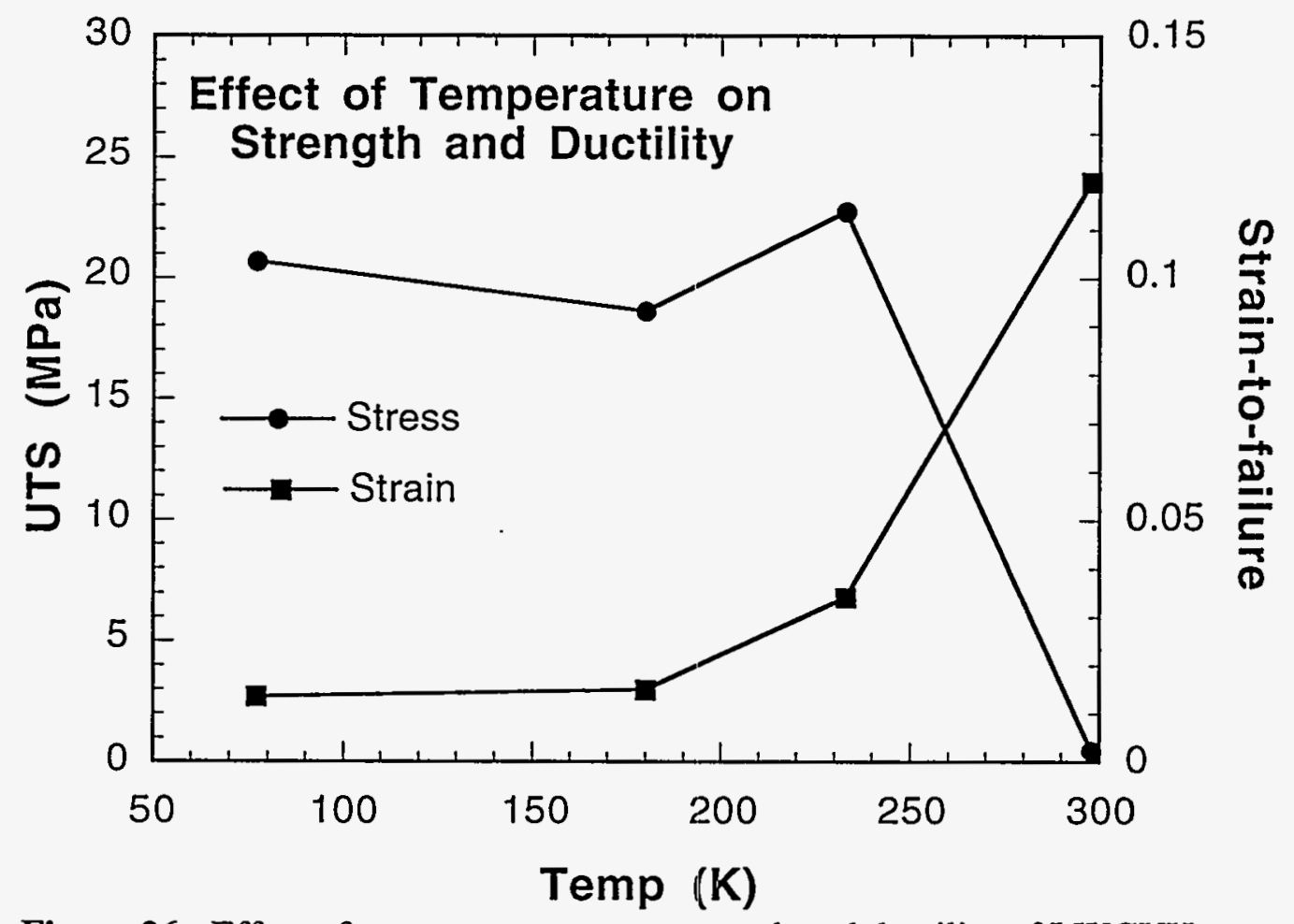

Figure 26. Effect of test temperature on strength and ductility of LWCYH. 
Accurate determination of the modulus of the LWCYH was subject to the same uncertainties and limitations as for the H-19 material. As before, modulus was also found to increase with decreasing test temperature. As with strength, there was an abrupt increase in modulus at test temperatures below ambient. At $77 \mathrm{~K}$ the modulus is well defined and equal to $1450 \mathrm{MPa}$. The temperature dependence of the modulus is shown in Figure 27.

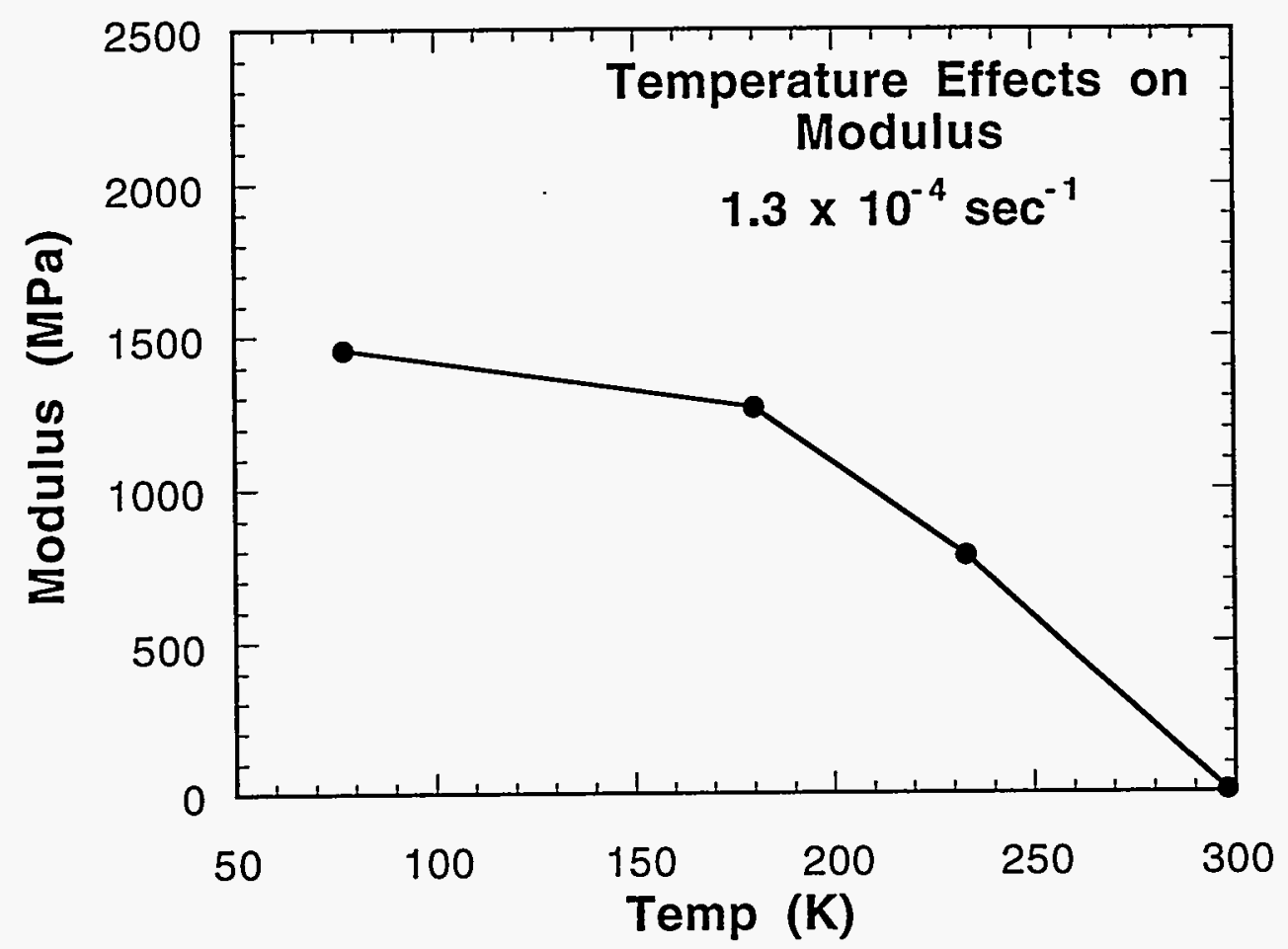

Figure 27. Modulus of LWCYH vs. test temperature.

The principal difference between the two.materials is seen by comparing Figures 22 and 26 . The transition from low strength ductile behavior to high strength, brittle behavior occurs at $\approx 200 \mathrm{~K}$ for $\mathrm{H}-19$ whereas it occurs at $\approx 250 \mathrm{~K}$ for $\mathrm{LWCYH}$. 


\section{APPENDIX. C}

\section{Mock Propellant Compression Testing}

New test fixtures and instrumentation methods were cleveloped to aid in measuring the compressive modulus and Poisson's ratio of mock propellant materials at cryogenic temperatures. This section outlines the new experimental arrangement and presents results verifying its accuracy both at room and cryogenic temperatures. Results and discussion for the mock propellant materials appear at the end of this section.

\section{Test Fixture and Instrumentation}

Difficulties with the measurement of modulus of elasticity and Poisson's ratio at cryogenic temperatures are associated with the strain measurement techniques applicable at these temperatures. These temperature related difficulties are compounded by the small size of typical compression specimens, which limits the type and number of strain-measuring devices that can be used in the resulting restricted workspace. Measurement of axial strain is required for both modulus and Poisson's ratio, while the latter also requires measurement of transverse (or diametral) strain.

Axial strain can be measured by a number of techniques, including (a) strain gages adhesively bonded to the surface of the specimen; (b) measurement of ram or crosshead displacement by the load frame LVDT; (c) submersible cryogenic extensometer mounted to the specimen; (d) submersible cryogenic COD (clip) gage measuring load platen displacement at or near the specimen ends; and (e) a rod-in-tube arrangement extending out of the liquid nitrogen bath that allows the use of a conventional non-cryogenic extensometer or clip gage to measure test platen displacement.

The use of strain gages (a) was rejected due to anticipated difficulties indentifying a suitable cryogenic adhesive. Ram displacement (b) was rejected as insufficiently accurate, even with a machine compliance correction. There is not enough space to mount an axial extensometer directly to the specimen (c) particularly when a diametral extensometer is also needed for determining Poisson's ratio. It was decided to use both of the last two techniques, (d) a submersed cryogenic COD gage and (e) a rod-in-tube extension outside the bath, to provide dual independent measures of axial displacement. Transverse strains were measured with a submersible cryogenic diametral extensometer.

The main body of the sub-assembly fixture consists of ceramic loading platens clamped in stainless steel alignment blocks. Two stainless steel rods are press fit into the bottom alignment block. The top alignment block is allowed to slide freely in the vertical plane but is restrained from rotating or translating horizontally by the rods. One of these alignment rods is extended through an outer tube press fit into the top alignment block. This long rod and tube extend out of the liquid nitrogen, providing a means to attach an MTS axial extensometer. Small stainless steel knife edge blocks attached between the top and bottom alignment blocks step down from the 0.75 inch specimen length to provide a 0.30 inch gage length for a low temperature MTS crack opening displacement (COD) gage. Alignment of the specimen is aided by a 0.50 inch diameter circle centered on the bottom loading platen.

This sub-assembly is compressed between steel loading platens in a small environmental chamber installed in a 20,000 pound MTS 808 electro-mechanical test frame. The total instrumentation system consists of an MTS load cell on the test frame, an MTS low temperature COD gage submersed in the liquid nitrogen to measure specimen end shortening, a second MTS axial extensometer attached outside of the liquid nitrogen to verify this end shortening 
measurement, and a low temperature MTS diametral extensometer to provide Poisson's ratio data. All tests are run in stroke control at a crosshead rate of 0.005 inches/minute. Data is acquired using a Nicolet 440 digital storage oscilloscope.

\section{Verification of Experimental Arrangement}

A series of tests were performed on 6061-T6 aluminum at both room and cryogenic temperatures to verify that this experimental arrangement can be used to accurately measure the compressive modulus and Poisson's ratio of a material. Table $\mathrm{V}$ presents the results of these tests.

\begin{tabular}{|c|c|c|c|c|}
\hline $\begin{array}{l}\text { Specimen } \\
\text { Name }\end{array}$ & \begin{tabular}{|l|} 
Test \\
Temperature
\end{tabular} & \begin{tabular}{|l|} 
Strain \\
Device
\end{tabular} & $\begin{array}{l}\text { Modulus, E } \\
\text { (Msi) }\end{array}$ & \begin{tabular}{|l} 
Poisson's \\
Ratio, $v$
\end{tabular} \\
\hline ALRT1 & $298 \mathrm{~K}$ & $\begin{array}{l}\text { COD gage } \\
\text { Extensometer }\end{array}$ & $\begin{array}{l}9.5 \\
10.0\end{array}$ & $\begin{array}{l}0.31 \\
0.33\end{array}$ \\
\hline ALRT2 & $298 \mathrm{~K}$ & $\begin{array}{l}\text { COD gage } \\
\text { Extensometer }\end{array}$ & $\begin{array}{l}10.1 \\
10.3\end{array}$ & $\begin{array}{l}0.35 \\
0.37\end{array}$ \\
\hline ALRT3 & $298 \mathrm{~K}$ & \begin{tabular}{|l|} 
COD gage \\
Extensometer
\end{tabular} & $\begin{array}{l}10.0 \\
11.0\end{array}$ & $\begin{array}{l}0.32 \\
0.37\end{array}$ \\
\hline ALCT1 & $77 \mathrm{~K}$ & \begin{tabular}{|l|} 
COD gage \\
Extensometer
\end{tabular} & $\begin{array}{l}9.8 \\
11.0 \\
\end{array}$ & $\begin{array}{l}0.32 \\
0.36\end{array}$ \\
\hline ALCT2 & $77 \mathrm{~K}$ & \begin{tabular}{|l|} 
COD gage \\
Extensometer
\end{tabular} & $\begin{array}{l}9.9 \\
11.2\end{array}$ & $\begin{array}{l}0.31 \\
0.35\end{array}$ \\
\hline ALCT3 & $77 \mathrm{~K}$ & $\begin{array}{l}\text { COD gage } \\
\text { Extensometer }\end{array}$ & \begin{tabular}{|l|}
9.7 \\
10.1
\end{tabular} & $\begin{array}{l}0.32 \\
0.35\end{array}$ \\
\hline
\end{tabular}

Table V. Experimental results for aluminum specimens.

Several things should be noted about these results. The measured moduli and Poisson's ratios are within the accepted range for aluminum alloys, the results are very reproducible, and the cryogenic temperatures do not appear to have an adverse affect on the experimental arrangement and instrumentation system. It is noted, however, that the extensometer consistently yields lower longitudinal strains than the COD, resulting in higher moduli and Poisson's ratios. For the worst case, ALCT2, this creates a difference of $12 \%$ in the measured moduli. For the majority of the cases this difference is less than $8 \%$. If this difference is caused by any rocking of the subassembly due to non-parallelism of the specimen or loading platens the effect should be greatly reduced for the mock propellant tests because their stiffness is around an order of magnitude less than the aluminum. Figure 28 shows the stress strain curves for ALRT3 and ALCT1. 


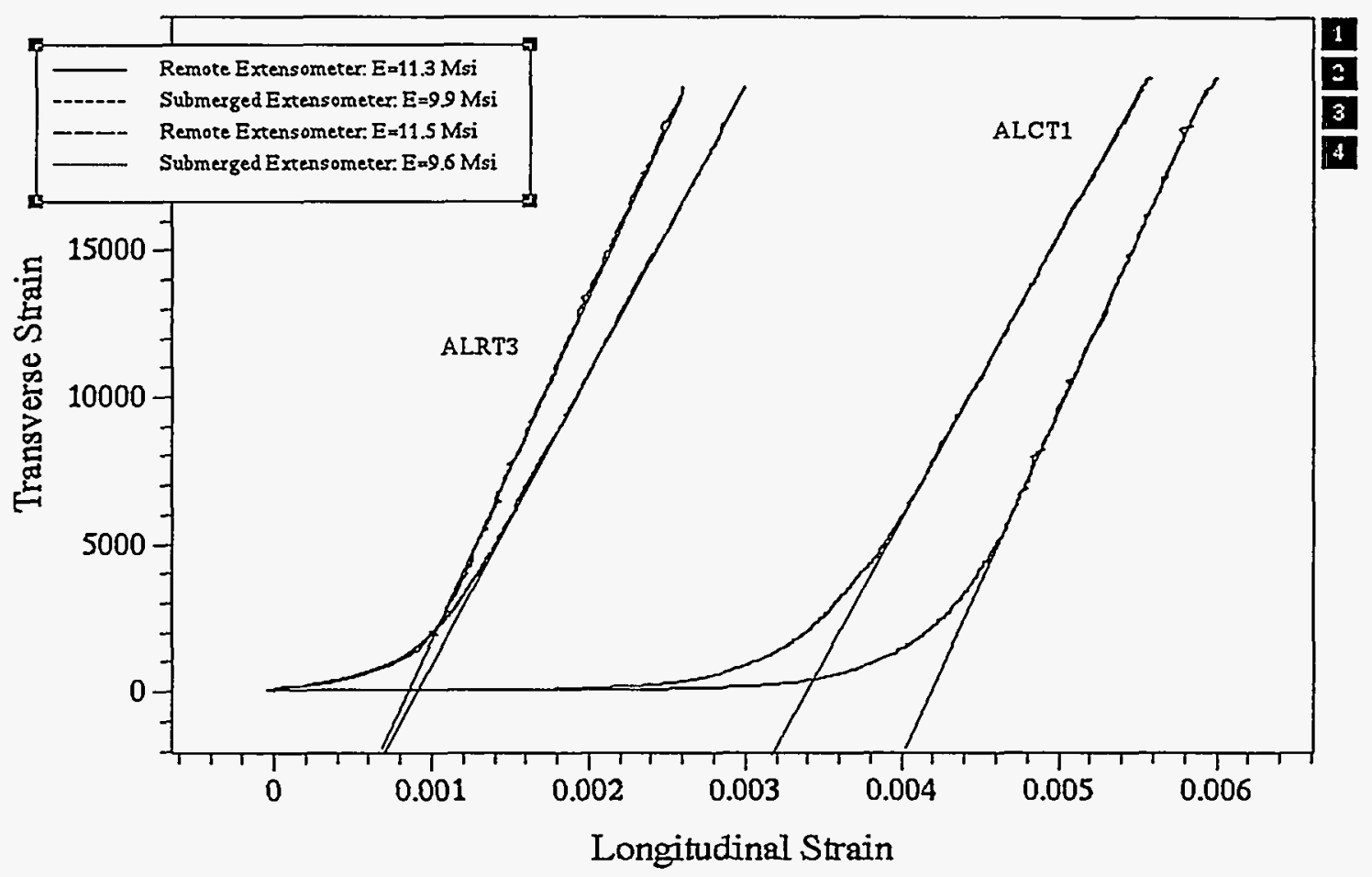

Figure 28: Typical stress vs. strain for aluminum tests.

\section{Mock Propellant Results: Compressive Modulus}

After it was determined that this experimental arrangement yields reasonable results, compression tests were performed on the two material systems under consideration. The H-19 had a uniform light-gray appearance, while the LWCYH was darker gray with white speckles. Table VI presents the compressive modulus results for these two materials. Note that for individual tests there is very good agreement between the moduli given by the two different means of measuring end shortening. There is much less scatter in the data for the H-19. One possible reason for the data scatter in the LWCYH is material nonhomogeneity. Even with the data scatter, however, the modulus of the LWCYH appears to be around $35 \%$ lower than that of the $\mathrm{H}-19$. 


\begin{tabular}{|c|c|c|c|}
\hline $\begin{array}{c}\text { Specimen } \\
\text { Name }\end{array}$ & $\begin{array}{c}\text { Material } \\
\text { Type }\end{array}$ & $\begin{array}{c}\text { Strain } \\
\text { Device }\end{array}$ & $\begin{array}{c}\text { E } \\
\text { (Msi) }\end{array}$ \\
\hline \hline MHEU1 & $\mathrm{H}-19$ & COD gage & 1.4 \\
& & Extensometer & 1.4 \\
\hline MHEU2 & $\mathrm{H}-19$ & COD gage & 1.3 \\
& & Extensometer & 1.2 \\
\hline MHEU3 & $\mathrm{H}-19$ & COD gage & 1.4 \\
& & Extensometer & 1.3 \\
\hline MHES1 & LWCYH & COD gage & 0.71 \\
& & Extensometer & 0.71 \\
\hline MHES2 & LWCYH & COD gage & 0.95 \\
& & Extensometer & 1.0 \\
\hline MHES3 & LWCYH & COD gage & 0.87 \\
& & Extensometer & 0.82 \\
\hline
\end{tabular}

Table VI. Mock Propellant Compressive Modulus Results at 77K.

In addition to the difference in stiffness, the materials differed greatly in their inelastic behavior and failure modes. Figures 29 and 30 present stress vs. strain curves for MHEU2 and MHES3 which are representative of the $\mathrm{H}-19$ and LWCYH materials, respectively.

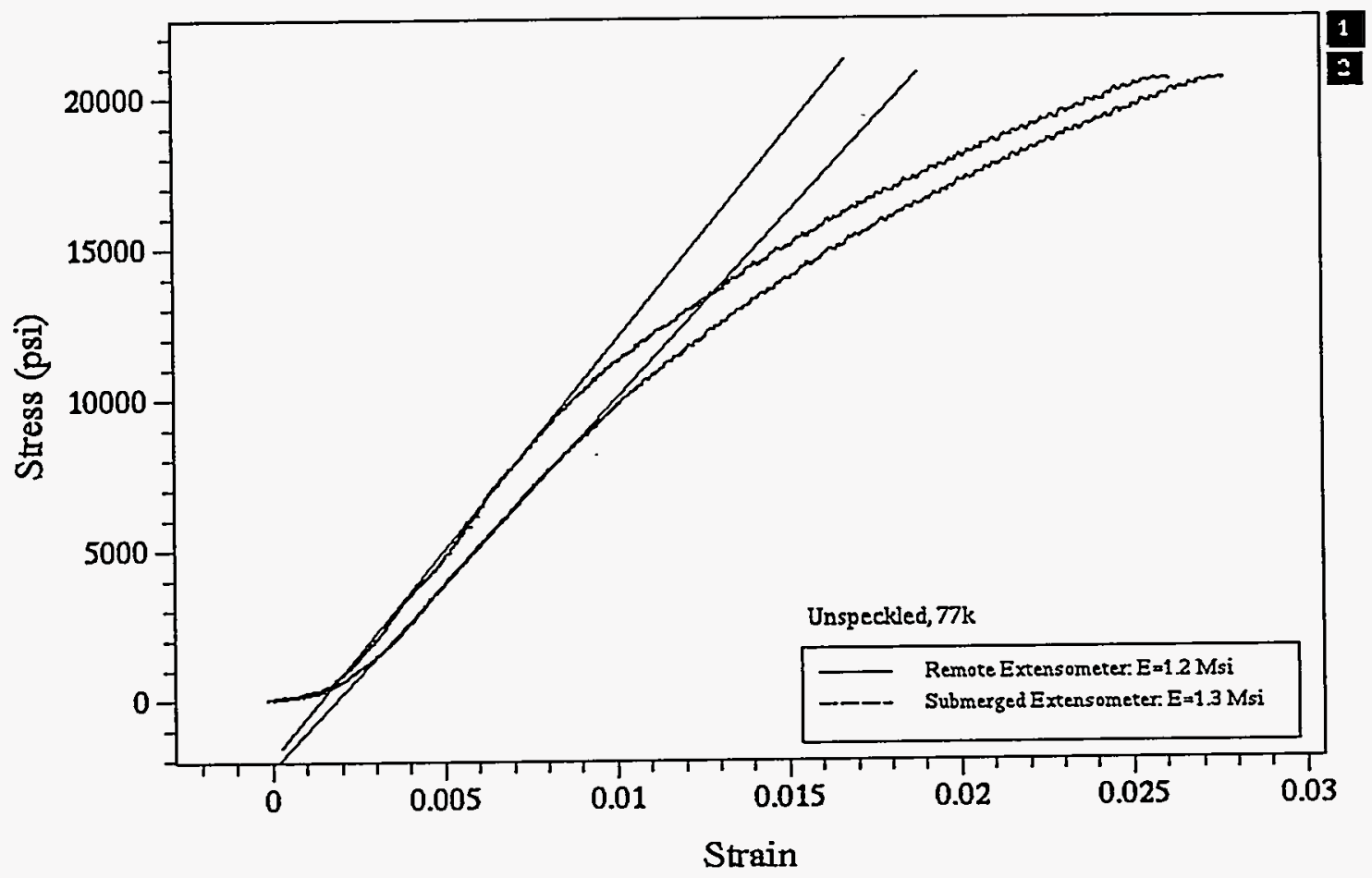

Figure 29. Stress vs. strain for MHEU2 (H-19). 


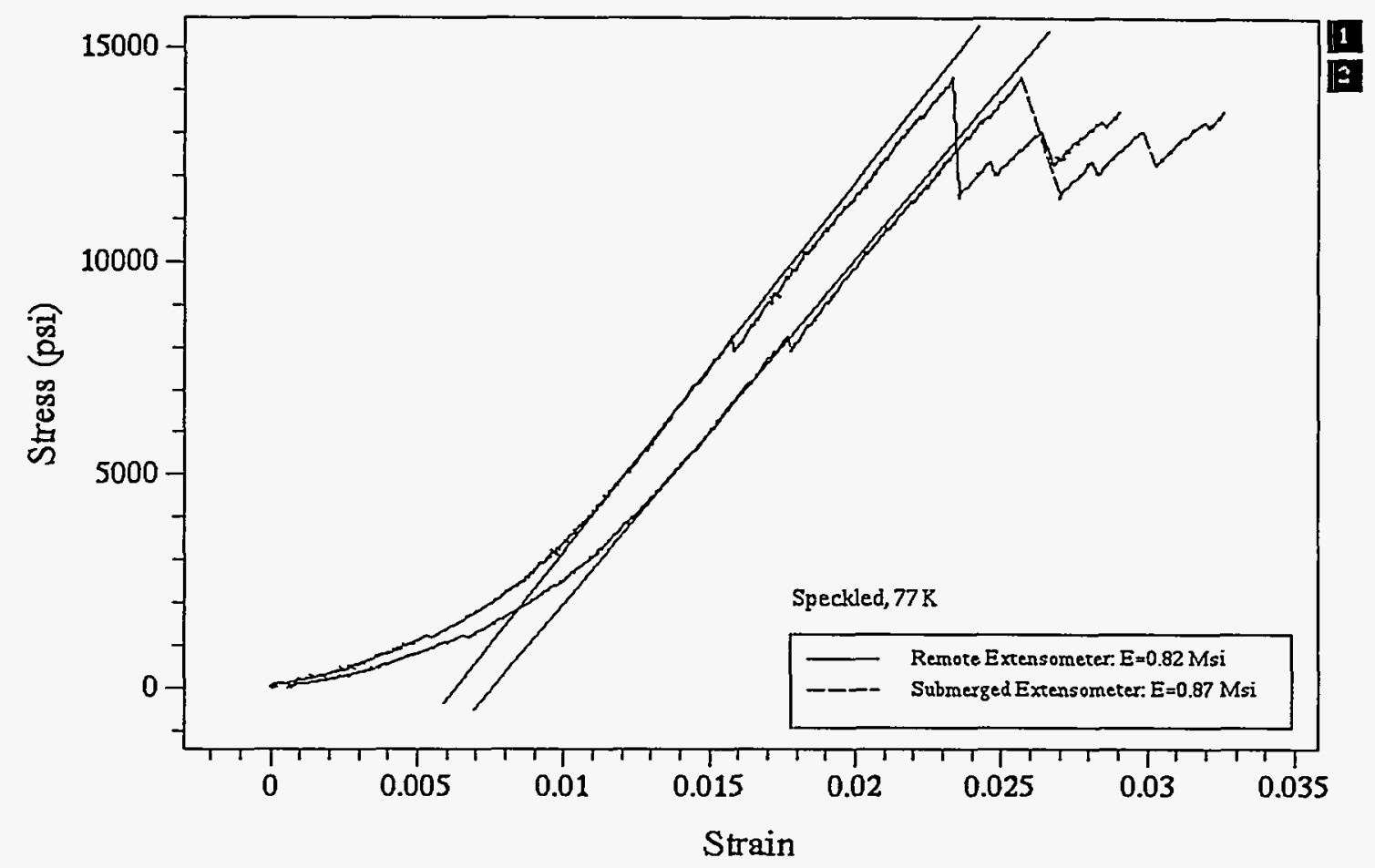

Figure 30. Stress vs. strain for MHES3 (LWCYH).

Notice that the $\mathrm{H}-19$ has a distinct linear-elastic region and then begins to "yield" at around 9000 psi. This material did not fail before $20000 \mathrm{psi}$, the upper stress limit of all tests. The LWCYH, on the other hand, has a very linear stress strain response with brittle fractures occurring at higher stress levels. The specimens MHES1 and MHES3 both failed catastrophically before the 20000 psi limit was reached, while specimen MHES2 was relatively intact at the end of the test. Examining the specimen after completing the test revealed significant cracks running longitudinally along the centerline of the specimen, implying failure due to transverse tension.

\section{Mock Propellant Results: Poisson's Ratio}

Figures 31 through 33 present the transverse vs. longitudinal strain plots for the H-19, and figures 34 through 36 present the transverse vs. Iongitudinal strain plots for the LWCYH. 


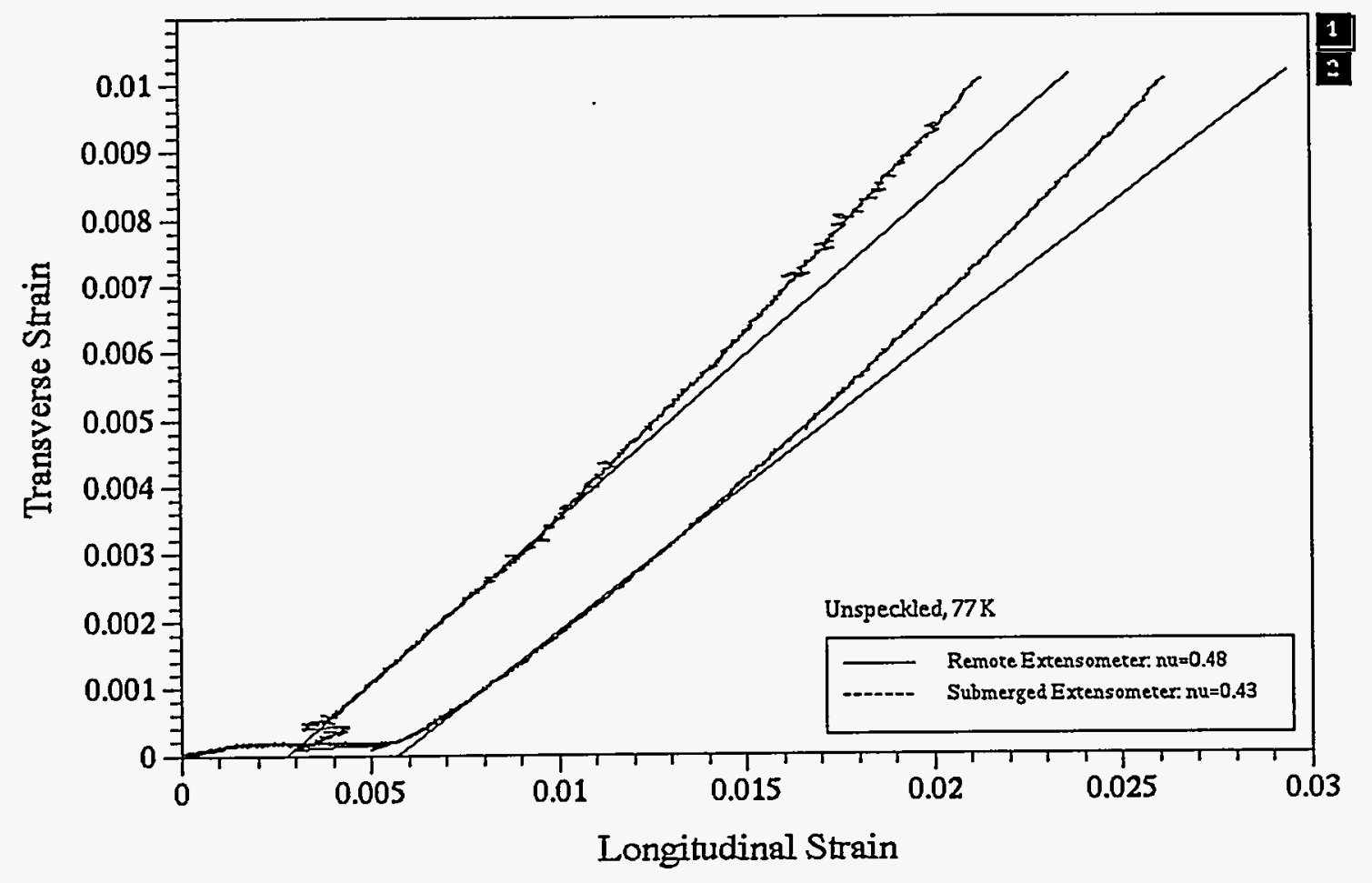

Figure 31. Transverse vs. longitudinal strain for MHEU1. 


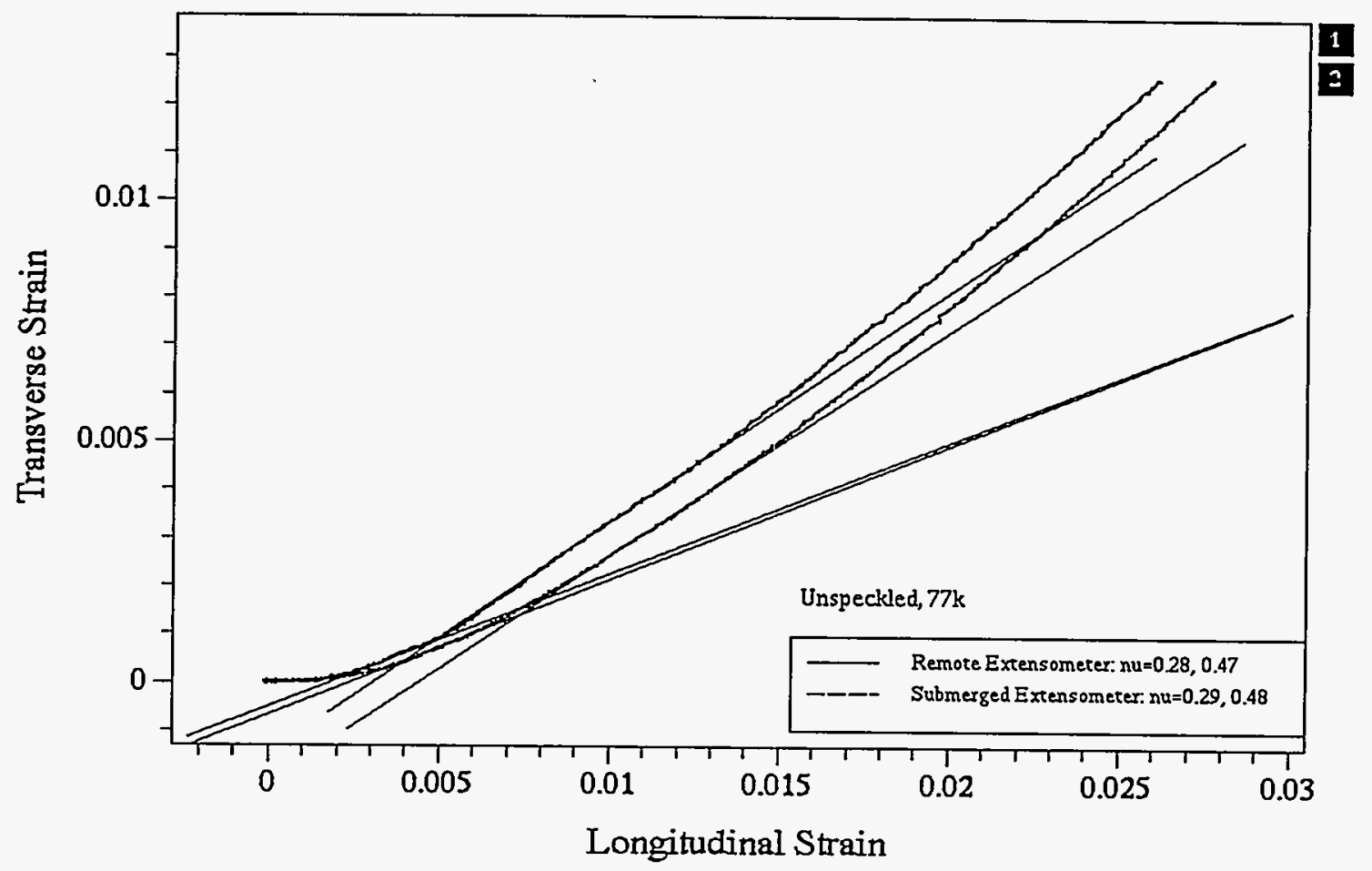

Figure 32. Transverse vs. longitudinal strain for MHEU2. 


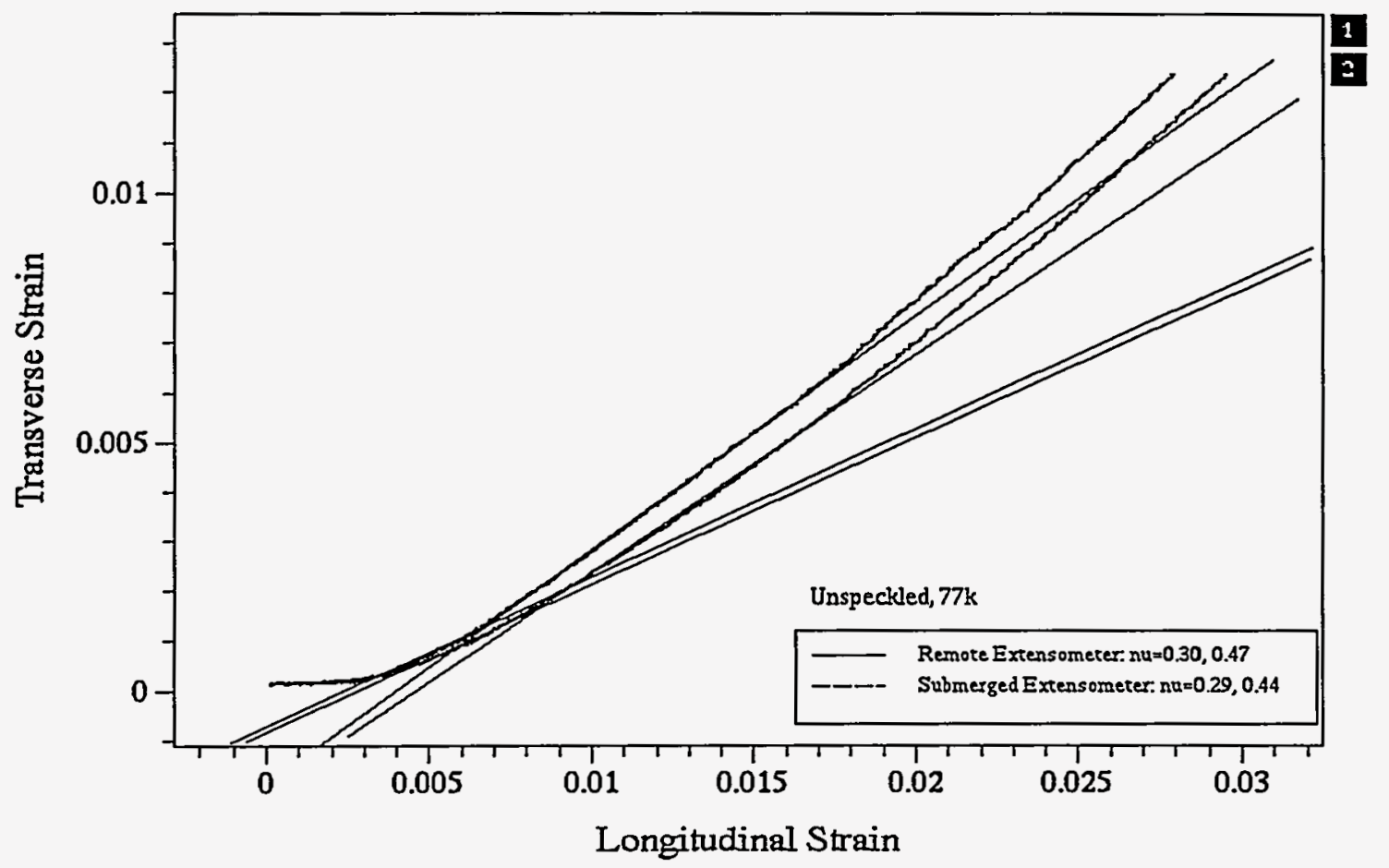

Figure 33. Transverse vs. longitudinal strain for MHEU3.

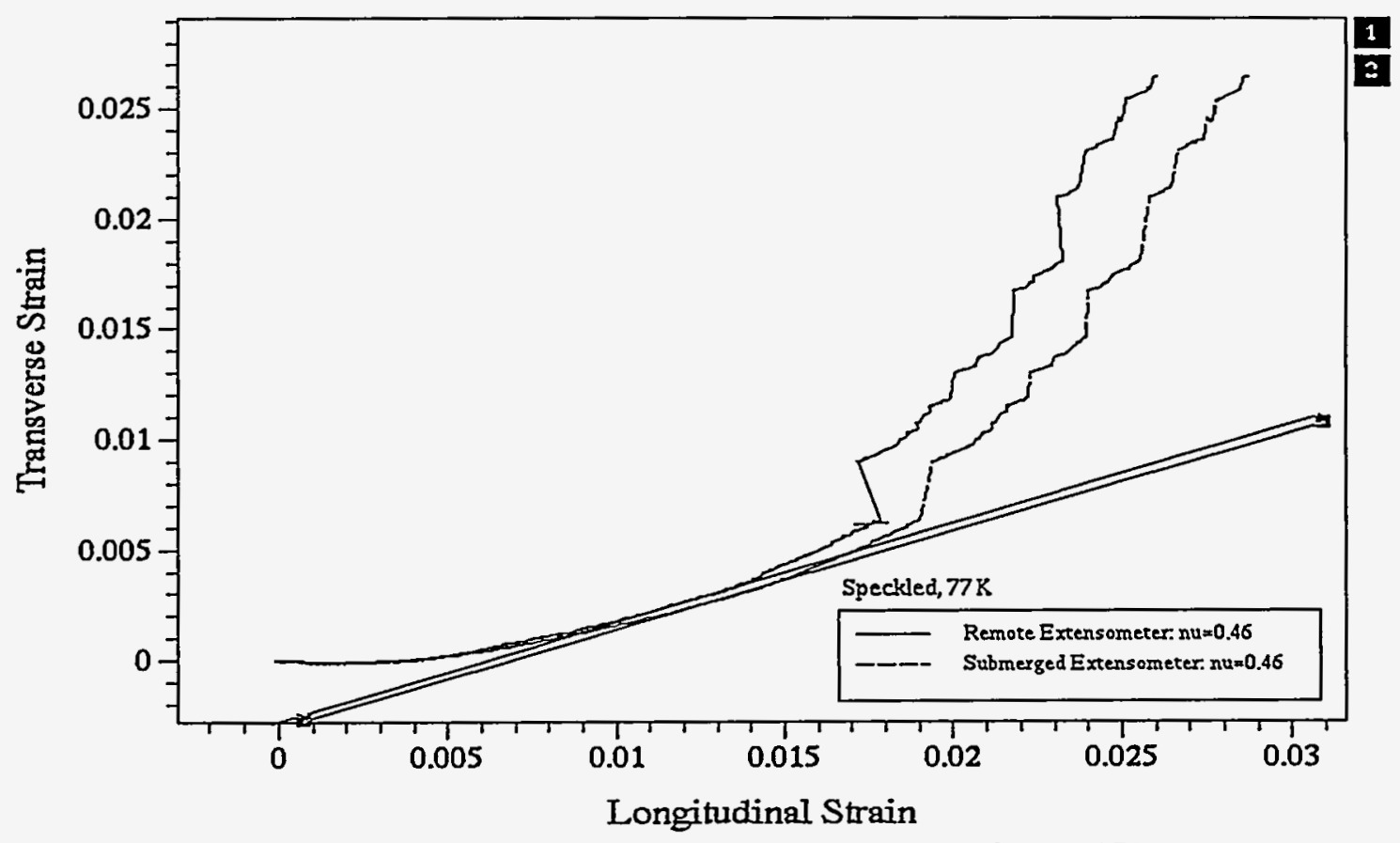

Figure 34: Transverse vs. longitudinal strain for MHES1. 


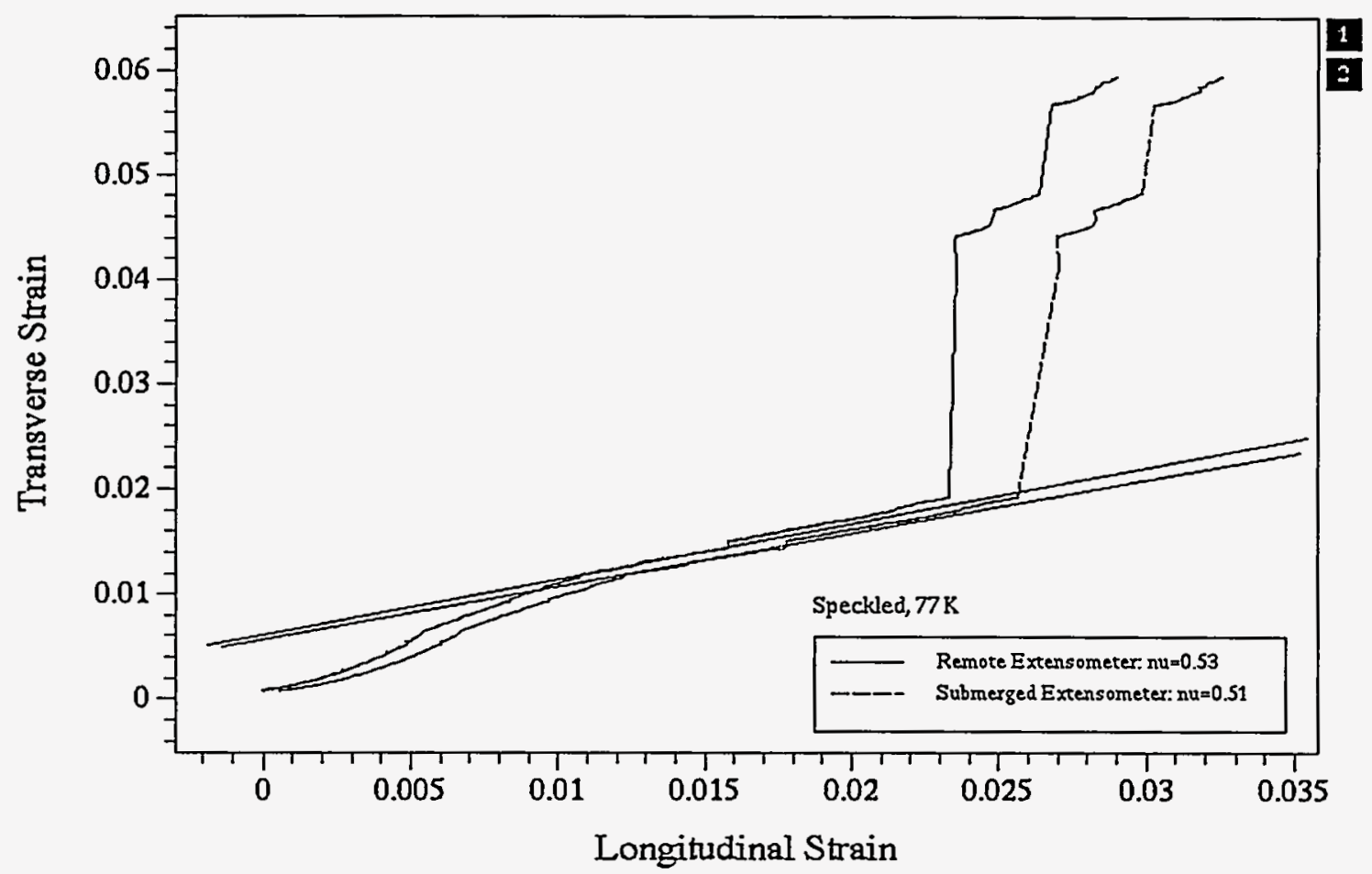

Figure 35. Transverse vs. longitudinal strain for MHES2.

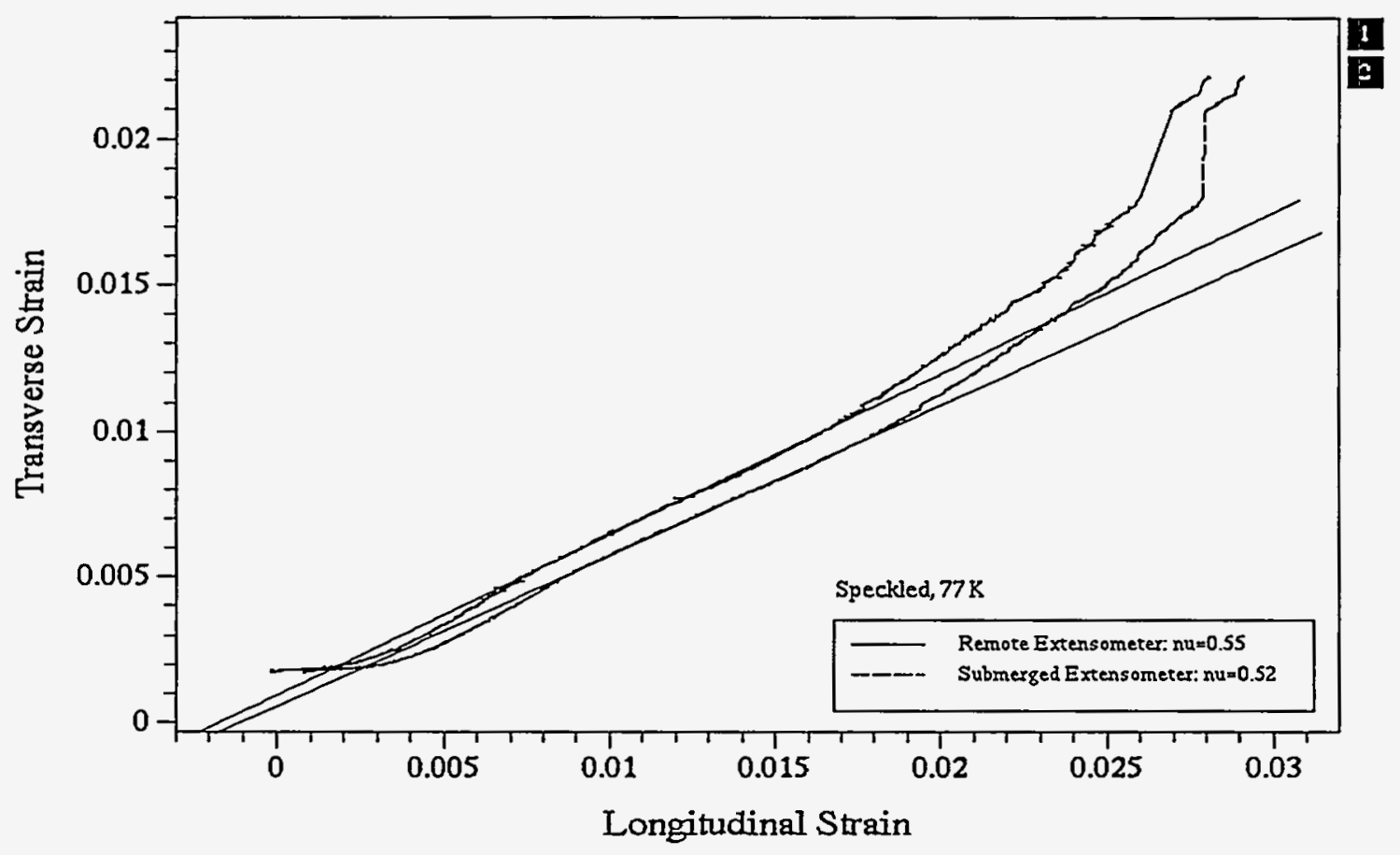

Figure 36. Transverse vs. longitudinal strain for MHES3. 
It is clear from the preceding figures that it is not a straightforward process to compute Poisson's ratio. For the H-19 material, there are two distinct linear regions of the curve, with the transition point being near the "yield" strain level on the stress vs. strain plots. Both of these pre and post "yield" values are reported in Table VII. Since the LWCYH had a linear stress vs. strain response up to the point of fracture, the transverse vs. longitudinal strain curves do not exhibit this bi-linear response.

\begin{tabular}{|c|c|c|c|}
\hline $\begin{array}{c}\text { Specimen } \\
\text { Name }\end{array}$ & $\begin{array}{c}\text { Material } \\
\text { Type }\end{array}$ & $\begin{array}{c}\text { Strain } \\
\text { Device }\end{array}$ & Poisson's Ratio, $v$ \\
\hline \hline MHEU1 & H-19 & COD gage & 0.43 \\
& & Extensometer & 0.48 \\
\hline MHEU2 & H-19 & COD gage & $0.29,0.48$ \\
& & Extensometer & $0.28,0.47$ \\
\hline MHEU3 & H-19 & COD gage & $0.29,0.44$ \\
& & Extensometer & $0.30,0.47$ \\
\hline MHES1 & LWCYH & COD gage & 0.46 \\
& & Extensometer & 0.46 \\
\hline MHES2 & LWCYH & COD gage & 0.52 \\
& & Extensometer & 0.52 \\
\hline MHES3 & LWCYH & COD gage & 0.51 \\
& & Extensometer & 0.51 \\
\hline
\end{tabular}

Table VII. Mock propellant poisson's ratio results at $77 \mathrm{~K}$.

These results do warrant some discussion, especially the values greater than 0.5 for MHES2 and MHES3. Typically, for compression tests, shallow concentric grooves are machined into the ends of the specimen and the outer $2 / 3$ of these are filled with a thin coating of grease. This allows the ends of the specimen to expand radially to prevent the specimen from barreling. If the specimen does barrel, the middle of the specimen exhibits higher transverse strain than it would if the specimen were expanding uniformly along its entire length, causing higher Poisson's ratio measurements. Due to the nature of the material and environmental test conditions, neither the grooves nor lubrication were used so there was a possibility of barreling with these tests. There is an additional warning for the LWCYH. As soon as a longitudinal crack develops through the gage section of the diametral extensometer, the transverse strain measurements will be unnaturally high, again yielding large Poison's ratios. 


\section{APPENDIX D}

\section{Finite Difference Model}

In order to predict the effectiveness of cryocycling as a means of fragmenting solid bodies such as propellant grains, it is necessary to have a reasonably detailed mathematical model for the process. Such a model naturally divides itself into two parts, which determine in succession (a) the thermal stresses induced by heat transfer to the boiling nitrogen and (b) the fracture pattern resulting from the given stress distribution. The first of these would appear to be the more straightforward, provided that the geometry is not overly complicated and the necessary physical properties are available. This memo describes a thermal stress model which is fairly simple but which should nonetheless capture the main features of the process.

\section{Governing Equations}

The propellant grain to be modeled here is a hollow cylinder (of inner and outer radii $R_{0}$ and $R_{1}$ ) whose ends may be either fixed or free, and which may or may not be bonded to a motor case on the outer surface. Assuming that all variations in the axial and circumferential directions may be neglected and that the stresses are quasi-steady, the equation of equilibrium is

$$
\frac{\partial p_{r}}{\partial r}+\frac{p_{r}-p_{\theta}}{r}=0
$$

and the stress-strain relations can be written in the form

$$
\begin{aligned}
\frac{\partial^{2} u_{r}}{\partial r \partial t}=\frac{\partial e_{r}}{\partial t} & =\frac{1}{E} \frac{\partial p_{r}}{\partial t}-\frac{v}{E}\left(\frac{\partial p_{\theta}}{\partial t}+\frac{\partial p_{z}}{\partial t}\right)+\alpha_{r} \frac{\partial T}{\partial t} \\
\frac{1}{r} \frac{\partial u_{r}}{\partial t}=\frac{\partial e_{\theta}}{\partial t} & =\frac{1}{E} \frac{\partial p_{\theta}}{\partial t}-\frac{v}{E}\left(\frac{\partial p_{r}}{\partial t}+\frac{\partial p_{z}}{\partial t}\right)+\alpha_{\theta} \frac{\partial T}{\partial t} \\
\frac{d e_{z}}{d t} & =\frac{1}{E} \frac{\partial p_{z}}{\partial t}-\frac{v}{E}\left(\frac{\partial p_{r}}{\partial t}+\frac{\partial p_{\theta}}{\partial t}\right)+\alpha_{z} \frac{\partial T}{\partial t}
\end{aligned}
$$

Here $e_{r}, e_{\theta}$, and $e_{z}$ are the strains in the radial, circumferential, and axial directions, respectively, the $p$ 's are the corresponding stresses, the $\alpha$ 's are the corresponding thermal expansion coefficients, $u_{r}$ is the radial displacement, $T$ is the temperature, $E$ is the elastic modulus, and $v$ is Poisson's ratio. The fact that $e_{z}$ is independent of position is in keeping with the assumption of plane strain. If the ends of the cylinder are fixed, then $e_{z}$ is identically zero; however, if the ends are free then the appropriate condition is one of zero net force:

$$
\int_{R_{0}}^{R_{1}} p_{z} r d r=0
$$

The appearance of three separate $\alpha$ 's in Eqs. (2)-(4) is a consequence of the fact that the thermal expansion in a given direction is a function of the stresses when $E$ (or $v$ ) is temperaturedependent. In particular, it can be shown that

$$
\alpha_{r}=p_{r} \frac{d}{d T}\left(\frac{1}{E}\right)-\left(p_{\theta}+p_{z}\right) \frac{d}{d T}\left(\frac{v}{E}\right)+\alpha_{0}(T)
$$

with analogous expressions for $\alpha_{\theta}$ and $\alpha_{z}$. Here $\alpha_{0}$ is the conventional thermal expansion coefficient for zero stress.

The system of equations is now completed by writing down the variable properties version of the heat conduction equation: 


$$
\rho C_{p} \frac{\partial T}{\partial t}=k\left(\frac{\partial^{2} T}{\partial r^{2}}+\frac{1}{r} \frac{\partial T}{\partial r}\right)+\frac{d k}{d T}\left(\frac{\partial T}{\partial r}\right)^{2}
$$

where $\rho, C_{p}$, and $k$ are respectively the density, heat capacity, and thermal conductivity of the propellant. On the inner surface of the cylinder $\left(r=R_{0}\right)$, the thermal boundary condition is an equality between the conductive heat flux in the propellant and the convective heat flux to the boiling nitrogen:

$$
k \frac{\partial T}{\partial r}=h\left(T-T_{\infty}\right)
$$

where $h$ is the heat-transfer (film) coefficient and $T_{\infty}$ is the bath temperature (77 K). The corresponding mechanical boundary condition is simply that $p_{r}=0$. If the propellant is not bonded to a case on its outer surface, then the boundary conditions at $r=R_{1}$ are similar (with, however, a sign change in Eq. (8)). On the other hand, for a case-bonded propellant one has $u_{r}=0$ at $r=R_{1}$, and additionally $\partial T / \partial r=0$ if the case material is a good insulator. Finally, the initial conditions for the problem are simply that $T \equiv T_{0}$ (room temperature, say) and all stresses, strains, and displacements are zero.

\section{Physical Properties}

For purposes of illustration, the model will be applied to cylinders composed of the mock propellant H-19. Some thermophysical properties of this material have been measured at Purdue, ${ }^{22}$ and the results are represented reasonably well by the following equations:

$$
\begin{aligned}
\rho\left(\mathrm{g} / \mathrm{cm}^{3}\right) & =1.716 \\
C_{p}(\mathrm{~J} / \mathrm{g} \cdot \mathrm{K}) & =0.970-1.75 e^{-0.0131 T} \\
\frac{k}{\rho C_{p}}\left(\mathrm{~cm}^{2} / \mathrm{s}\right) & =0.0512-1.69 \times 10^{-4} T+5.59 \times 10^{-4} e^{0.0107 T} \\
\alpha_{0} & =5.70 \times 10^{-5}-3.02 \times 10^{-4} e^{-0.0208 T}
\end{aligned}
$$

where $T$ is in Kelvins. The elastic modulus of $\mathrm{H}-19$ has been measured by Steve Goods at Sandia. Since the experimental values are strain-rate dependent, and since the material undergoes a glass transition in the neighborhood of $200 \mathrm{~K}$, any equation representing the data must inevitably be both complicated and uncertain. Accepting this, one can write

$$
E(\mathrm{MPa})=\frac{1}{2}(1-f) E_{1}+\frac{1}{2}(1+f) E_{2}
$$

where

$$
\begin{aligned}
& E_{1}=2152-6.898 T \\
& E_{2}=18130 e^{-0.02880 T}
\end{aligned}
$$

and

$$
f=\operatorname{erf}[0.1(T-206)]
$$

${ }^{22}$ R. E. Taylor, J. B. Henderson, and H. Groot, "Thermophysical Properties of H-19 (An Inert Propellant)," Report \#TPRL 1126, School of Mechanical Engineering, Purdue University, West Lafayette, IN (1992). 
Basically, $E_{1}$ and $E_{2}$ are the moduli below and above the transition temperature, respectively, and $f$ is a modified step function that selects the appropriate value of $E$ to use. In the absence of further information, Poisson's ratio $v$ is taken to be constant at 0.3.

Finally, one must have the boiling heat-transfer coefficient $h$ for liquid nitrogen. Correlations for the associated heat flux $Q=h\left(T-T_{\infty}\right)$ in both the nucleate and film boiling regimes are reported by Clark and Thorogood ${ }^{23}$. As with the elastic modulus above, one can use an empirical function to join the results for the two regimes and thus obtain an expression valid over the entire temperature range. Letting $\Delta T \equiv T-T_{\infty}$, one has

$$
\ln Q\left(\mathrm{erg} / \mathrm{cm}^{2} \mathrm{~s}\right)=\frac{f_{1} y_{1}+f_{2} y_{2}}{f_{1}+f_{2}}
$$

where

$$
\begin{aligned}
& f_{1}=9.930 \times 10^{7} \\
& y_{1}=2.494 \ln \Delta T+12.88 \\
& f_{2}=(\Delta T)^{5.914}
\end{aligned}
$$

and

$$
y_{2}=0.9561 \ln \Delta T+12.02
$$

It should be noted that this result is valid only at 1 atm and for surfaces having a radius of curvature of at least $1 \mathrm{~cm}$ or so.

\section{Sample Results}

Rather than attempting to carry out a parameter study here, we will simply show the predictions of the model for a typical case. The propellant grain is taken to have inner and outer radii of 10 $\mathrm{cm}$ and $30 \mathrm{~cm}$, respectively, and is assumed to be tightly bonded to an insulating motor case on the outside surface. On the other hand, the ends of the grain are assumed to be free. The initial temperature is uniform and equal to $298 \mathrm{~K}$. The equations are solved by writing the spatial derivatives as finite differences and then using DASSL to integrate the resulting differential/algebraic system in time.

The computed temperature profiles at uniform time intervals are shown in Figure 37. The general behavior is just as one would expect, except perhaps for the sharp drop in the inner surface temperature between $t=3000 \mathrm{~s}$ and $t=4000 \mathrm{~s}$. This is brought about by the transition from film boiling to nucleate boiling, which begins when $\Delta T$ drops to about $30 \mathrm{~K}$ and is accompanied by a rapid increase in the rate of heat transfer.

The corresponding stress profiles are shown in Figures 38-40. The radial stresses are entirely tensile and rise monotonically with time; the stresses are locked in by the motor case even after the temperature has become uniform at its final value $(77 \mathrm{~K})$. The circumferential stresses are also mostly (although not always entirely) tensile, but they tend to be larger in magnitude; furthermore, they reach their maximum value at the inner surface, where the radial stress is identically zero. The axial stresses have a more complicated time behavior, rising at first (albeit

${ }^{23}$ J. A. Clark and R. M. Thorogood, "Heat Transfer," chapter 3 in Cryogenic Fundamentals, edited by

G. G. Haselden. Academic Press, London (1971), p. 124. 
to a relatively low value) and then slowly decaying away. At any time the stresses are compressive in some places and tensile in others, this being a direct consequence of Eq. (5).

Needless to say, these results could be dramatically different if, for example, the propellant became debonded from its case, for this would change both the thermal and the mechanical boundary conditions. It should also be acknowledged that treating the propellant as a perfectly elastic solid is a rather crude approximation, especially above the glass transition temperature. Nevertheless, the results do provide a basis for understanding some of the basic features of cryocycling.

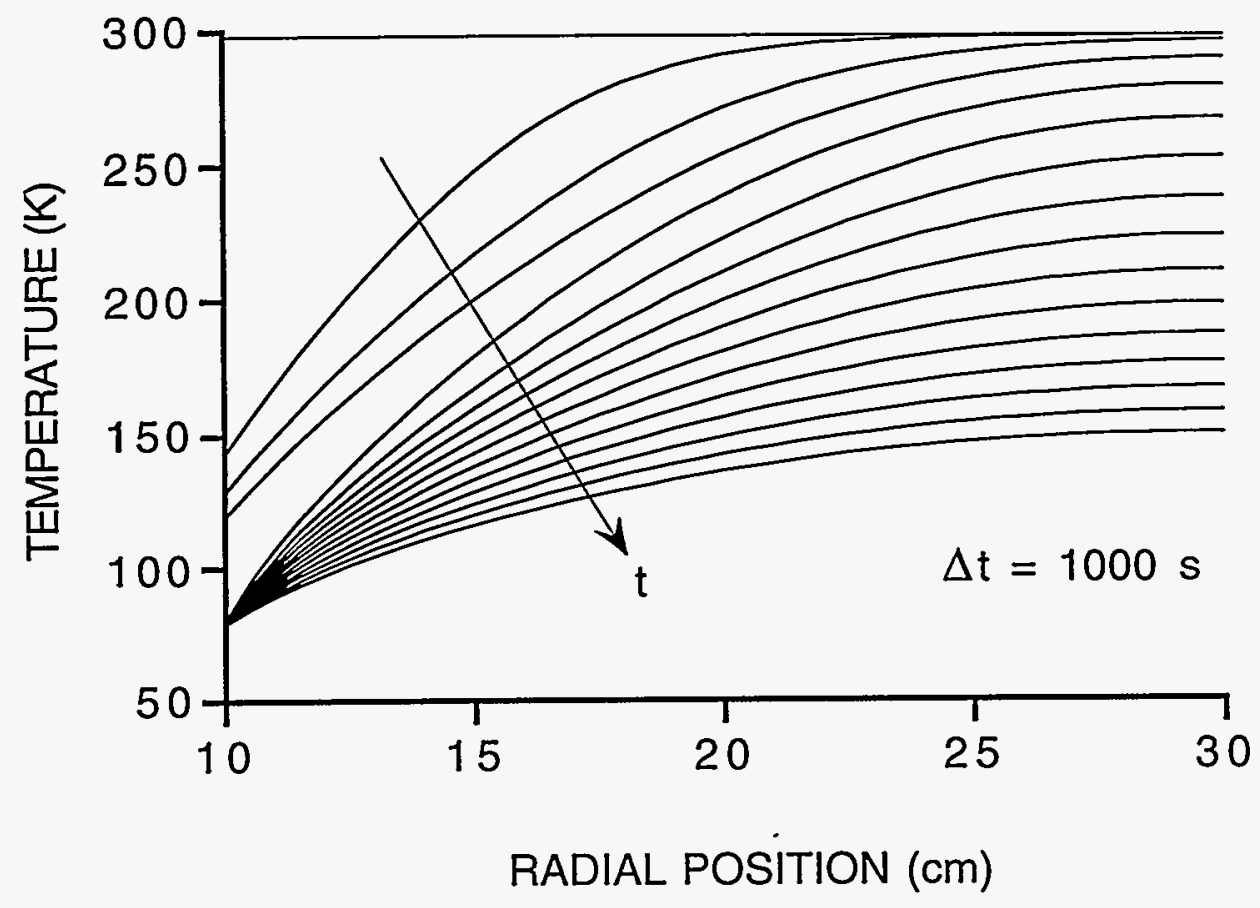

Figure 37. Temperature profiles in sample problem. 


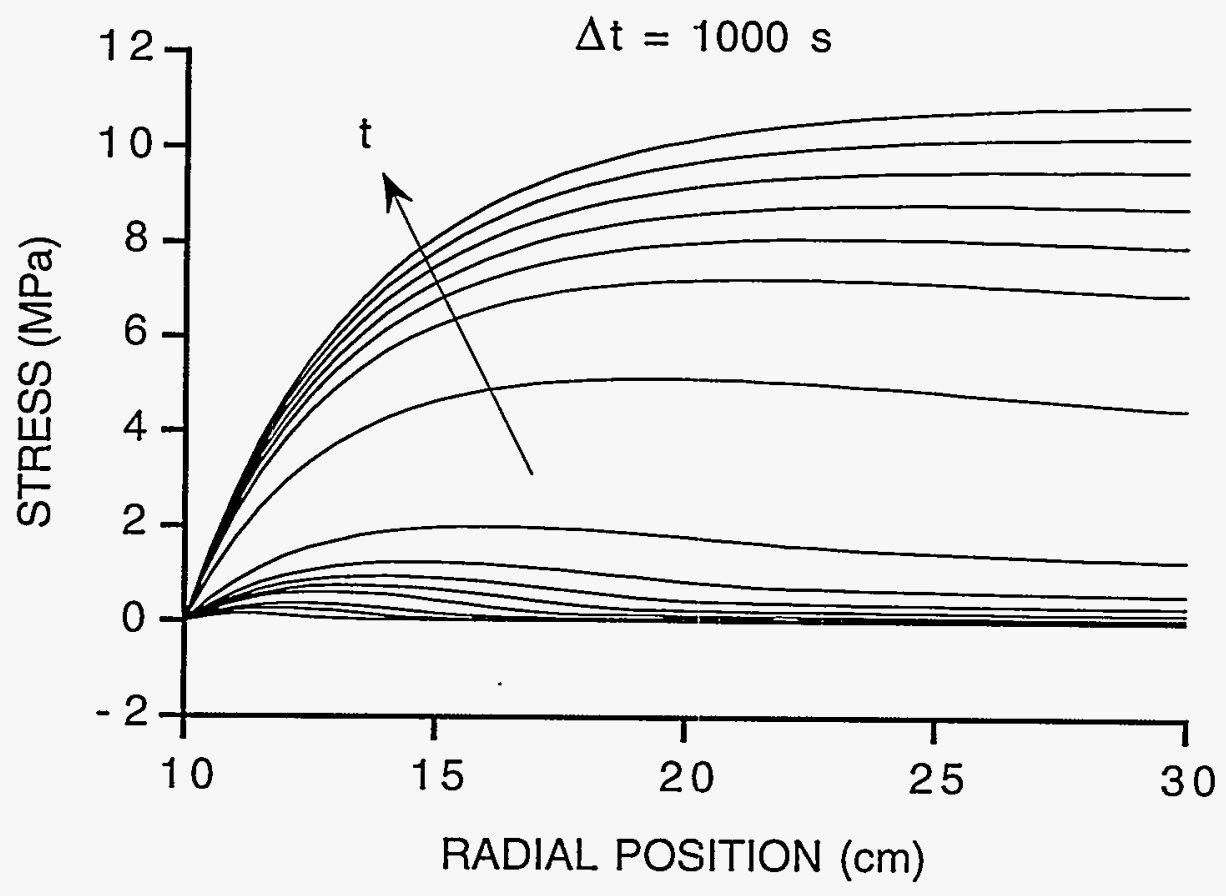

Figure 38. Radial stress profiles in sample problem.

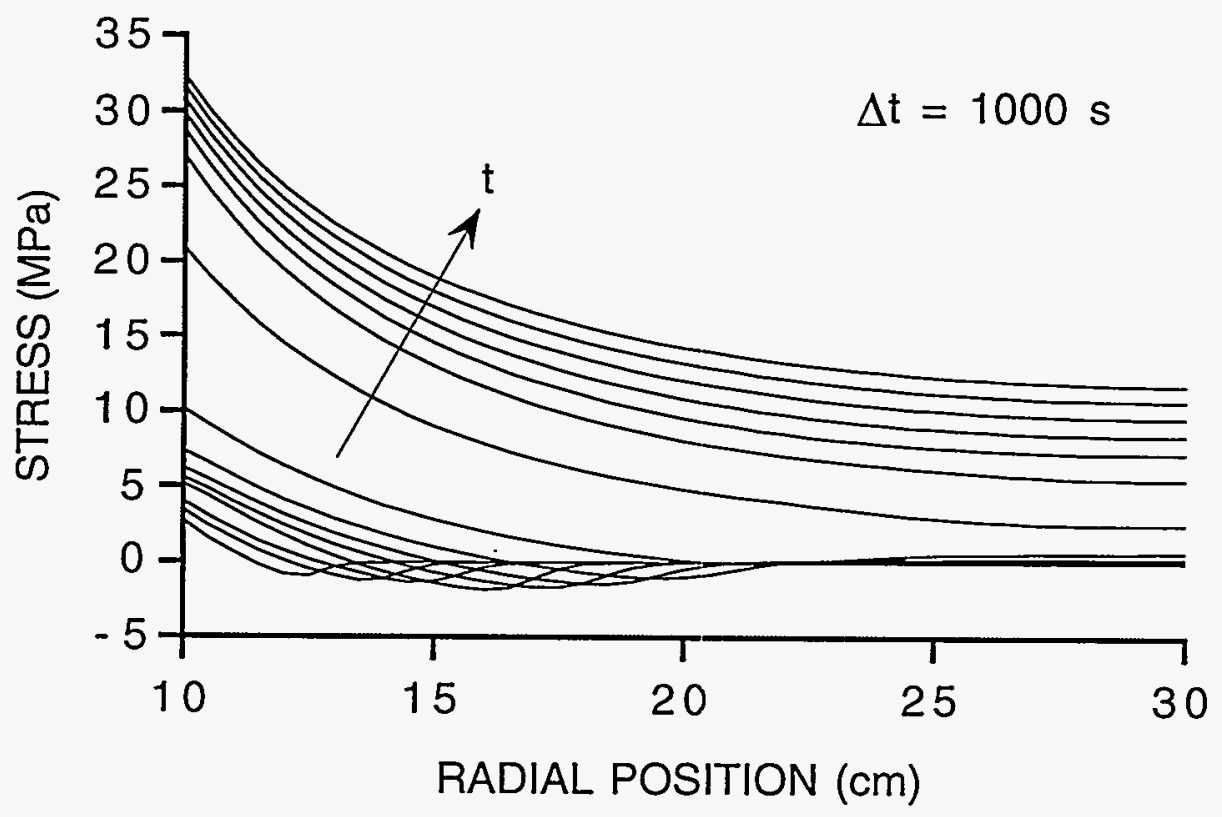

Figure 39. Hoop stress profiles in sample problem. 


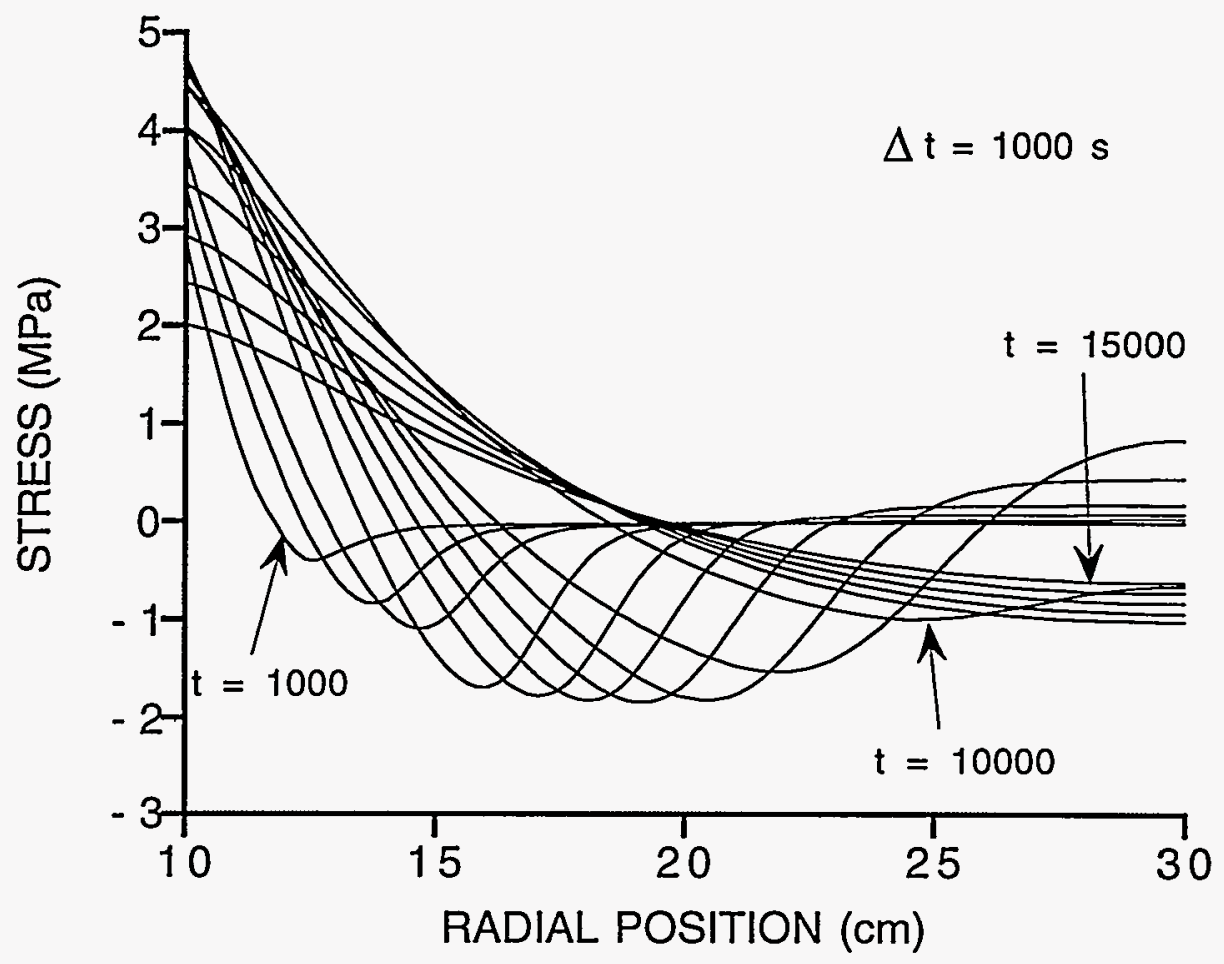

Figure 40. Axial stress profiles in sample problem. 


\section{APPENDIX E}

\section{Publications and Presentations}

- LeRoy Whinnery, Stewart Griffiths, Steve Goods, Jill Hruby, Rich Larson, Joel Lipkin, and Bruce Long, "Cryocycling of Solid Propellants," paper presented at the Energetic Materials Waste Management Colloquium, San Ramon, CA, June 14-17, 1992.

- LeRoy Whinnery, Stewart Griffiths, Jill Hruby, Joel Lipkin, Bruce Long, and Carl Schoenfelder, "Propellant Removal from Rocket Motors Containing Double-Base Compositions," presented at the $23^{\text {rd }}$ International Annual Conference of Fraunhofer-Institut fur Chemische Technologie (ICT), Germany, June 30-July 3, 1992.

- LeRoy Whinnery, Stewart Griffiths, Steve Goods, Jill Hruby, Rich Larson, Joel Lipkin, and Bruce Long, "Cryocycling as a Propellant Removal Technology for Rocket Motors Containing Double-Base Compositions," presented at the International Symposium on Energetic Materials Technology, New Orleans, October 4-7, 1992.

- LeRoy Whinnery, "Swords into Plowshares," presented at Ithaca College, Ithaca, March 2, 1993.

- LeRoy Whinnery, "Propellant Size Reduction via Cryocycling," invited presentation at the Life Cycles of Energetic Materials Conference, Santa Fe, October 25-29, 1993.

- Pat Oyler, Bruce Isom, Joel Lipkin, LeRoy Whinnery, and Stewart Griffiths, "Applications of Cryocycling to Processing Solid Rocket Motor Propellants," to be presented at the JOCG/ADPA Demilitarization Symposium, Arlington, Virginia, May 24-25, 1994.

Invention Disclosures

- Carl Schoenfelder and LeRoy Whinnery, "A Novel Method for Removal of Hazard Class 1.1 Propellants from Rocket Motors," (SD-5054, S-74, 176).

- Carl Schoenfelder, LeRoy Whinnery, and Bruce Long "Cryocycling as a Method for Removal of Hazard Class 1.1 Solid Propellants from Rocket Motors," (SD-5055, S-74, 177).

- Jack Swearengen, LeRoy Whinnery, Joel Lipkin, and Ken Tschritter, : "Disablement of Strategic Rocket Motors."

\section{Patents}

N/A

\section{Copyrights \\ N/A}

\section{Employee Recruitment}

N/A

\section{Students}

N/A

\section{Follow-on Work}

- DOE-DoD MOU "Removal and Sizing of Explosives by Cryocycling."

- Pyrotechniques, Explosives, and Propellants Evaluation and Reapplication (PEPER) "Reuse Applications of Energetic Materials." 
UNLIMITED RELEASE

\section{INITIAL DISTRIBUTION}

US Army MICOM

Propulsion Directorate

Attn: Bill Melvin

Redstone Arsenal, Alabama 35898-5249.

Thiokol Corporation

Attn: Lou Cannizzo, MS 244

Bill Munson, MS 300

Brigham City, Utah 84302

Global Environmental Solutions, Inc.

Attn: Kevin Farnsworth, MS X1D1

Clark de Nevers, MS X1D1

Pat Oyler, MS X1D1

4100 South 8400 West

Annex 16

Magna, Utah 84044-0098

$\begin{array}{ll}\text { MS0861 } & \text { W. K. Tucker, 9121 } \\ \text { MS1436 } & \text { C. Meyers, 1011 } \\ \text { MS1436 } & \text { D. L. Chavez, 1011 } \\ \text { MS9004 } & \text { M. John, 8100 } \\ & \\ \text { MS9001 } & \text { J. C. Crawford, 8000 } \\ \text { MS9002 } & \text { Attn: P. N. Smith, 8500 } \\ \text { MS9003 } & \text { D. L. Crawford, 8900 } \\ \text { MS9037 } & \text { R. J. Detry, 8200 } \\ \text { MS9054 } & \text { W. J. McLean, 8300 } \\ \text { MS9105 } & \text { L. A. Hiles, 8400 } \\ \text { MS9141 } & \text { T. M. Dyer, 8800 } \\ \text { MS9901 } & \text { L. A. West, 8600 }\end{array}$

MS9042 G. N. Benedetti, 8741

MS9042 R. J. Kee, 8745

MS9042 R. Nilson, 8745

MS9042 R. S. Larson, 8745

MS9042 S. K. Griffiths, 8745

MS9043 J. Handrock, 8742

MS9043 L. Weingarten, 8742

MS9043 M. L. Callabresi, 8743

MS9043 P. Nielan, 8742

MS9043 V. Revelli, 8742

MS9044 C. Hackett, 8746

MS9044 D. Dawson, 8746

MS9044 W. A. Kawahara, 8746

MS9055 R. Behrens, 8353

MS9101 D. Kasberg, 8411

MS9203 H. Radloff, 5354

MS9401 R. C. Wayne, 8700

MS9402 G. J. Thomas, 8715 


$\begin{array}{ll}\text { MS9402 } & \text { M. W. Perra, 8714 } \\ \text { MS9402 } & \text { S. Goods, 8714 } \\ \text { MS9403 } & \text { J. E. Costa, 8711 } \\ \text { MS9403 } & \text { M. I. Baskes, 8712 } \\ \text { MS9404 } & \text { B. Long, 8716 } \\ \text { MS9404 } & \text { B. Mills, 8713 } \\ \text { MS9404 } & \text { D. Meeker, 8716 } \\ \text { MS9404 } & \text { J. C. F. Wang, 8713 } \\ \text { MS9404 } & \text { J. Hruby, 8716 } \\ \text { MS9404 } & \text { L. Whinnery, 8716 (10) } \\ \text { MS9404 } & \text { M. Nichols, 8716 } \\ \text { MS9404 } & \text { T. Shepodd, 8713 } \\ \text { MS9405 } & \text { D. L. Lindner, 5404 } \\ \text { MS9410 } & \text { J. C. Swearengen, 8113 (10) } \\ \text { MS9410 } & \text { J. Lipkin, 8113 (20) } \\ & \\ \text { MS0899 } & \text { Technical Library Department, 13414 (4) } \\ \text { MS9018 } & \text { Central Technical Files, 8523-2 (3) } \\ \text { MS9022 } & \text { Mail Distribution, 8533-1, OSTI (10) } \\ \text { MS9022 } & \text { Mail Team Distribution, 8533-1 }\end{array}$

